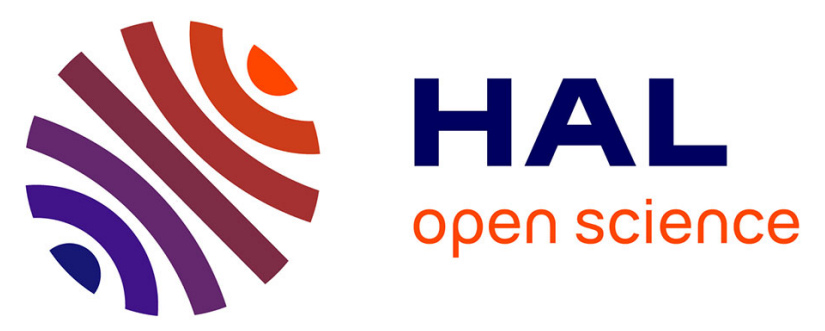

\title{
Kinetic model assessment for the synthesis of $\gamma$-valerolactone from n-butyl levulinate and levulinic acid hydrogenation over the synergy effect of dual catalysts Ru/C and Amberlite IR-120
}

Jose Delgado, Wenel Naudy Vasquez Salcedo, Giulia Bronzetti, Valeria Casson Moreno, Mélanie Mignot, Julien Legros, Christoph Held, Henrik Grénman, Sébastien Leveneur

\section{- To cite this version:}

Jose Delgado, Wenel Naudy Vasquez Salcedo, Giulia Bronzetti, Valeria Casson Moreno, Mélanie Mignot, et al.. Kinetic model assessment for the synthesis of $\gamma$-valerolactone from n-butyl levulinate and levulinic acid hydrogenation over the synergy effect of dual catalysts $\mathrm{Ru} / \mathrm{C}$ and Amberlite IR-120. Chemical Engineering Journal, 2022, 430, Part 3, pp.133053. 10.1016/j.cej.2021.133053 . hal-03498093

\section{HAL Id: hal-03498093 \\ https://hal.science/hal-03498093}

Submitted on 21 Dec 2021

HAL is a multi-disciplinary open access archive for the deposit and dissemination of scientific research documents, whether they are published or not. The documents may come from teaching and research institutions in France or abroad, or from public or private research centers.
L'archive ouverte pluridisciplinaire $\mathbf{H A L}$, est destinée au dépôt et à la diffusion de documents scientifiques de niveau recherche, publiés ou non, émanant des établissements d'enseignement et de recherche français ou étrangers, des laboratoires publics ou privés. 
Kinetic model assessment for the synthesis of $\gamma$-valerolactone from $n$-butyl levulinate and levulinic acid hydrogenation over the synergy effect of dual catalysts $\mathrm{Ru} / \mathrm{C}$ and Amberlite IR-120.

Jose Delgado $^{1,4 \pm}$, Wenel Naudy Vasquez Salcedo ${ }^{1 \pm}$, Giulia Bronzetti ${ }^{1,2}$, Valeria Casson Moreno ${ }^{2}$, Mélanie Mignot ${ }^{3}$, Julien Legros ${ }^{3}$, Christoph Held ${ }^{5}$, Henrik Grénman ${ }^{4}$, Sébastien Leveneur ${ }^{*}$ ${ }^{I}$ Normandie Univ, INSA Rouen, UNIROUEN, LSPC, EA4704, 76000 Rouen, France, E-mail: sebastien.leveneur@insa-rouen.fr

${ }^{2}$ Dipartimento di Ingegneria Chimica, Civile, Ambientale e dei Materiali, Alma Mater StudiorumUniversità di Bologna, via Terracini 28, 40131 Bologna, Italy

${ }^{3}$ Normandie Université, INSA Rouen, UNIROUEN, CNRS, COBRA Laboratory, F-76000 Rouen, France

${ }^{4}$ Laboratory of Industrial Chemistry \& Reaction Engineering, Johan Gadolin Process Chemistry Centre, Abo Akademi University, FI-20500 Åbo-Turku, Finland

${ }^{5}$ Laboratory of Thermodynamics, TU Dortmund, Germany

${ }^{ \pm}$These authors contributed equally to the work. 


\begin{abstract}
The production of platform molecules from the valorization of lignocellulosic biomass is increasing. Among these plateform molecules, $\gamma$-valerolactone (GVL) is a promising one and could be used for different industrial applications. This molecule is synthesized from levulinic acid (LA) or alkyl levulinates (AL) through a tandem hydrogenation/cyclization (lactonization) cascade. A lot of investigations have been carried out to develop the best catalyst for the hydrogenation step by using solely LA or AL. However, one should keep in mind that in the AL production via fructose alcoholysis, there is also LA production, and both are present in the product mixture during the further conversion. To the best of our knowledge, no article exists describing the hydrogenation of LA and AL simultaneously in one-pot. Also, the literature reporting the use of solid catalyst for the second cyclization step is rare. To fill this gap, the hydrogenation of levulinic acid and butyl levulinate was studied over Ru/C and Amberlite IR-120. Several kinetic models were evaluated via Bayesian inference and K-fold approach. The kinetic assessment showed that a non-competitive Langmuir-Hinshelwood with no dissociation of hydrogen where LA, BL and $\mathrm{H}_{2}$ are adsorbed on different sites (NCLH1.2) and non-competitive Langmuir-Hinshelwood with dissociation of hydrogen where LA, BL (butyl levulinate) and $\mathrm{H}_{2}$ are adsorbed on different sites (NCLH2.2) are the best model to describe this system. The presence of LA and Amberlite IR-120 allows to increase the kinetics of cyclization steps, and in fine to accelerate the production of GVL.
\end{abstract}

Keywords: $\gamma$-valerolactone, kinetic modeling, Bayesian statistics, cross-validation, levulinic acid. 


\section{INTRODUCTION}

The valorization of biomass to chemicals, fuels, or materials is essential to decrease the use of fossil raw materials, reduce $\mathrm{CO}_{2}$ emission, and favor circular economies [1,2]. To make biorefineries efficient in production and energy consumption, knowledge ok kinetics, catalysis, and thermodynamics is vital [3]. Currently, academia and the private sectors are focusing their efforts on the valorization of lignocellulosic biomass (LCB) to avoid the dilemma of "food versus fuels" [4].

There are several platform molecules that can be derived from the valorization of LCB [5-7] such as 1,4-diacid, 5-HMF and 2,5-FDCA, 3-HPA, aspartic acid, glutamic acid, glucaric acid, itaconic acid, sorbitol, ABE or levulinic acid.

Research interest at the academy and industrial levels for the utilization of levulinic acid platform chemicals is increasing. Levulinic acid (LA) or alkyl levulinate (AL) are produced from the solvolysis or alcoholysis of cellulose-hemicellulose [8][9]. The market for these molecules (LA or $\mathrm{AL})$ is growing $[10,11]$ due to the versatile use and valorization of these molecules in different industrial sectors.

The hydrogenation of LA or AL leads to the production of $\gamma$-valerolactone (GVL), also considered as a platform molecule [12-14]. GVL is regarded as an excellent green aprotic polar solvent [15] $[16][17][18]$ due to its low vapor pressure and high flash point $[14,19,20]$. GVL is stable, renewable and non-toxic [21]. This platform molecule can be used as an intermediate in the production of many value-added chemicals [1]. From an energetic viewpoint, GVL is a good intermediate for biojet fuel production via its decomposition into butene [22][23]. 
There are several routes for the production of GVL [24,25]; among those involving the hydrogenation of AL or LA, one can distinguish:

-use of molecular hydrogen [26-38];

-in situ decomposition of formic acid into hydrogen [39-47];

-the Meerwein-Ponndorf-Verley reaction, i.e., the use of alcohols for catalytic transfer hydrogenation [48-50].

Hence, one can notice that the literature concerning the production of GVL from the hydrogenation of AL or LA is quite vast. Researchers have put a lot of effort into developong catalysts, evaluating reaction pathway, and using different feedstock.

The most common method for the production of GVL is the hydrogenation of AL or LA with molecular hydrogen over $\mathrm{Ru} / \mathrm{C}$, since it provides the best atom economy. This reaction comprises of two steps [38] (Fig. 1) : the hydrogenation of the substrate to obtain an intermediate, and the cyclization of the intermediate to GVL. During the first step, the carbonyl group of AL or LA is hydrogenated. During the second step, the hydroxyl group of the intermediate reacts with the ester group leading to a cyclization.

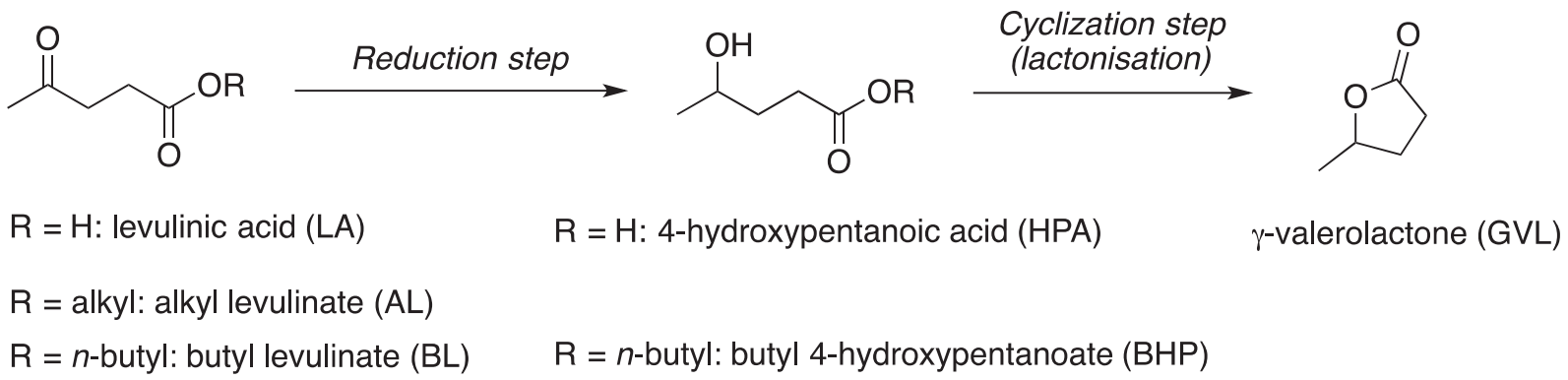

Fig. 1. Hydrogenation of LA or AL to GVL over Ru/C. 
One should remember that the alcoholysis of fructose leads to LA and the corresponding AL [51]. Thus, in the case of GVL production from fructose via alcoholysis and consecutive hydrogenation, LA is also present in this chemical system. Piskun et al. [38] observed that protons from LA dissociation can catalyze the cyclization step. Thus, it could be beneficial for the production of GVL to start from the products of fructose alcoholysis, namely the presence of LA and AL.

Highly concentrated LA solutions present a corrosion risk, which is why, the use of AL has gained interest, but its reactivity is lower compared to LA. A good compromise could be to use a mixture of both reactants. Methyl, ethyl and n-butyl levulinates are the three most studied AL. A thermal risk assessment of AL hydrogenation [36] showed that the risk of thermal runaway for the hydrogenation of methyl levulinate is higher than for butyl levulinate (BL), and the use of butanol for the alcoholysis of carbohydrates into BL is a promising route [52].

The choice of solvent is also important. A previous study showed that the solubility of hydrogen is higher in GVL solvent [28]. Besides, the hydrogenation of BL in GVL solvent allows to work at higher temperature due to the high vapor pressure of the different chemicals [52].

For that reason, the current study focuses on:

1) the hydrogenation of LA and BL reactants into GVL.

2) the use of cation exchange resins under $\mathrm{H}$ form to catalyze the cyclization reaction. The cyclization step has been shown to be slower for alkyl levulinates than for LA [38]. The use of such acid resin catalyst can significantly increase the reaction kinetics. To the best of our knowledge, there are few studies in this field [53,54]. In the first study, Moreno-Marrodan and Barbaro [53] demonstrated that the use of heterogeneous catalyst based on sulfonated cation exchange resin and embedded $\mathrm{Ru}$ nanoparticles leads to the complete conversion of LA to GVL with remarkable selectivity at low temperatures and $\mathrm{H}_{2}$ pressure, as well as excellent catalyst durability and no need 
for additives. The second study [54] analysed the hydrogenation of LA to GVL catalysed by a commercial Ru supported catalyst in combination with Amberlyst A70, showing a high selectivity to GVL also at mild processing conditions.

This article aims to assess different plausible kinetic models for the hydrogenation of BL and LA synergically catalyzed by $\mathrm{Ru} / \mathrm{C}$ and Amberlite IR-120 via Bayesian inference. The Bayesian approach to developing a kinetic model for catalytic systems has become increasingly popular [5559].

Traditionally, kinetic models are evaluated mainly by the fit to experimental data and the coefficient of determination. Some researchers incorporate in the assessment: the residual analysis, the credible intervals of the estimated parameters, the number of parameters via the Akaike information criterion (AIC) [60] and the correlation matrix. All these analyses are done solely on the training dataset, and few studies use a validation dataset to evaluate prediction quality of the kinetic model. The validation stage is rarely done because some experimental data are not used in the regression stage, so the model accuracy is lower. To overcome this issue, cross-validation, and more particularly the K-fold approach, is used in this investigation [61]. Cross-validation is also a way to determine the best model. 


\section{MATERIALS AND METHODS}

\subsection{Chemicals}

Chemicals used in this work, without further purification, are described in this section. Hydrogen gas $\left(\mathrm{H}_{2}\right.$ purity $>99.999$ vol \%) from Linde. $n$-Butyl levulinate (BL purity $\left.=98 \mathrm{wt} \%\right)$, CAS: 205215-5, was purchased from Alfa-Aesar. Levulinic acid (LA purity $>98 \mathrm{wt} \%$ ), CAS: 123-76-2, was purchased from Acros Organics. $\gamma$-Valerolactone (GVL purity $\geq 99$ wt $\%$ ), CAS: 108-29- 2, was purchased from Sigma Aldrich. Acetone (analytical grade), CAS: 67-64-1, was bought from VWR. Ruthenium, $5 \%$ on activated carbon powder, reduced, nominally $50 \%$ water, CAS: $7440-18-8$, was purchased from Alfa-Aesar. Amberlite IR120, H-Form, ion-exchange resin, CAS: 78922-04-0, was purchased from Acros Organics.

\subsection{Analytical methods}

For the quantitative analysis of the samples, gas chromatography coupled with flame ionization detection technique was used. The equipment (GC) used is from supplier Scion Instruments, equipped with a GC capillary column ZB-5, a versatile, low polarity column. This column is composed of $95 \%$ of dimethylpolysiloxane and $5 \%$ of phenyl groups. The column has $30 \mathrm{~m}$ of length, $0.32 \mathrm{~mm}$ of diameter and $0.25 \mu \mathrm{m}$ of film internal coating.

Helium (99.99\%) was used as the carrier gas at a constant flow rate of $1.2 \mathrm{~mL} . \mathrm{min}-1$ to transfer the sample from the injector, through the column, and into the FID-detector. The temperature of the injector and the detector were set at $250^{\circ} \mathrm{C}$. The oven temperature ramp was set to $50^{\circ} \mathrm{C}(1 \mathrm{~min})$ $20^{\circ} \mathrm{C} \mathrm{min}^{-1}-200^{\circ} \mathrm{C}(1 \mathrm{~min})$. Samples were diluted in acetone and injected into the GC. The injection volume was $1 \mu \mathrm{L}$, and the split ratio was 20:1. 


\subsection{Kinetic experiments}

To develop kinetic models for GVL synthesis from the hydrogenation of $n$-BL with LA, a total of 14 experiments were carried out varying the initial operating conditions such as pressure, temperature, initial concentrations of the reactants, and catalyst loadings (Table 1). GVL was used as a solvent. Experiments carried out with Amberlite IR 120 were done at a reaction temperature lower than $120^{\circ} \mathrm{C}$ to avoid the leaching of sulfonic groups.

Table 1. Experimental matrix for the kinetic study of the reaction scheme shown in Fig. 1.

\begin{tabular}{|c|c|c|c|c|c|c|c|c|c|c|}
\hline Run & $\begin{array}{c}\text { Pressure } \\
\text { bar }\end{array}$ & Temp K & $\begin{array}{c}\text { mcat_Ru kg } \\
(50 \% \text { weight } \\
\text { moisture })\end{array}$ & $\begin{array}{c}\text { mcat_Ambk } \\
\mathrm{g}(\text { dried })\end{array}$ & $\begin{array}{c}\text { m0GVL } \\
\mathrm{kg}\end{array}$ & $\begin{array}{c}\mathrm{m} 0 \mathrm{BL} \\
\mathrm{kg}\end{array}$ & $\begin{array}{c}\mathrm{m} \text { OLA } \\
\mathrm{kg}\end{array}$ & $\begin{array}{c}\mathrm{BL}_{0} \\
\mathrm{~mol} / \mathrm{m}^{3}\end{array}$ & $\begin{array}{c}\mathrm{GVL}_{0} \\
\mathrm{~mol} / \mathrm{m}^{3}\end{array}$ & $\begin{array}{c}\mathrm{LA}_{0} \\
\mathrm{~mol}^{3} \mathrm{~m}^{3}\end{array}$ \\
\hline 1 & 20.6 & 404.15 & 0.0005 & 0 & 0.083 & 0.027 & 0.015 & 1272 & 7703 & 1105 \\
\hline 2 & 20 & 403.15 & 0.0005 & 0 & 0.083 & 0.042 & 0 & 1912 & 6311 & 0 \\
\hline 3 & 20.6 & 404.15 & 0.0005 & 0 & 0.083 & 0.027 & 0.015 & 1249 & 6606 & 1029 \\
\hline 4 & 22 & 383.15 & 0.0005 & 0 & 0.083 & 0.027 & 0.015 & 1249 & 6606 & 1029 \\
\hline 5 & 10.9 & 403.15 & 0.0005 & 0 & 0.083 & 0.027 & 0.015 & 1351 & 7169 & 1029 \\
\hline 6 & 21.5 & 402.15 & 0.0005 & 0 & 0.083 & 0.022 & 0.02 & 1055 & 6831 & 1372 \\
\hline 7 & 21.4 & 374.15 & 0.0005 & 0 & 0.083 & 0.027 & 0.015 & 1450 & 6606 & 1300 \\
\hline 8 & 21.6 & 373.15 & 0.001 & 0 & 0.083 & 0.027 & 0.015 & 1313 & 6841 & 1077 \\
\hline 9 & 21.7 & 383.15 & 0.0015 & 0 & 0.083 & 0.022 & 0.02 & 879 & 5950 & 719 \\
\hline 10 & 21.3 & 385.15 & 0.0015 & 0.010479 & 0.083 & 0.022 & 0.02 & 1093 & 6819 & 1390 \\
\hline 11 & 9.7 & 375.15 & 0.0012 & 0.010 & 0.083 & 0.022 & 0.025 & 1117 & 6769 & 1597 \\
\hline 12 & 9.5 & 414.15 & 0.0010 & 0.000 & 0.083 & 0.027 & 0.010 & 1415 & 7431 & 582 \\
\hline 13 & 10.5 & 391.15 & 0.0012 & 0.010 & 0.083 & 0.022 & 0.025 & 1058 & 6586 & 1707 \\
\hline 14 & 15.4 & 394.15 & 0.0012 & 0.006 & 0.083 & 0.03 & 0.015 & 1337 & 6515 & 1154 \\
\hline
\end{tabular}

The autoclave (stirred tank reactor) used for these experiments is a stainless- steel laboratory-scale vessel with a capacity of $300 \mathrm{~mL}$, which is equipped with a stirrer set at $1000 \mathrm{RPM}$, an electrically heating jacket, a cooling coil, a pressure sensor, and a temperature sensor (Fig. 2). Each experiment was carried out in isothermal and isobaric conditions. During these experiments, samples were taken at different times and then analyzed via GC-FID. 
The concentration measurement uncertainty was evaluated via the standard deviation of replicate measurements. Each sample was analyzed thrice.

$\mathrm{R}_{1}, \mathrm{R}_{2}$ : Pressure regulator

$\mathrm{V}_{1}, \mathrm{~V}_{2}, \mathrm{~V}_{3}, \mathrm{~V}_{4}, \mathrm{~V}_{5}$ : Gas valve

$\mathrm{V}_{6}:$ Water valve

$P$ : Pressure sensor

$\mathrm{T}:$ Temperature sensor

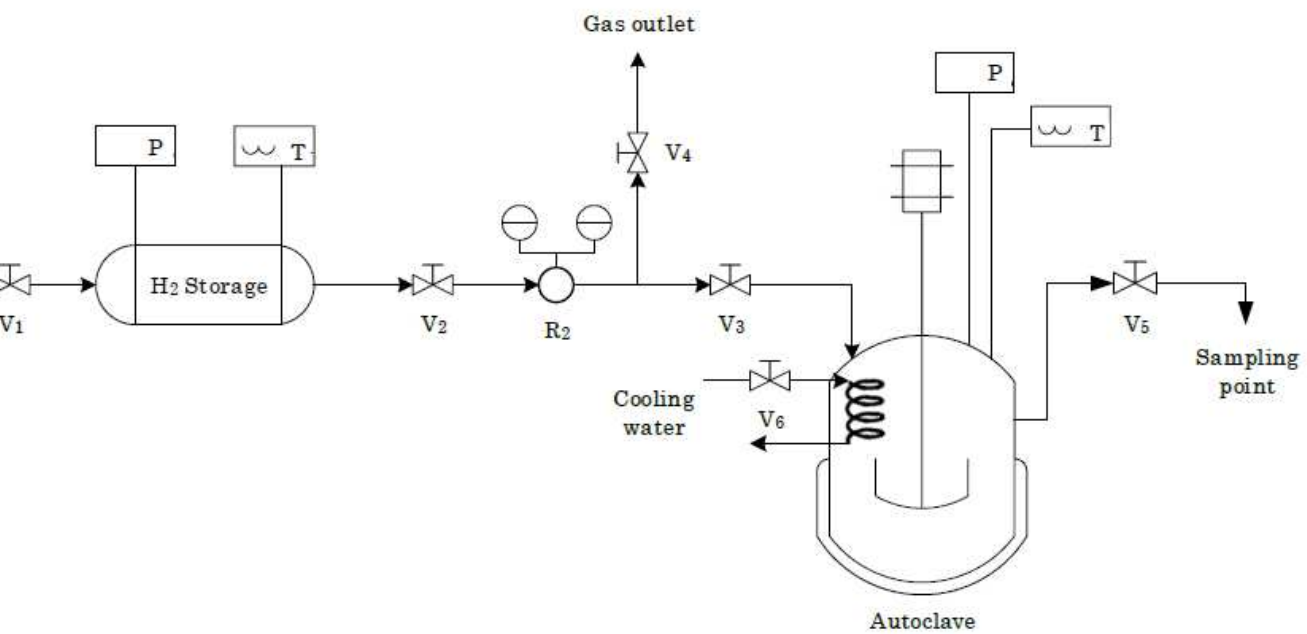

Fig. 2. Experimental setup of the autoclave. 


\section{RESULTS}

This section describes the effects of experimental parameters such as temperature, pressure, and concentrations. on the hydrogenation and cyclization reactions from a phenomenological viewpoint. The hydrogenation of butyl levulinate or levulinic acid over $\mathrm{Ru} / \mathrm{C}$ to GVL is a two-step reaction illustrated by Fig. 1[28,29,36,38]. In the first step, the carbonyl group of BL or LA is hydrogenated. In the second step, the hydroxyl group of the intermediate attacks the ester group leading to a cyclization.

The hydrogenation step was evaluated by the ratios $[\mathrm{BL}] /[\mathrm{BL}]_{0}$ and $[\mathrm{LA}] /[\mathrm{LA}]_{0}$. The cyclization step was assessed by the ratios $[\mathrm{BHP}] /[\mathrm{BL}]_{0}$ and $[\mathrm{HPA}] /[\mathrm{LA}]_{0}$. The standard deviations for BL, LA, BHP and HPA concentrations were found to be in average $1.76 \%, 3.64 \%, 2.41 \%$ and $3.64 \%$, respectively. All the samples were analyzed three times. In Figs 3-8, the replicated points are also displayed.

\subsection{Repeatability}

In addition, to replicate three times the sample analysis, two similar experiments were reproduced to evaluate the repeatability of the results. Experiments 1 and 3 (Table 1) were carried in similar operating conditions in the experimental matrix. Fig. 3 shows that the protocol used in this study is repeatable. Experiments 1 and 3 resulted in practice in identical results. 

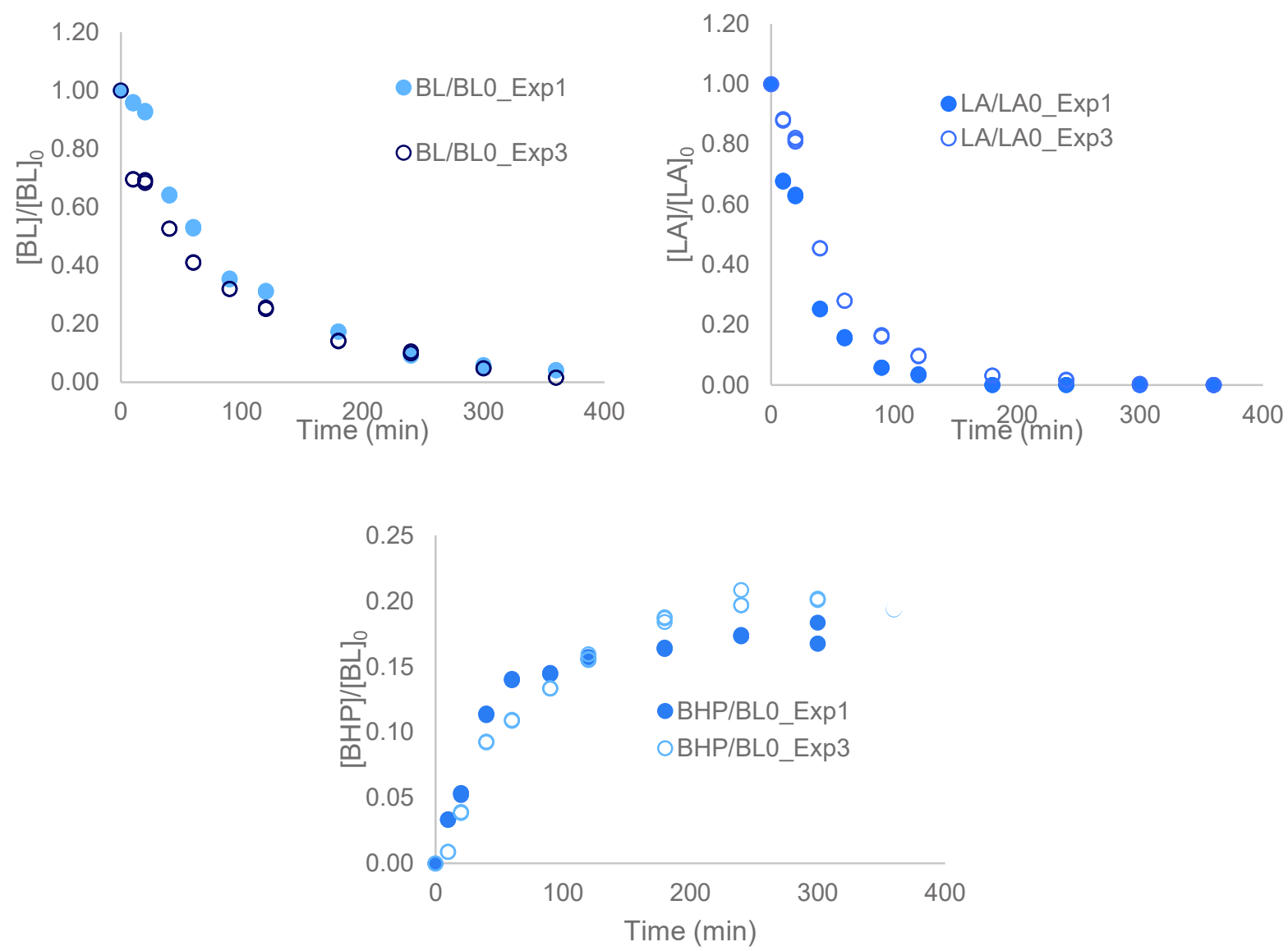

Fig. 3. Evolution of $[\mathrm{BL}] /[\mathrm{BL}]_{0},[\mathrm{LA}] /[\mathrm{LA}]_{0}$ and $[\mathrm{BHP}] /[\mathrm{BL}]_{0}$ for experiments $1 \& 3$.

\subsection{Effect of temperature}

The effect of temperature on the kinetics was evaluated through Experiments 3 and 4 (Table 1) because only temperature change in these two experiments. Fig. 4 shows that hydrogenation steps are faster with increasing temperature. The temperature increase leads to a rise in the cyclization kinetics, and hence the decrease of the intermediate concentrations (BHP and HPA) is faster. 

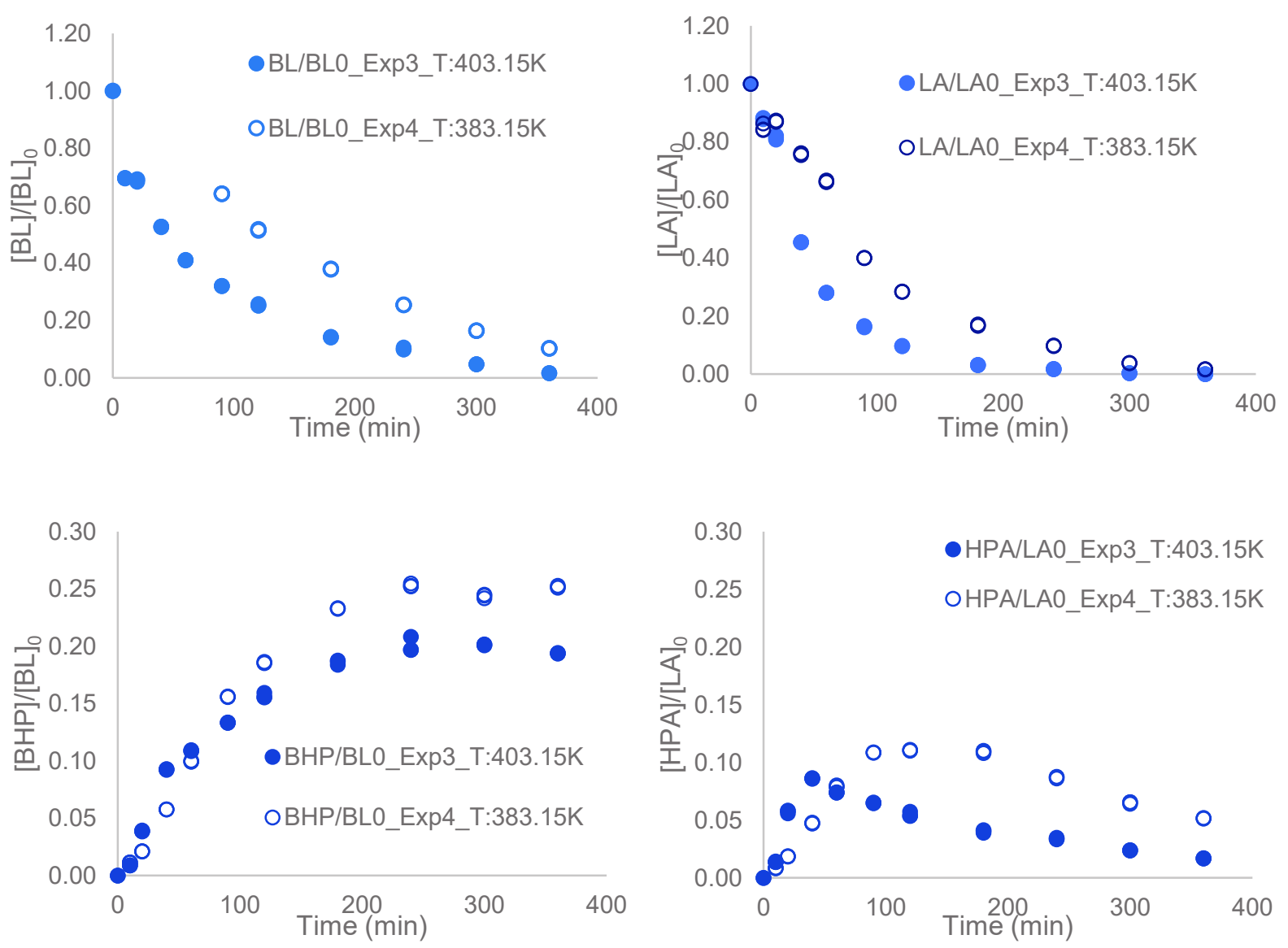

Fig. 4. Effect of temperature on hydrogenation and cyclization reactions for experiments $3 \& 4$.

\subsection{Effect of hydrogen hydrostatic pressure}

Fig. 5 shows the $\mathrm{H}_{2}$ pressure effect by comparing Experiments 3 and 5 (Table 1). One can observe that the increase of hydrostatic pressure leads to accelerate the hydrogenation steps. The consequence of this acceleration is an increase of intermediate concentrations (BHP and HPA). The pressure has an indirect effect on the cyclization step. 

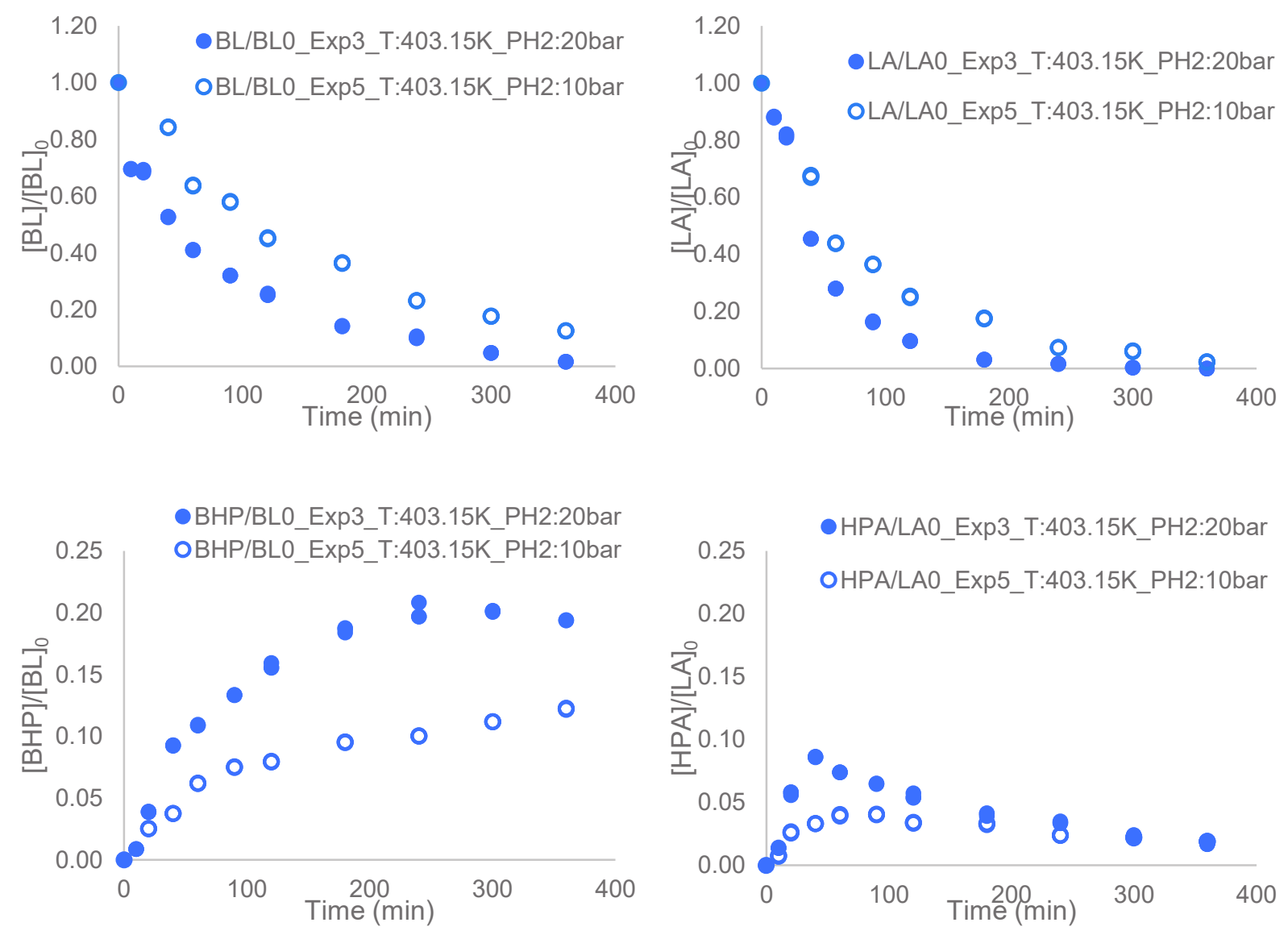

Fig. 5. Effect of pressure on the kinetics of hydrogenation and cyclization steps for experiments $3 \& 5$.

\subsection{Effect of catalyst $\mathrm{Ru} / \mathrm{C}$}

The effect of $\mathrm{Ru} / \mathrm{C}$ loading on the kinetics were evaluated by comparing Experiments 7 and 8 . The increase of $\mathrm{Ru} / \mathrm{C}$ augments hydrogenation kinetics, leading to the rise of intermediate concentrations (Fig. 6). 

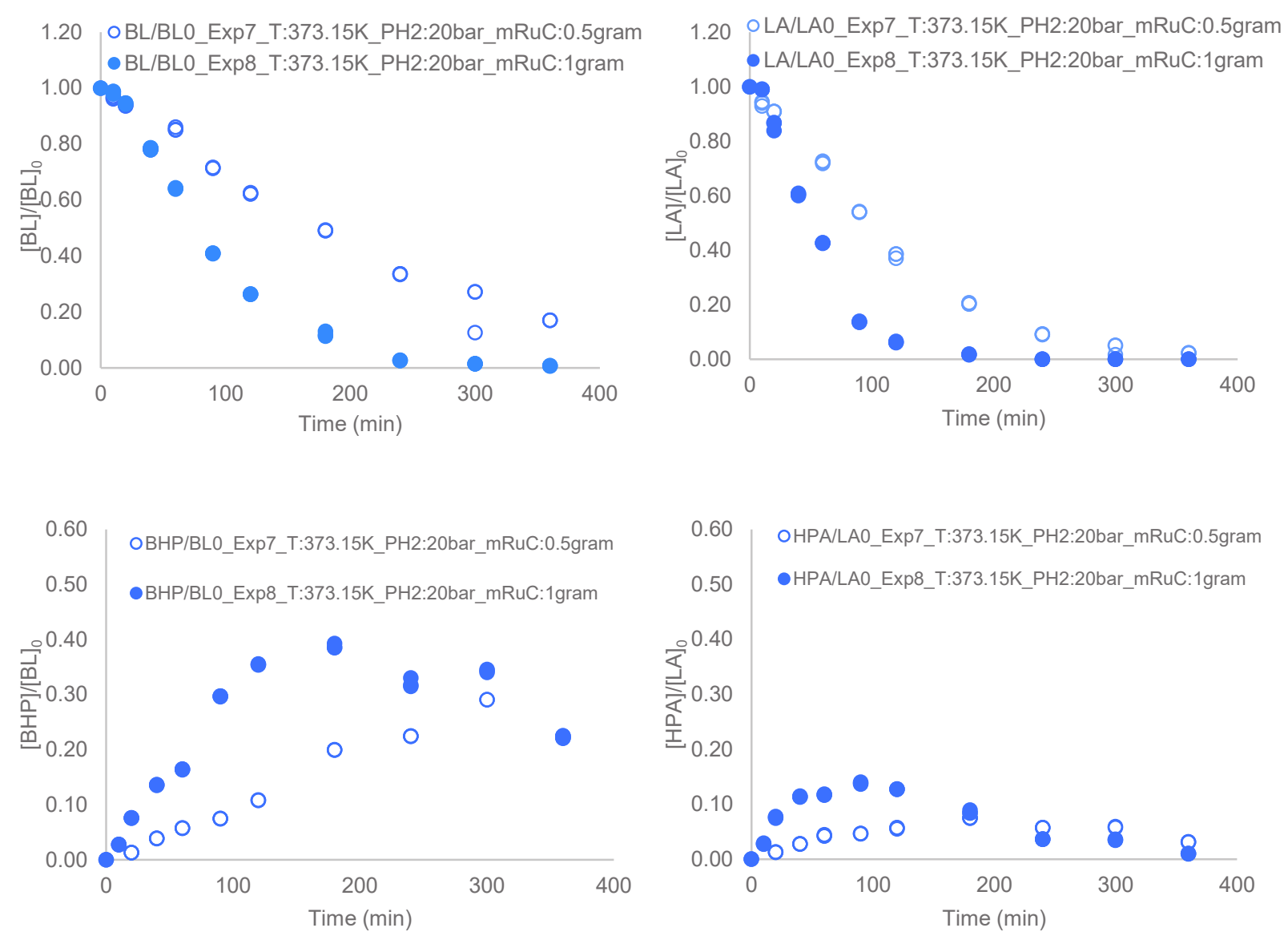

Fig. 6. Effect of pressure on $\mathrm{Ru} / \mathrm{C}$ loadings on the kinetics for Experiments $7 \& 8$.

\subsection{Effect of catalyst Amberlite IR-120}

Experiments 9 and 10 (Table 1) give information on the catalytic effect of Amberlite IR-120. Fig. 7 shows that this catalyst does not have an impact on the first reaction step as expected. The HPA concentrations were too low to be detected, but one can notice that Amberlite IR-120 strongly affects the consumption kinetics of the intermediate (BHP). 

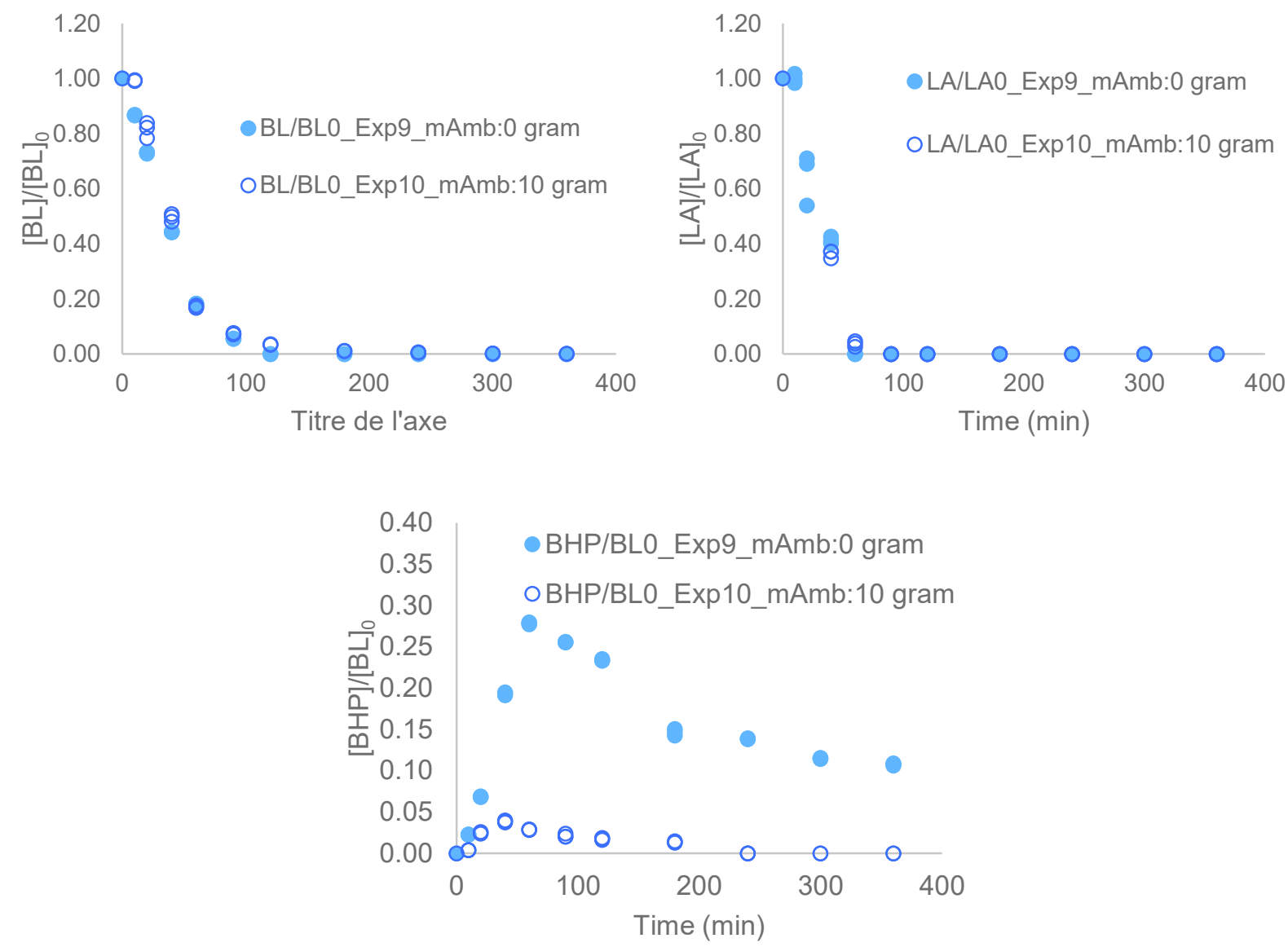

Fig. 7. Effect of Amberlite IR120 loadings on the kinetics of hydrogenation and cyclization for Experiments $9 \& 10$.

\subsection{Effect of LA amount}

Levulinic acid dissociates in the reaction mixture producing protons, which can catalyze the second reaction step. To verify this assumption, the results from Experiments 3 and 6 were compared. The kinetics of BL hydrogenation are similar (Fig. 8). The kinetics of LA hydrogenation is to be slightly faster when the concentration of LA is higher. One can notice that the increase of LA concentration accelerates the cyclization of HPA and BHP steps (Fig. 8). 

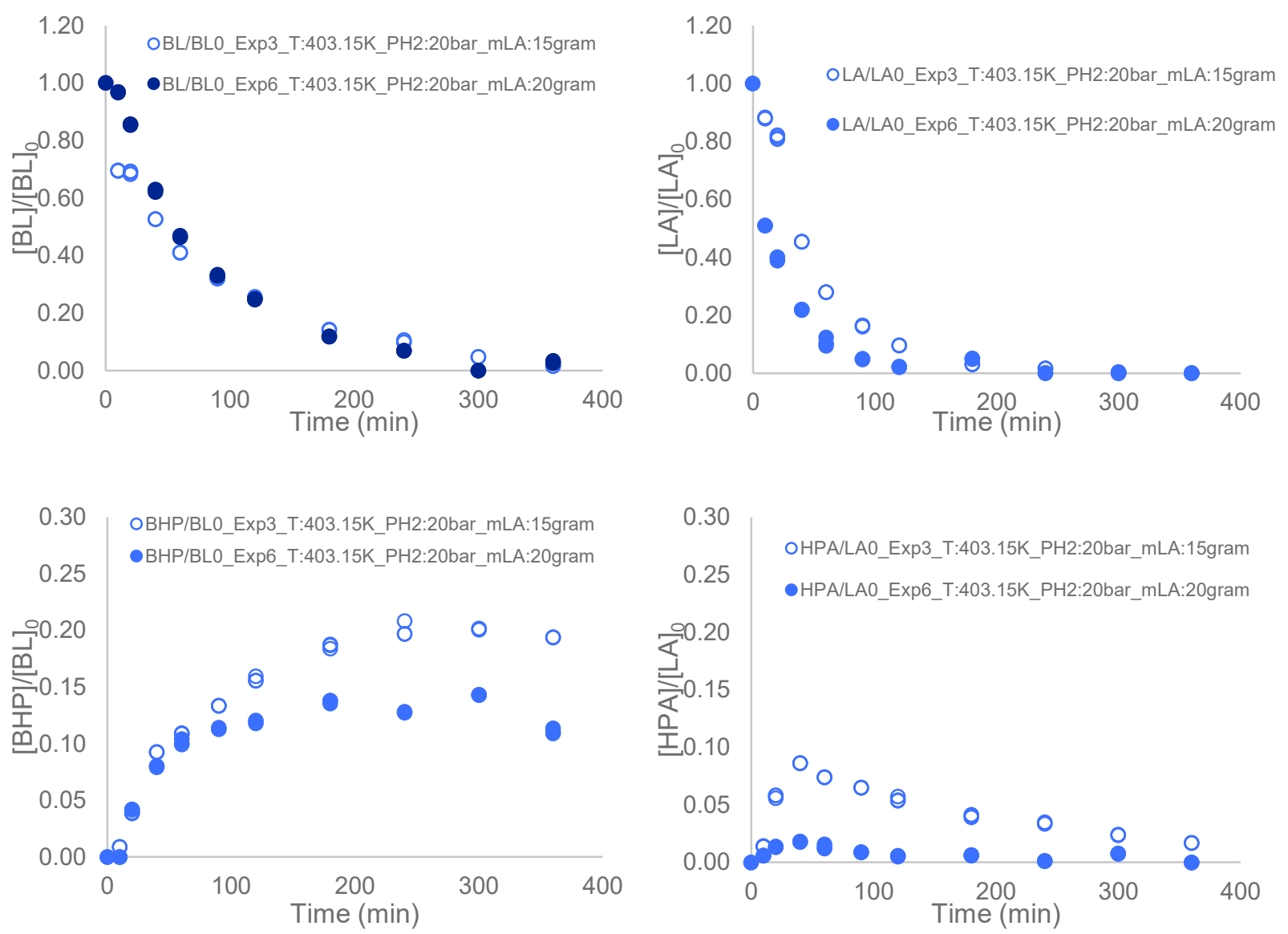

Fig. 8. Effect of LA concentration on the kinetics of hydrogenation and cyclization steps for Experiments $3 \& 6$. 


\section{DISCUSSION}

\subsection{Kinetics}

From the Results section, several reaction mechanisms are possible for the hydrogenation and cyclization steps. The work of Capecci et al.[29] described that the surface reaction for the hydrogenation step of BL followss a non-competitive Langmuir-Hinshelwood model with no dissociation of molecular hydrogen. It means that there are two kinds of $\mathrm{Ru}$ sites and that the carbonyl group and hydrogen adsorb on each of them without competing. It was also found that the cyclization step can be catalyzed by $\mathrm{Ru} / \mathrm{C}$ catalyst.

In this reaction system, $\mathrm{BL}$ and $\mathrm{LA}$ underwent similar reaction pathways. We neglected the esterification reaction of levulinic acid by butanol, because from the experimental data levulinic acid consumption is faster than the BHP cyclization.

Therefore, in the present work, seven kinetic models were evaluated for the hydrogenation step:

- competitive Langmuir-Hinshelwood with no dissociation of hydrogen (LH1),

- competitive Langmuir-Hinshelwood with dissociation of hydrogen (LH2),

- non-competitive Langmuir-Hinshelwood with no dissociation of hydrogen where LA and BL are in competitive adsorption on the same site but not hydrogen (NCLH1.1),

- non-competitive Langmuir-Hinshelwood with no dissociation of hydrogen where LA, BL and $\mathrm{H}_{2}$ are adsorbed on different sites (NCLH1.2),

- Eley-Rideal with no adsorption of hydrogen on the active sites (ER),

- non-competitive Langmuir-Hinshelwood with dissociation of hydrogen where LA and BL are in competitive adsorption on the same site but not hydrogen (NCLH2.1),

- non-competitive Langmuir-Hinshelwood with dissociation of hydrogen where LA, BL and H2 are adsorbed on different sites (NCLH2.2). 
For the sake of clarity, the derivation of the seven kinetic models are described in Supplementary

Material (S1). Table 2 displays the hydrogenation rate expression for each model.

Table 2. Rate expression for the hydrogenation steps.

\begin{tabular}{|c|c|c|}
\hline MODELS & Rate expression for $\mathrm{BL}, R_{B L, H y d}$ & Rate expression for LA, $R_{L A, H y d}$ \\
\hline (LH1) & $\frac{k_{1} *\left[H_{2}\right] *[B L] * \omega_{\text {cat. }}}{\left.\frac{K_{H 2} *\left[H_{2}\right]+K_{B L} *[B L]+K_{B H P} *[B H P]}{+K_{L A} *[L A]+K_{H P A} *[H P A]+1}\right)^{2}}$ & $\frac{k_{1} *\left[H_{2}\right] *[L A] * \omega_{\text {cat. }}}{\frac{\left(\begin{array}{c}K_{H 2} *\left[H_{2}\right]+K_{B L} *[B L]+K_{B H P} *[B H P] \\
+K_{L A} *[L A]+K_{H P A} *[H P A]+1\end{array}\right)^{2}}{2}}$ \\
\hline$(\mathrm{LH} 2)$ & $\frac{k_{1} *\left[H_{2}\right] *[B L] * \omega_{\text {cat. }}}{\left(\begin{array}{c}\boldsymbol{K}_{\boldsymbol{H}} * \sqrt{\left[H_{2}\right]}+K_{B L} *[B L]+K_{B H P} *[B H P]+K_{i} *[B L] * \sqrt{\left[H_{2}\right]} \\
+K_{L A} *[L A]+K_{H P A} *[H P A]+K_{i 2} *[L A] * \sqrt{\left[H_{2}\right]}+1\end{array}\right)^{2}}$ & $\frac{k_{1} *\left[H_{2}\right] *[L A] * \omega_{\text {cat. }}}{\left(\begin{array}{c}\sqrt{K_{H} *\left[H_{2}\right]}+K_{B L} *[B L]+K_{B H P} *[B H P]+K_{i} *[B L] * \sqrt{\left[H_{2}\right]} \\
+K_{L A} *[L A]+K_{H P A} *[H P A]+K_{i 2} *[L A] * \sqrt{\left[H_{2}\right]}+1\end{array}\right)^{2}}$ \\
\hline$(\mathrm{ER} 1)$ & $\frac{k_{1} *\left[H_{2}\right] *[B L] * \omega_{\text {cat. }}}{\frac{\left(\begin{array}{c}K_{B L} *[B L]+K_{B H P} *[B H P]+K_{L A} *[L A] \\
+H P A *[H P A]+1\end{array}\right)}{}}$ & $\frac{k_{1} *\left[H_{2}\right] *[L A] * \omega_{\text {cat. }}}{\left(\begin{array}{c}K_{B L} *[B L]+K_{B H P} *[B H P] \\
+K_{L A} *[L A]+H P A *[H P A]+1\end{array}\right)}$ \\
\hline (NCLH1.1) & $\begin{array}{c}\frac{k_{1} *\left[H_{2}\right]}{\left(1+K_{H 2} *\left[H_{2}\right]\right)} \\
* \frac{[B L] * \omega_{\text {Cat. }}}{\left(\begin{array}{cc}1+K_{B H P} & *[B H P]+K_{B L} *[B L] \\
+K_{H P A} & *[H P A]+K_{L A} *[L A]\end{array}\right)}\end{array}$ & 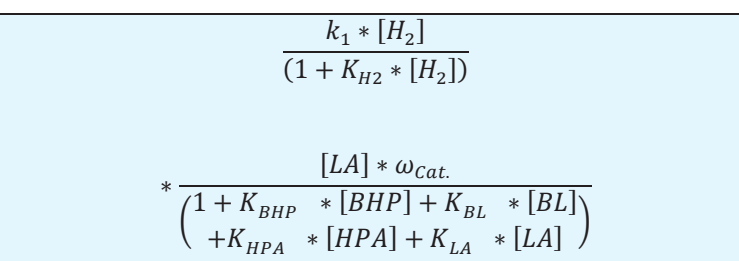 \\
\hline (NCLH1.2) & $\begin{array}{c}\frac{k_{1} *\left[H_{2}\right]}{\left(1+K_{H 2} *\left[H_{2}\right]\right)} \\
* \frac{[B L] * \omega_{\text {Cat. }}}{\left(1+K_{B H P} *[B H P]+K_{B L} *[B L]\right)}\end{array}$ & $\begin{array}{c}\frac{k_{1} *\left[H_{2}\right]}{\left(1+K_{H 2} *\left[H_{2}\right]\right)} \\
* \frac{[L A] * \omega_{\text {Cat. }}}{\left(1+K_{H P A} *[H P A]+K_{L A} *[L A]\right)}\end{array}$ \\
\hline (NCLH2.1) & $\begin{array}{c}\frac{k_{1} *\left[H_{2}\right]}{K_{H} * \sqrt{\left[H_{2}\right]}+1} * \\
\frac{[B L] * \omega_{\text {Cat. }}}{\left(\begin{array}{c}K_{B L} \cdot[B L]+K_{C} \cdot \sqrt{\left[H_{2}\right]} \cdot[B L] \cdot+K_{B H P} \cdot[B H P]+K_{L A} \cdot[L A] \\
+K_{C 2} \cdot \sqrt{\left[H_{2}\right]} \cdot[L A]+K_{H P A^{\wedge} \cdot} \cdot[H P A]+1\end{array}\right)}\end{array}$ & $\begin{array}{c}\frac{k_{1} *\left[H_{2}\right]}{\sqrt{K_{H} *\left[H_{2}\right]}+1} \\
* \frac{[L A] * \omega_{\text {Cat. }}}{\left(\begin{array}{c}K_{B L} \cdot[B L]+K_{C} \cdot \sqrt{\left[H_{2}\right]} \cdot[B L]+K_{B H P} \cdot[B H P]+K_{L A} \cdot[L A] \\
+K_{C 2} \cdot \sqrt{\left[H_{2}\right]} \cdot[L A]+K_{H P A^{\wedge}} \cdot[H P A]+1\end{array}\right)}\end{array}$ \\
\hline$(\mathrm{NCLH} 2.2)$ & $\begin{array}{c}\frac{k_{1} *\left[H_{2}\right]}{K_{H} * \sqrt{\left[H_{2}\right]}+1} * \\
\frac{[B L] * \omega_{\text {Cat. }}}{\left(K_{B L} \cdot[B L]+K_{C} \cdot \sqrt{\left[H_{2}\right]} \cdot[B L]+K_{B H P} \cdot[B H P]+1\right)}\end{array}$ & $\begin{array}{c}\frac{k_{1} *\left[H_{2}\right]}{\sqrt{K_{H} *\left[H_{2}\right]}+1} \\
* \frac{[L A] * \omega_{C a t .}}{\left(K_{L A} \cdot[L A]+K_{C 2} \cdot \sqrt{\left[H_{2}\right]} \cdot[L A]+K_{H P A^{\wedge} \cdot}[H P A]+1\right)}\end{array}$ \\
\hline
\end{tabular}


For the second cyclization reaction, four different types of reaction were considered: non-catalytic cyclization of BHP and HPA, the catalytic routes due to the presence of acid sites on $\mathrm{Ru} / \mathrm{C}$, the acidic groups on Amberlite IR-120 and the protons from the dissociation of levulinic acid. Due to space limitation, the derivation for these rate equations are explained in Supplementary Material (S3).

Rate equations for the cyclization steps are:

$$
\begin{aligned}
& R_{\text {BHP_noncat }}=k_{B H P \_n o n c a t} \cdot[B H P] \\
& R_{H P A \_n o n c a t}=k_{H P A \_n o n c a t} \cdot[H P A] \\
& R_{B_{H} P_{-} R u C}=k_{B H P_{-} R u C} \cdot[B H P] \cdot \frac{1}{K_{\mathbf{n} H P A} \cdot[H P A]+K_{\mathbf{n} H P} \cdot[B H P]+1} \cdot \omega_{C a t . R u C} \\
& R_{H P A_{-} R u C}=k_{H P A_{-} R u C} \cdot[H P A] \cdot \frac{1}{K_{\bullet H P A} \cdot[H P A]+K_{\bullet} B H P \cdot[B H P]+1} \cdot \omega_{C a t . R u C} \\
& R_{\text {BHP_SO3H }}=k_{\text {BHP_SO3H }} \cdot[B H P] \cdot \frac{1}{K_{S O 3 H-H P A} \cdot[H P A]+K_{S O} \mathrm{SH}_{-B H P} \cdot[\mathrm{BHP}]+1} \cdot \omega_{\text {Cat.Amb }} \\
& R_{H P A_{-} S O 3 H}=k_{H P A_{-} S O 3 H} \cdot[H P A] \cdot \frac{1}{K_{S O 3 H-H P A} \cdot[H P A]+K_{S O} \mathrm{SH}_{-B H P} \cdot[B H P]+1} \cdot \omega_{\text {Cat.RuC }} \\
& R_{\text {BHP_diss }}=k_{\text {BHP_diss }} \cdot[\text { BHP] }] \cdot[L A] \\
& R_{H P A_{-} d i s S}=k_{H P A_{-} d i s S} \cdot[H P A] \cdot[L A]
\end{aligned}
$$




\subsection{Material balances}

Kinetic experiments were carried out under isobaric and isothermal conditions. Our previous study [46] found that external and internal mass transfer can be assumed to be negligible by using the operating conditions described in Section 2.

Material balances for different compounds in the liquid phase can be expressed as:

$\frac{d C_{B L}}{d t}=-R_{B L_{-} h y d}$

$\frac{d\left[\mathrm{H}_{2}\right]_{l i q}}{d t}=k_{L} \cdot a *\left(\left[\mathrm{H}_{2}\right]_{\text {liq }}^{*}-\left[\mathrm{H}_{2}\right]_{\text {liq }}\right)-R_{B L_{-} \text {hyd }}-R_{\text {LA_hyd }}$

$\frac{d C_{B H P}}{d t}=R_{B L_{-} \text {hyd }}-R_{\text {BHP_noncat }}-R_{\text {BHP_RuC }}-R_{\text {BHP_SO3H }}-R_{\text {BHP_diss }}$

$\frac{d C_{\text {BuOH }}}{d t}=R_{\text {BHP_noncat }}+R_{\text {BHP_RuC }}+R_{\text {BHP_sO3H }}+R_{\text {BHP_diss }}$

$\frac{d C_{L A}}{d t}=-R_{L A \_} h y d$

$\frac{d C_{H P A}}{d t}=R_{L A \_h y d}-R_{H P A_{-} n o n c a t}-R_{H P A \_R u C}-R_{H P A \_S O 3 H}-R_{H P A \_d i s S}$

$\frac{d C_{\text {Water }}}{d t}=R_{H P A_{\text {noncat }}}+R_{H P A_{R u C}}+R_{H P A_{S O 3 H}}+R_{H P A_{-} \text {diss }}$

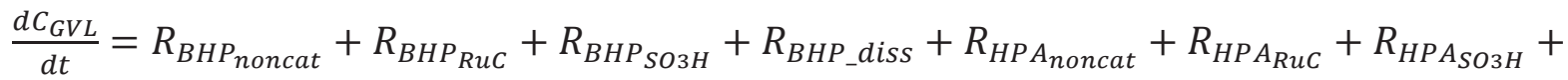

$R_{H P A_{-} d i s S}$

The term $\left[\mathrm{H}_{2}\right]_{\text {liq }}^{*}$ is the concentration of hydrogen at the gas-liquid interface. The values of this term were determined through Henry's constant in GVL solvent $H e(T)=\frac{\left[\mathrm{H}_{2}\right]_{\text {liq }}^{*}}{P_{\mathrm{H}_{2}, \text { Reactor }}}[38]$. In this study 
the values of $k_{L} \cdot a$, i.e., volumetric gas to liquid mass transfer coefficient for hydrogen was expressed as a function of density, viscosity and temperature [19].

\subsection{Modeling}

The commercial software Athena Visual Studio, using Bayesian statistics, was used for the simulation and estimation stages $[62,63]$. A Bayesian framework is considered to be more suitable for multi-response parameter estimation than the classical method of nonlinear least squares $[55,64]$. For the parameter estimation in Bayesian, one needs to determine the determinant criterion $[65]$.

The concentrations of BL, BHP, LA and HPA were used as observables during the parameter estimation stage. The ODEs (9-16) were integrated by the DDAPLUS solver, included in Athena Visual Studio software. This solver is a modified Newton algorithm with a fixed leading coefficient backward difference formula to approximate the first-order derivative [66].

The subroutine package named GREGPLUS, was used to minimize the objective function $S(\partial)$, to calculate the credible intervals for each estimated parameter and to produce the normalized parameter covariance matrix.

To minimize the objective function $S(\partial)$, GREGPLUS uses successive quadratic programming starting from the user's initial guesses [62,64].

$S(\partial)=(a+b+1) \cdot \ln |v(\partial)|$

where, $a$ is the number of events in response, $b$ is the number of responses and $|v(\partial)|$ is the determinant of the covariance matrix of the responses. Each element of this matrix is defined as $v_{i j}(\partial)=\sum_{u=1}^{n}\left[Y_{i u}-f_{i u}(\partial)\right] \cdot\left[Y_{j u}-f_{j u}(\partial)\right]$

With $Y_{i u}$ the experimental concentration and $f_{i u}(\partial)$ the estimated value for response $i$ and event $u$; $Y_{j u}$ the experimental concentration and $f_{j u}(\partial)$ the estimated value for response $j$ and event $u$. 
The interval estimates for each estimated parameter are calculated from the final quadratic expansion of the objective function. The precision of the estimated parameters was evaluated by the marginal highest posterior density (HPD). The 95\% marginal HPD was calculated by GREGPLUS package.

The modified Arrhenius equation is used to decrease the correlation between the pre-exponential factor and the activation energy.

$k\left(T_{R}\right)=k\left(T_{\text {ref }}\right) \cdot \exp \left(-\frac{E_{a}}{R x}\left(\frac{1}{T_{R}}-\frac{1}{T_{r e f}}\right)\right)$

where $T_{r e f}$ is the reference temperature chosen in the considered experimental temperature range.

During the modeling stage of the seven models, the following constants tended to approach zero during the preliminary iteration:

-the adsorption constants for BHP and HPA on $\mathrm{Ru} / \mathrm{C}$ for the hydrogenation steps,

-the activation energy for the cyclization of BHP and HPA over Amberlite IR-120,

-the adsorption constants for BHP and HPA over Amberlite IR-120 for the cyclization steps,

-the activation energy for the cyclization of BHP and HPA due to the acid sites from $\mathrm{Ru} / \mathrm{C}$,

-the adsorption constant for BHP and HPA over the acid sites from $\mathrm{Ru} / \mathrm{C}$,

-The equilibrium constant $\mathrm{K}_{\mathrm{C} 2}$ was also found to be low in model NCLH2.2.

For that reason, it was deemed reasonable to fix the values of these estimated parameters to zero.

Table 3 shows the regression parameters for each model:

-Sum of Squared Residuals (SSR) $\left(Y_{j u}-f_{j u}(\partial)\right)^{2}$

-Objective function defined by Equation $17 S(\partial)$ 
-Number of estimated parameters

- Akaike information criterion (AIC) calculated by

AIC: number of independant event $\cdot \ln \left(\frac{\left[Y_{j u}-f_{j u}(\partial)\right]^{2}}{\text { number of independant event }}\right)+2$. Number of estimated parameters (20).

The AIC value [60] allows including the number of estimated parameters in the model discrimination. Models with low AIC are the most reliable.

Table 3. Regression parameters for each model

\begin{tabular}{|c|c|c|c|c|}
\hline & SSR & $\begin{array}{c}\text { Objective } \\
\text { function }\end{array}$ & $\begin{array}{c}\text { Number of estimated } \\
\text { parameters }\end{array}$ & AIC \\
\hline LH1 & 11693900 & 24125 & 19 & 13224.9 \\
\hline LH2 & 11665200 & 24127 & 19 & 13221.3 \\
\hline NCLH1.1 & 11697000 & 24154 & 19 & 13225.3 \\
\hline NCLH1.2 & 10757800 & 23987 & 19 & 13102.4 \\
\hline ER1 & 11685300 & 24153 & 19 & 13223.8 \\
\hline NCLH2.1 & 11773600 & 24142 & 17 & 13230.9 \\
\hline NCLH2.2 & 10443600 & 23940 & 18 & 13056.9 \\
\hline
\end{tabular}

Table 3 shows that NCLH1.2 and NCLH2.2 yield to low values of SSR, objective function and AIC. Due to space limitation, the estimated parameters, normalized covariance matrix and fit of these two models hereby reported, whereas the results obtained for the rest of the models analysed are included in the Supplementary Materials (S3). The results obtained in the present work is in agreement with with our previous work [29], where we found that NCLH1 was the most probable model for the hydrogenation of BL. 
Table 4 shows the estimated values and the associated credible intervals (HPD\%). The credible intervals for $\mathrm{K}_{\mathrm{H} 2}$ and for $k_{\text {HPA_noncat }}\left(T_{R e f}\right)$ are large due to the difficulty of estimating these values. The difficulty in estimating $\mathrm{K}_{\mathrm{H} 2}$ is linked to the fact that the hydrogen pressure does not significantly affect the kinetics. The high uncertainty for $k_{H P A_{-} n o n c a t}\left(T_{R e f}\right)$ is linked to the difficulty to tract HPA due to its high reactivity. The HPD intervals can be considered as low or medium for the other estimated parameters showing that the variation of the operating conditions was significant. Table 4 shows that the rate constant of LA hydrogenation is higher than the one of BL hydrogenation. The rate constants of HPA cylization are higher than the ones of BHP cyclization (Table 4). 
Table 4. Estimated Values at $\mathrm{T}_{\text {ref }}=392.72 \mathrm{~K}$ and statistical Data for NCLH1.2

\begin{tabular}{|c|c|c|c|c|}
\hline \multicolumn{2}{|c|}{ Parameters } & Units & Estimates & HPD\% \\
\hline Par1 & $k_{B L \_ \text {hyd }}\left(T_{R e f}\right)$ & $\mathrm{m}^{3} \cdot \mathrm{mol}^{-1} \cdot \mathrm{s}^{-1} \cdot \mathrm{kg}$ _dry basis $\mathrm{RuC}^{-1}$ & $3.11 \mathrm{E}-06$ & 14.57 \\
\hline Par2 & $E a_{B L \_h y d}$ & ${\mathrm{~J} . \mathrm{mol}^{-1}}^{-1}$ & $3.62 \mathrm{E}+04$ & 7.43 \\
\hline Par3 & $K_{H 2}$ & $\mathrm{~m}^{3} \cdot \mathrm{mol}^{-1}$ & $7.36 \mathrm{E}-04$ & $>100 \%$ \\
\hline Par4 & $K_{B L^{\wedge}}$ & $\mathrm{m}^{3} \cdot \mathrm{mol}^{-1}$ & $9.14 \mathrm{E}-04$ & 29.02 \\
\hline Par5 & $K_{B H P^{\wedge}}$ & $\mathrm{m}^{3} \cdot \mathrm{mol}^{-1}$ & Fixed to zero & - \\
\hline Par6 & $k_{\text {BHP_cat_Amb }}^{\prime}\left(T_{R e f}\right)$ & $\mathrm{s}^{-1} \cdot \mathrm{kg}$ _dry basis $\mathrm{Amb}^{-1}$ & 4.17E-05 & 49.21 \\
\hline Par7 & $E a_{B H P \_c a t \_A m b}^{\prime}$ & $\mathrm{J}^{\mathrm{mol}}{ }^{-1}$ & Fixed to zero & - \\
\hline Par8 & $k_{\text {BHP_noncat }}\left(T_{\text {Ref }}\right)$ & $\mathrm{s}^{-1}$ & $5.78 \mathrm{E}-05$ & 30.35 \\
\hline Par9 & $E a_{\text {BHP_noncat }}$ & ${\mathrm{J} . \mathrm{mol}^{-1}}^{-1}$ & $8.67 \mathrm{E}+04$ & 32.38 \\
\hline Par10 & $k_{L A \_h y d}\left(T_{R e f}\right)$ & $\mathrm{m}^{3} \cdot \mathrm{mol}^{-1} \cdot \mathrm{s}^{-1} \cdot \mathrm{kg}$ dry basis $\mathrm{RuC}^{-1}$ & $8.08 \mathrm{E}-06$ & 12.03 \\
\hline Par11 & $E a_{L A_{\_} h y d}$ & $\mathrm{~J}^{\mathrm{mol}}{ }^{-1}$ & $4.65 E+04$ & 6.47 \\
\hline Par12 & $K_{L A^{\wedge}}$ & $\mathrm{m}^{3} \cdot \mathrm{mol}^{-1}$ & $1.75 \mathrm{E}-03$ & 15.80 \\
\hline Par13 & $K_{H P A^{\wedge}}$ & $\mathrm{m}^{3} \cdot \mathrm{mol}^{-1}$ & Fixed to zero & - \\
\hline Par14 & $k_{H P A \_c a t \_A m b}^{\prime}\left(T_{R e f}\right)$ & $\mathrm{s}^{-1} \cdot \mathrm{kg}$ _dry basis $\mathrm{Amb}^{-1}$ & 4.84E-04 & 49.37 \\
\hline Par15 & $E a_{H P A_{-} c a t}^{\prime} A m b$ & $\mathrm{~J}^{\mathrm{m} \mathrm{mol}^{-1}}$ & Fixed to zero & - \\
\hline Par16 & $k_{H P A \_n o n c a t}\left(T_{R e f}\right)$ & $\mathrm{s}^{-1}$ & $1.12 \mathrm{E}-06$ & $>100 \%$ \\
\hline Par17 & $E a_{\text {HPA_noncat }}$ & ${\mathrm{J} . \mathrm{mol}^{-1}}^{-1}$ & $4.22 \mathrm{E}+05$ & 23.87 \\
\hline Par18 & $K_{B H P-S O 3 H}$ & $\mathrm{~m}^{3} \cdot \mathrm{mol}^{-1}$ & Fixed to zero & - \\
\hline Par19 & $K_{H P A-S O 3 H}$ & $\mathrm{~m}^{3} \cdot \mathrm{mol}^{-1}$ & Fixed to zero & - \\
\hline Par20 & $k_{\text {BHP_RuC }}\left(T_{R e f}\right)$ & $\mathrm{s}^{-1} \cdot \mathrm{kg} \_$dry basis $\mathrm{RuC}^{-1}$ & $2.43 \mathrm{E}-05$ & 16.96 \\
\hline Par21 & $E a_{B H P_{-} R u C}$ & $\mathrm{~J}^{\mathrm{mol}}{ }^{-1}$ & Fixed to zero & - \\
\hline Par22 & $k_{H P A \_R u C}\left(T_{R e f}\right)$ & $\mathrm{s}^{-1} . \mathrm{kg} \_$dry basis $\mathrm{RuC}^{-1}$ & $5.80 \mathrm{E}-05$ & 7.69 \\
\hline Par23 & $E a_{H P A \_R U C}$ & $\mathrm{~J}^{\mathrm{mol}}{ }^{-1}$ & Fixed to zero & - \\
\hline Par24 & $K_{\square B H P}$ & $\mathrm{~m}^{3} \cdot \mathrm{mol}^{-1}$ & Fixed to zero & - \\
\hline Par25 & $K_{\mathbf{n} H P A}$ & $\mathrm{~m}^{3} \cdot \mathrm{mol}^{-1}$ & Fixed to zero & - \\
\hline Par26 & $k_{\text {BHP_diss }}\left(T_{R e f}\right)$ & $\mathrm{m}^{3} \cdot \mathrm{mol}^{-1} \cdot \mathrm{s}^{-1}$ & $1.70 \mathrm{E}-06$ & 16.83 \\
\hline Par27 & $E a_{B H P \_d i s s}$ & $\mathrm{~J}^{\mathrm{mol}}{ }^{-1}$ & $1.06 \mathrm{E}+05$ & 13.31 \\
\hline Par28 & $k_{H P A \_d i s S}\left(T_{R e f}\right)$ & $\mathrm{m}^{3} \cdot \mathrm{mol}^{-1} \cdot \mathrm{s}^{-1}$ & 4.73E-06 & 6.99 \\
\hline Par29 & $E a_{H P A \_d i s S}$ & $\mathrm{~J}^{\mathrm{mol}}{ }^{-1}$ & $6.78 \mathrm{E}+04$ & 7.96 \\
\hline
\end{tabular}

Table S3.11 shows the correlation between the estimated parameters. In general, the correlations are low. The significant correlation between $k_{B L_{-} h y d}\left(T_{R e f}\right)$ and $K_{B L^{\wedge}}$ are due to the difficulty to 
estimate the adsorption constant, and the strong correlation $k_{B H P \_n o n c a t}\left(T_{R e f}\right)$ and $E a_{B H P_{-} n o n c a t}$ is because the non-catalytic cyclization of BHP is relatively slow.

Fig. S4.1 displays the parity plots for BL, BHP, LA and HPA. NCLH2.1 model can predict BL and LA concentrations very well. The prediction of BHP and HPA concentrations is slightly lower due to the difficulty of tracking these intermediates.

Fig. 9 shows the fit of the model to the experimental concentrations with the $95 \%$ Prediction Intervals and the mean estimated values. From these graphs, one can notice that the model fits the experiments, and most of the experimental concentrations lie between the intervals. The intermediate concentrations for Experiment 10 are low due to the presence of Amberlite IR-120. 

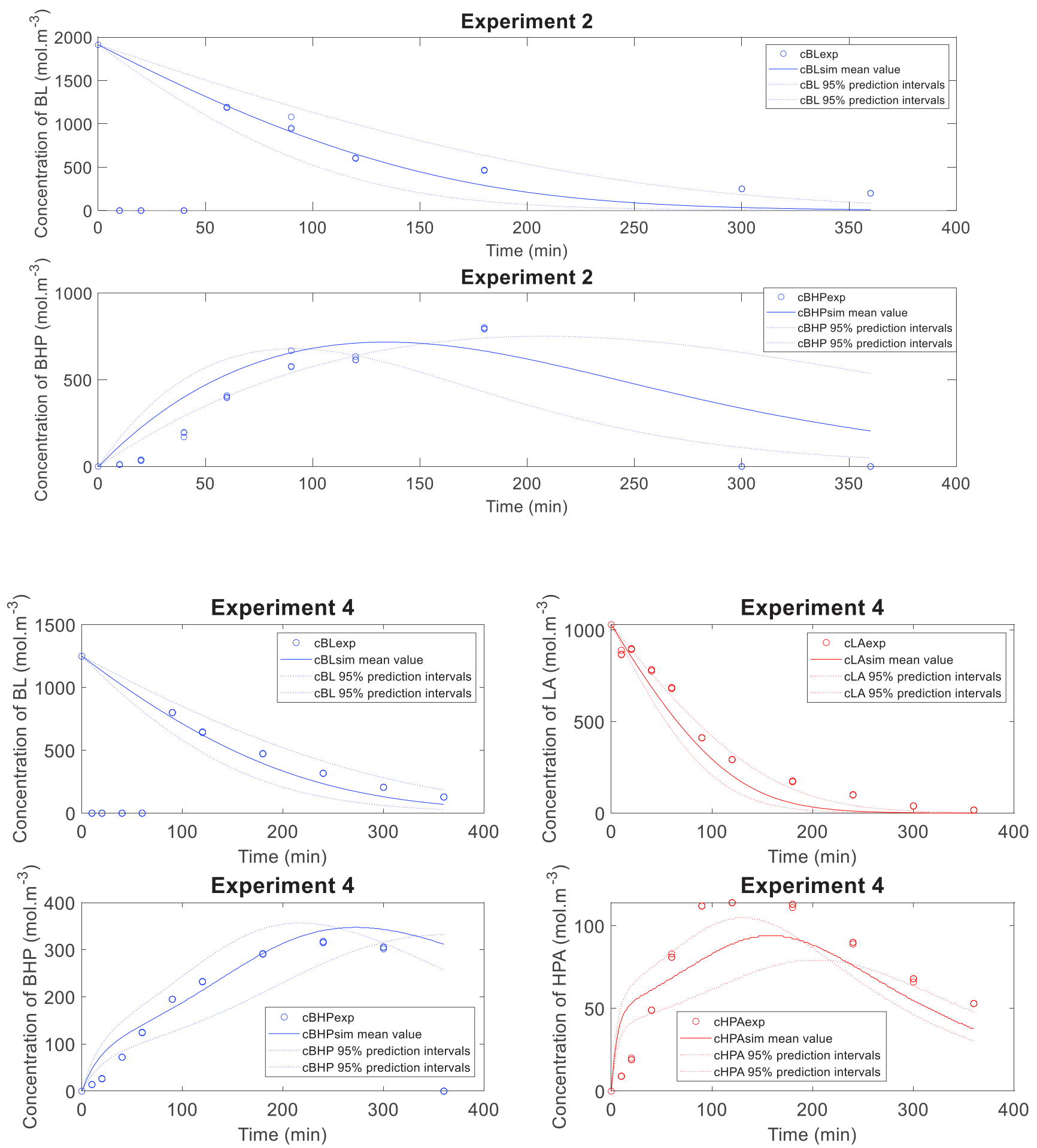

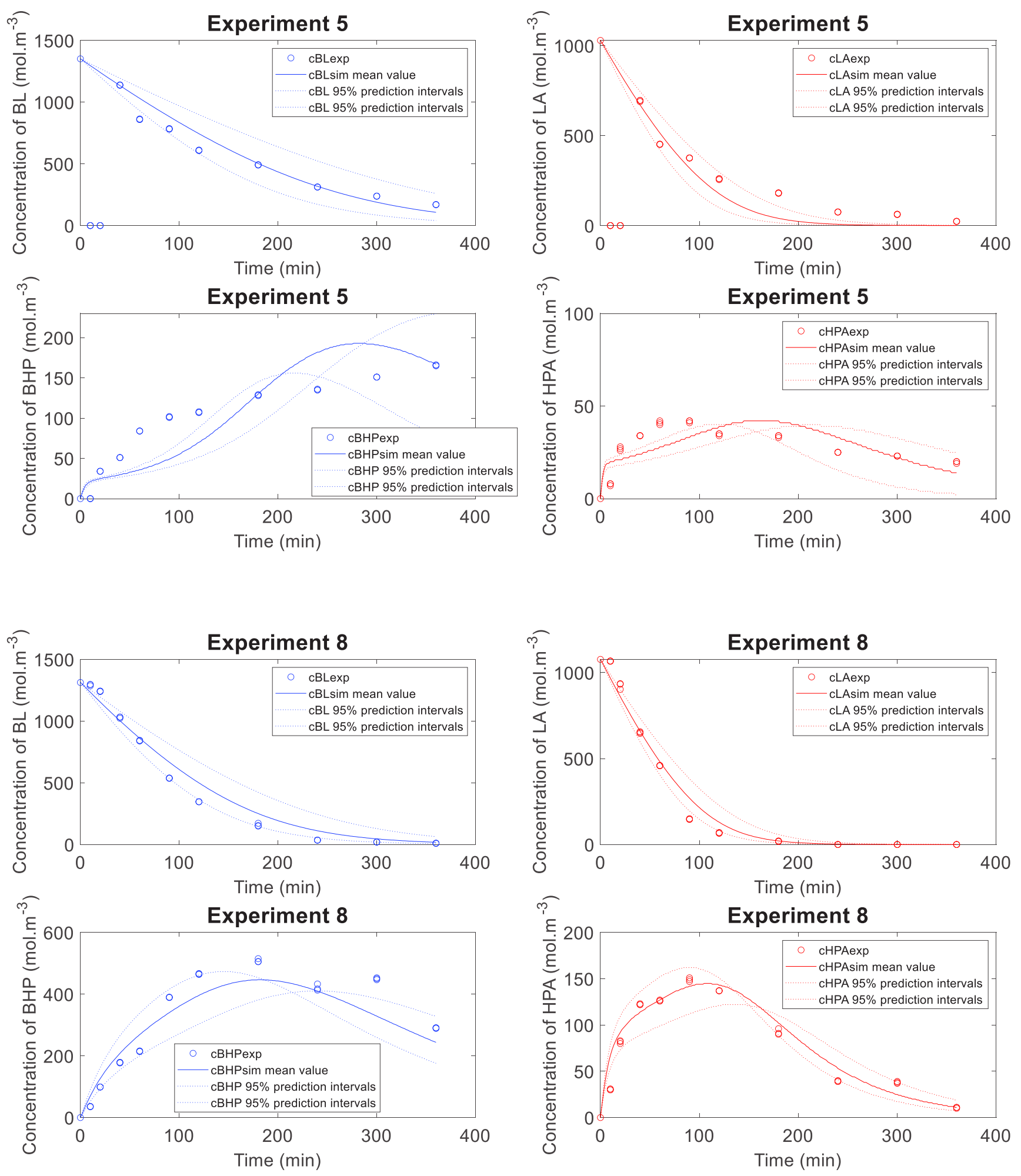

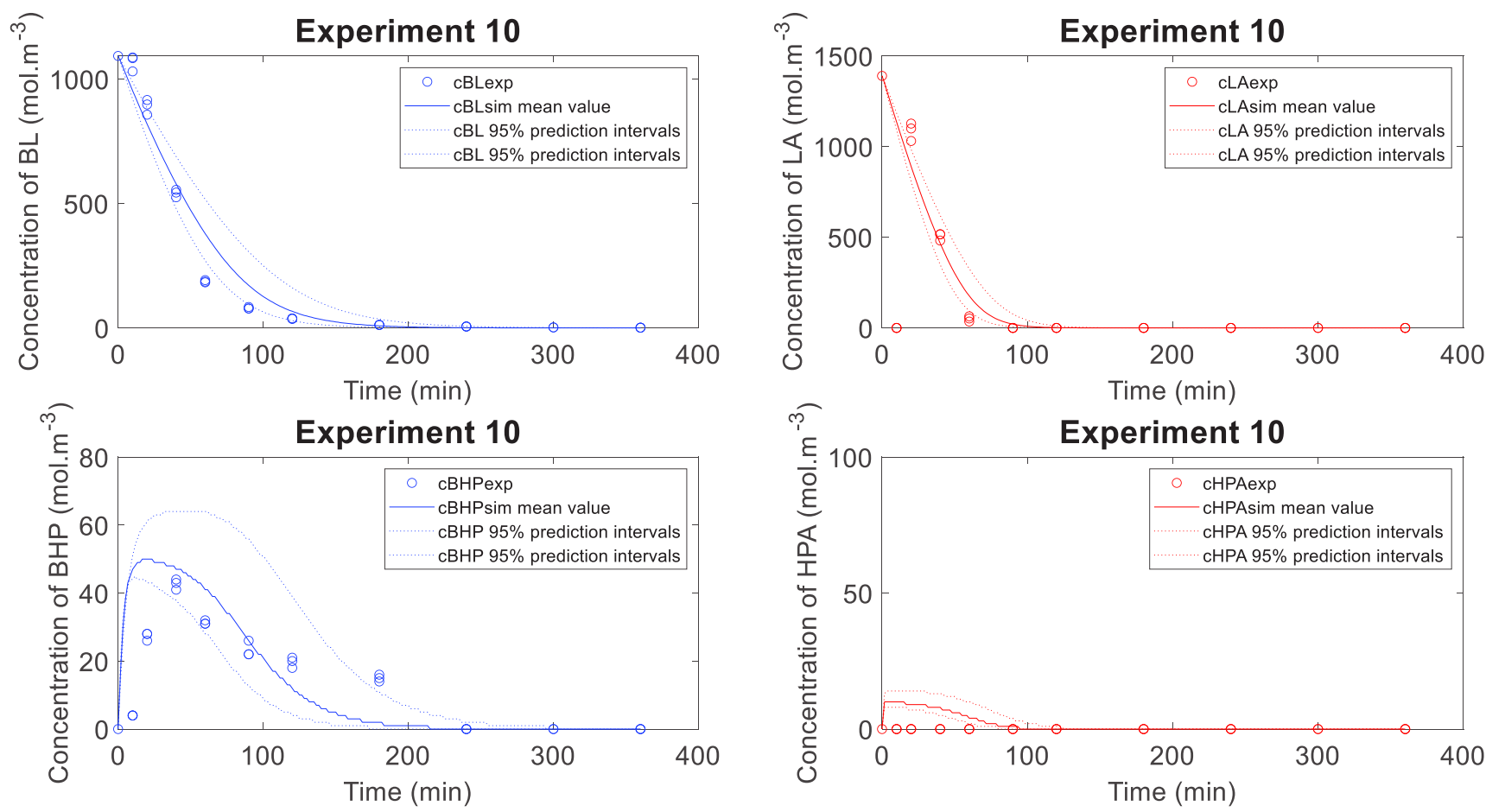

Fig. 9. Fit of Model NCLH1.2 to the experimental concentrations with prediction intervals.

\section{$\mathrm{NCLH} 22$}

Table 5 displays the estimated values and their credible intervals. During the modeling for this model, it was not possible to estimate $K_{H 2}$. and $K_{B L^{\wedge}}$ for that reason, their values were fixed to zero. The $95 \%$ HPD for $k_{H P A \_n o n c a t}\left(T_{R e f}\right)$ is higher due to the high reactivity of HPA. The HPD intervals for the other parameters can be assumed to be medium or low. From Table 5, one can notice that the rate constant of LA hydrogenation is higher than the one of BL. The rate constants of HPA cylization (from LA dissociation, $\mathrm{Ru} / \mathrm{C}$ and Amerlite IR-120) are higher than the ones of BHP cyclization (Table 5). 
Table 5. Estimated Values at $\mathrm{T}_{\text {ref }}=392.72 \mathrm{~K}$ and Statistical Data for NCLH2.2

\begin{tabular}{|c|c|c|c|}
\hline \multicolumn{2}{|c|}{ Parameters } & Estimates & HPD $\%$ \\
\hline Par1 & $k_{B L_{-} h y d}\left(T_{R e f}\right)$ & $3.02 \mathrm{E}-06$ & 11.42 \\
\hline Par2 & $E a_{B L_{-} h y d}$ & $3.69 \mathrm{E}+04$ & 7.17 \\
\hline Par3 & $K_{H 2}$. & Fixed to zero & - \\
\hline Par4 & $K_{B L^{\wedge}}$ & Fixed to zero & - \\
\hline Par5 & $K_{B H P^{\wedge}}$ & Fixed to zero & - \\
\hline Par6 & $k_{B H P \_c a t \_A m b}^{\prime}\left(T_{R e f}\right)$ & $4.36 \mathrm{E}-05$ & 48.29 \\
\hline Par7 & $E a_{B H P \_c a t \_A m b}^{\prime}$ & Fixed to zero & - \\
\hline Par8 & $k_{\text {BHP_noncat }}\left(T_{R e f}\right)$ & $5.93 \mathrm{E}-05$ & 30.40 \\
\hline Par9 & $E a_{\text {BHP_noncat }}$ & $7.78 \mathrm{E}+04$ & 35.92 \\
\hline Par10 & $k_{L A \_h y d}\left(T_{R e f}\right)$ & $7.75 \mathrm{E}-06$ & 9.17 \\
\hline Par11 & $E a_{L A \_h y d}$ & $4.61 \mathrm{E}+04$ & 6.51 \\
\hline Par12 & $K_{L A^{\wedge}}$ & $1.69 \mathrm{E}-03$ & 15.86 \\
\hline Par13 & $K_{H P A^{\wedge}}$ & Fixed to zero & - \\
\hline Par14 & $k_{H P A_{\_} c a t \_A m b}^{\prime}\left(T_{R e f}\right)$ & 4.79E-04 & 49.34 \\
\hline Par15 & $E a_{H P A_{-} \text {cat_Amb }}^{\prime}$ & Fixed to zero & - \\
\hline Par16 & $k_{H P A \_n o n c a t}\left(T_{R e f}\right)$ & $1.25 \mathrm{E}-06$ & $>100 \%$ \\
\hline Par17 & $E a_{H P A \_n o n c a t}$ & $4.15 \mathrm{E}+05$ & 24.08 \\
\hline Par18 & $K_{B H P-S O 3 H}$ & Fixed to zero & - \\
\hline Par19 & $K_{H P A-S O 3 H}$ & Fixed to zero & - \\
\hline Par20 & $k_{\text {BHP_RuC }}\left(T_{R e f}\right)$ & $2.41 \mathrm{E}-05$ & 17.61 \\
\hline Par21 & $E a_{\text {BHP_RuC }}$ & Fixed to zero & - \\
\hline Par22 & $k_{\text {HPA_RuC }}\left(T_{R e f}\right)$ & $5.74 \mathrm{E}-05$ & 7.61 \\
\hline Par23 & $E a_{H P A \_R u C}$ & Fixed to zero & - \\
\hline Par24 & $K_{\mathbf{\square} B H P}$ & Fixed to zero & - \\
\hline Par25 & $K_{\square H P A}$ & Fixed to zero & - \\
\hline Par26 & $\mathrm{Kc}$ & $1.59 \mathrm{E}-04$ & 25.39 \\
\hline Par27 & $\mathrm{Kc} 2$ & Fixed to zero & - \\
\hline Par28 & $k_{\text {BHP_diss }}\left(T_{R e f}\right)$ & $1.69 \mathrm{E}-06$ & 16.19 \\
\hline Par29 & $E a_{\text {BHP_diss }}$ & $1.09 \mathrm{E}+05$ & 12.83 \\
\hline Par30 & $k_{H P A_{-} \text {disS }}\left(T_{R e f}\right)$ & 4.73E-06 & 6.71 \\
\hline Par31 & $E a_{H P A \_d i s S}$ & $6.70 \mathrm{E}+04$ & 8.01 \\
\hline
\end{tabular}


Table S3.12 shows the correlation between the estimated parameters. One can notice a significant correlation between the following parameters: $k_{B L_{-} h y d}\left(T_{R e f}\right)$ and $\mathrm{Kc} ; k_{B H P \_n o n c a t}\left(T_{R e f}\right)$ and $E a_{\text {BHP_noncat }} ; k_{L A \_ \text {hyd }}\left(T_{R e f}\right)$ and $K_{L A^{\wedge}}$ and $k_{H P A \_n o n c a t}\left(T_{R e f}\right)$ and $E a_{H P A \_n o n c a t}$.

Fig. S4.2 shows the parity plot for BL, LA, BHP and HPA. Similar to Model NCLH1.2, the prediction for BL and LA is better than for the intermediates.

Fig. 10 shows the fit of the model to the experimental concentrations with the $95 \%$ prediction. The fitting is similar to the previous model.
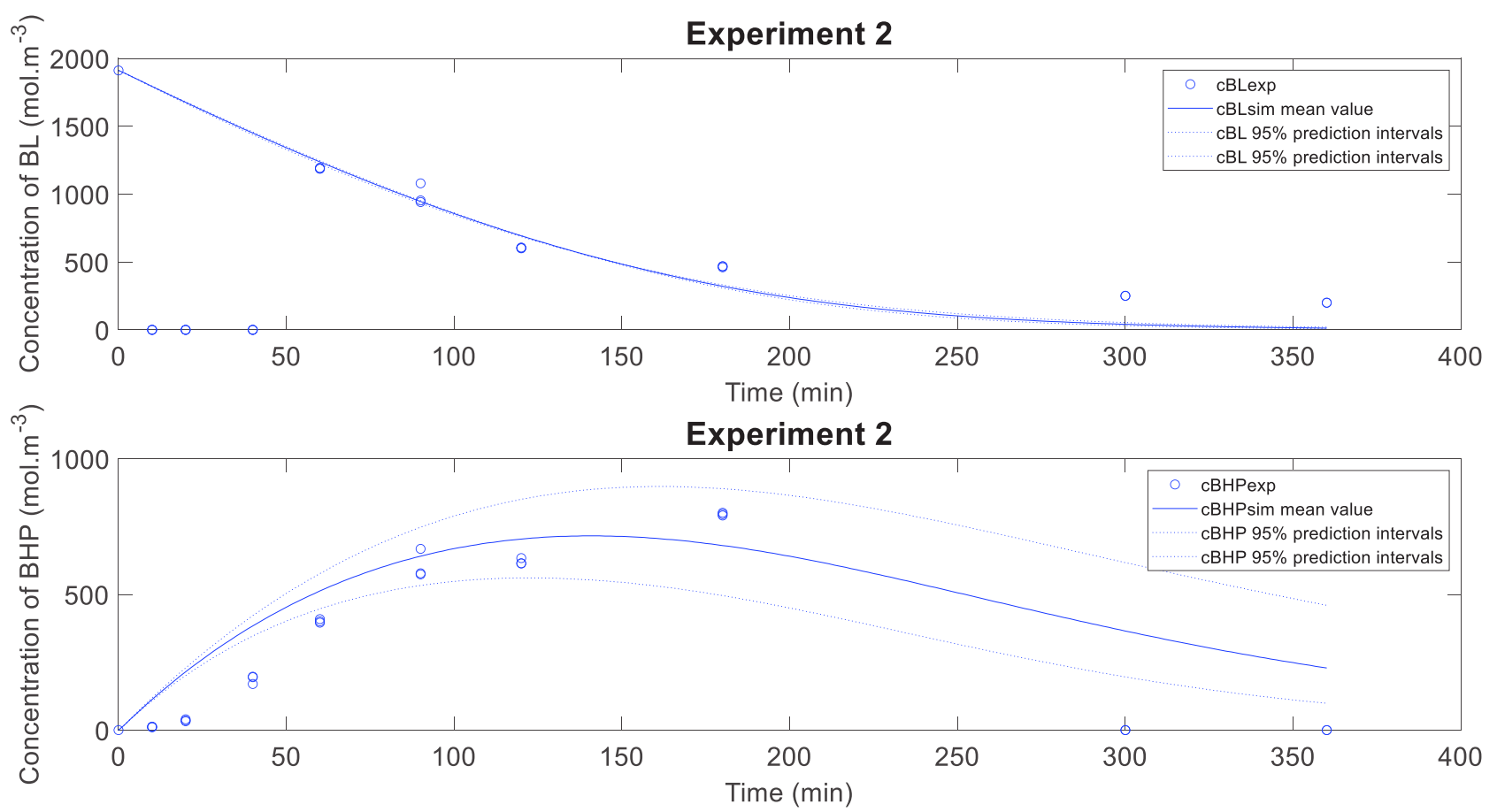

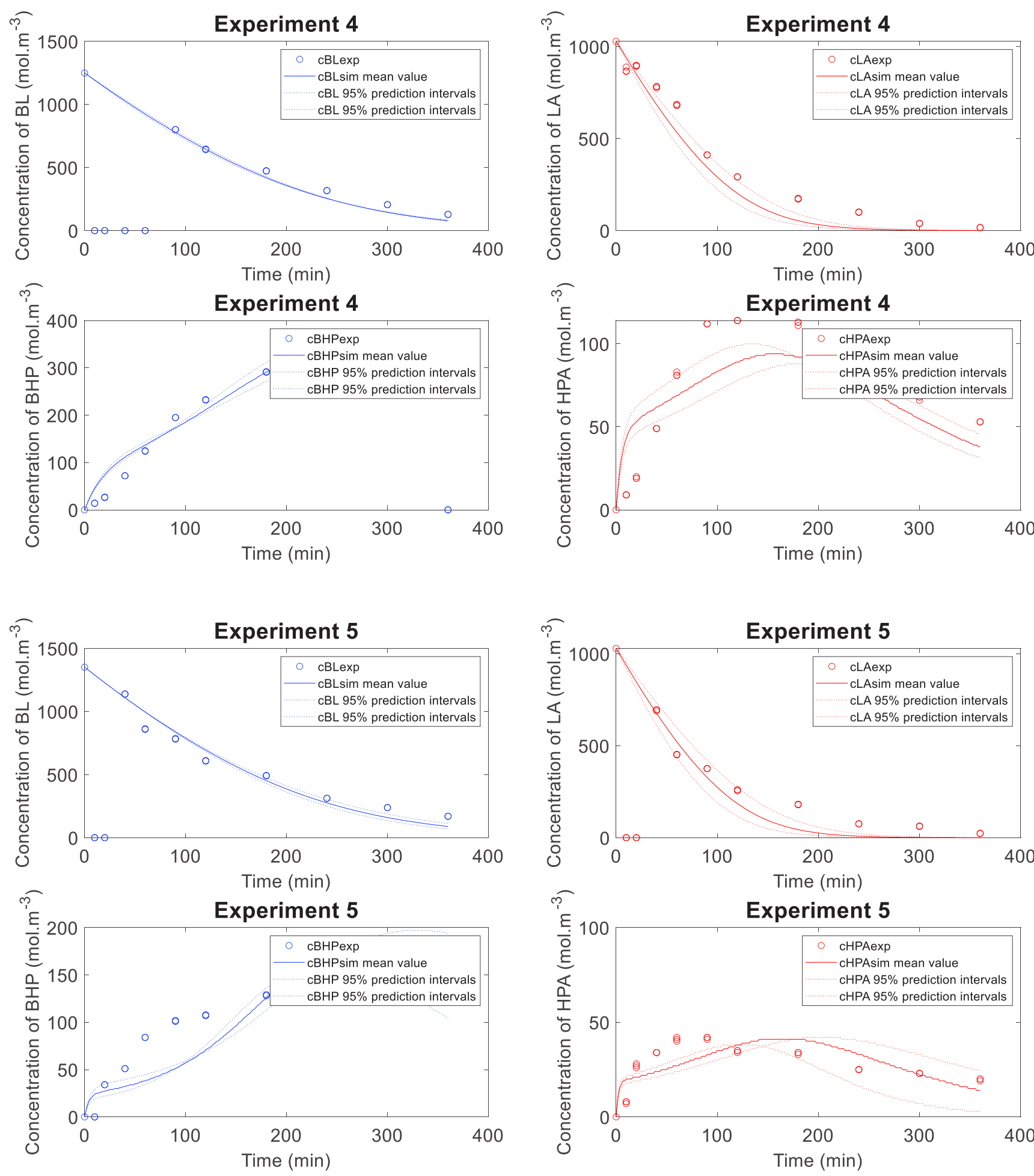

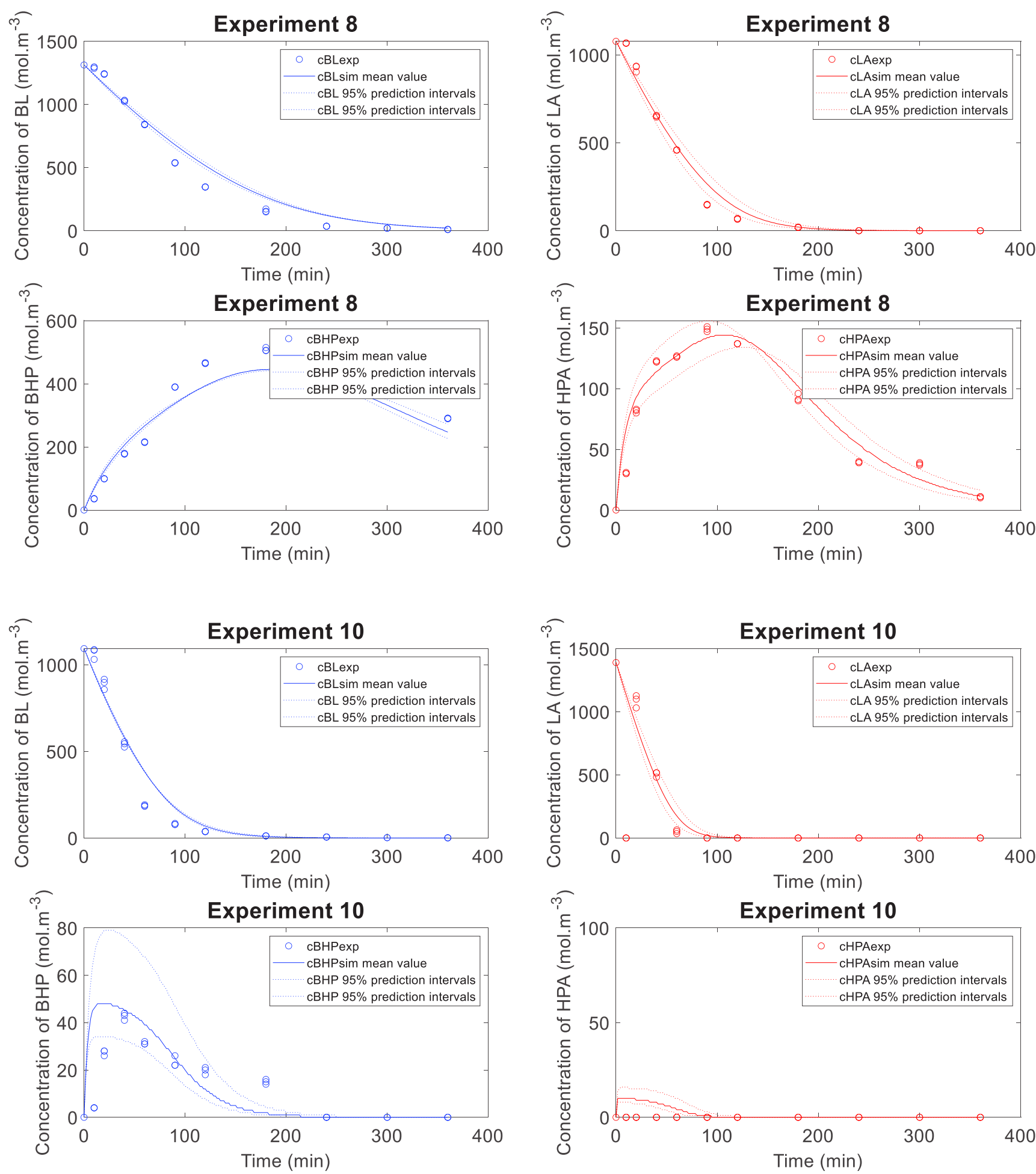

Fig. 10. Fit of Model NCLH2.2 with prediction intervals to the experimental concentrations. 


\subsection{Cross-validation: K-fold}

The final stage of the assessment was the cross-validation one. Cross-validation was used to evaluate the predictability of the models and to determine the most probable one. The K-fold method was used [61]. The14 experiments were divided randomly into 7 folds (Table 6). The regressions (a.k.a traning) were made on 6 folds and validation (a.k.a testing) on the remaining fold as illustrated by Table 7 .

Table 6. Distribution of the 14 experiments in the 7 folds.

\begin{tabular}{|l|c|}
\hline FOLD & EXPERIMENTS \\
\hline Fold 1 & 10 \\
& 11 \\
\hline Fold 2 & 14 \\
& 9 \\
\hline Fold 3 & 8 \\
& 1 \\
\hline Fold 4 & 13 \\
& 7 \\
\hline Fold 5 & 12 \\
& 2 \\
\hline Fold 6 & 6 \\
& 4 \\
\hline Fold 7 & 5 \\
& 3 \\
\hline
\end{tabular}


Table 7. Different Sets for regression and validation.

\begin{tabular}{|c|c|c|}
\hline Set & Regression/Train & Validation/Test \\
\hline Set 1 & Folds 1-2-3-4-5-6 & Fold 7 \\
\hline Set 2 & Folds 7-1-2-3-4-5 & Fold 5 \\
\hline Set 3 & Folds 6-7-1-2-3-4 & Fold 4 \\
\hline Set 4 & Folds 5-6-7-1-2-3 & Fold 3 \\
\hline Set 5 & Folds 4-5-6-7-1-2 & Fold 2 \\
\hline Set 6 & Folds 3-4-5-6-7-1 & Fold 1 \\
\hline Set 7 & Folds 2-3-4-5-6-7 & \\
\hline
\end{tabular}

The kinetic constants are estimated from each regression, and these estimated constants are used for the validation. To evaluate the prediction capacity of a model the $C V_{(K)}$ number is calculated.

$C V_{(K)}=\frac{1}{7} \cdot \sum_{K=1}^{7}\left(Y_{i, \text { experimental }}-Y_{i, \text { simulated }}\right)_{K}^{2}$

The lower the $\mathrm{CV}_{(\mathrm{K})}$, the better the model is predictable. Table 8 shows that $C V_{(K)}$ number is lower for NCLH1.2 and NCLH2.2. The standard deviation of $C V_{(K)}$ was calculated for each model, and it was found that the standard deviation was lower for NCLH1.2 and NCLH2.2. This means that the validation step was similar for each set. 
Table $8 . \mathrm{CV}_{(\mathrm{K})}$ and standard deviation for each model

\begin{tabular}{|c|c|c|}
\hline & $\mathrm{CV}_{(\mathrm{K})}$ & $\mathrm{SD}\left(\mathrm{CV}_{(\mathrm{K})}\right) / \%$ \\
\hline LH1 & 3586050 & 99.88 \\
\hline LH2 & 3656893 & 93.19 \\
\hline NCLH1.1 & 3635269 & 94.19 \\
\hline NCLH1.2 & 2168016 & 28.66 \\
\hline ER1 & 3595498 & 95.09 \\
\hline NCLH2.1 & 3690655 & 92.00 \\
\hline NCLH22 & 1978294 & 27.47 \\
\hline
\end{tabular}

In Supplementary Materials (S5), the estimated values for each regression set were displayed for NCLH1.2 and NCLH2.2. One can notice that the estimation was similar for each set compared to the estimation with the whole experimental data, i.e., the ones displayed in Tables 4 and 6.

To validate the models by cross-validation, Fig. 11 displays the coefficient of determination for the training step, test set and all data (i.e., Figs S4.1 and S4.2). One can notice that these values are similar, meaning that both models are validated. 

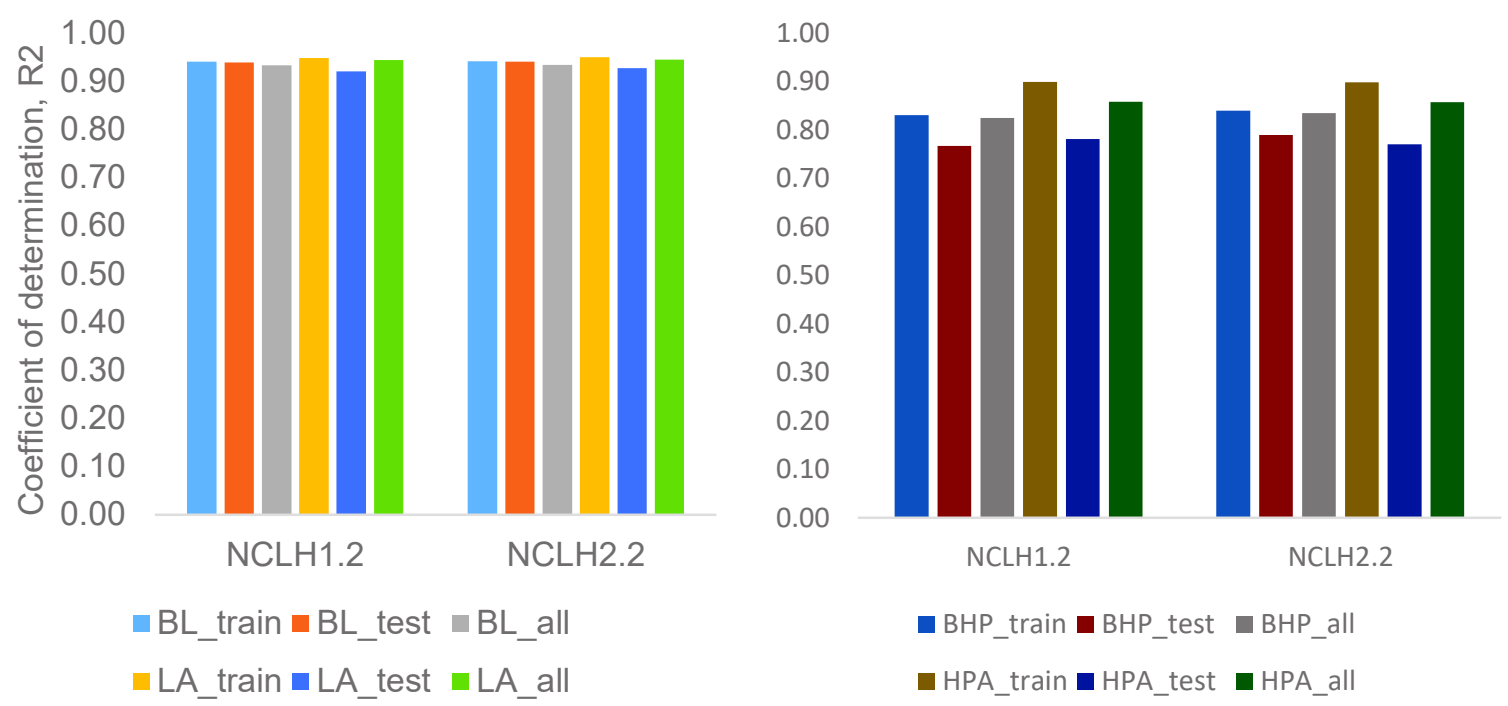

Fig. 11. Coefficient of determinations for training, test and all for the different models. 


\section{Conclusions}

One of the most common routes for the production of GVL is the hydrogenation of levulinic acid or alkyl levulinates. When alkyl levulinates produced from the alcoholysis of fructose, there is the presence of levulinic acid is also produced in the system. This paper proposed to investigate the kinetics of the hydrogenation of butyl levulinate and levulinic acid in GVL solvent over $\mathrm{Ru} / \mathrm{C}$. To increase the kinetics of the cyclization step, Amberlite IR-120 catalyst was added in the reaction mixture.

In the first analysis, it was found that the presence of LA can increase the kinetics of cyclization and Amberlite IR-120 has a significant catalytic effect on this reaction.

In the second step, several kinetic models, via Bayesian inference, were evaluated for the hydrogenation steps throughout K-fold approach. Seven kinetic models were evaluated: competitive Langmuir-Hinshelwood with no dissociation of hydrogen (LH1), competitive Langmuir-Hinshelwood with dissociation of hydrogen (LH2), non-competitive LangmuirHinshelwood with no dissociation of hydrogen where LA and BL are in competitive adsorption on the same site but not hydrogen (NCLH1.1), non-competitive Langmuir-Hinshelwood with no dissociation of hydrogen where LA, BL and $\mathrm{H}_{2}$ are adsorbed on different sites (NCLH1.2), EleyRideal with no adsorption of hydrogen on the active sites (ER), non-competitive LangmuirHinshelwood with dissociation of hydrogen where LA and BL are in competitive adsorption on the same site but not hydrogen (NCLH2.1), and non-competitive Langmuir-Hinshelwood with dissociation of hydrogen where LA, BL and $\mathrm{H} 2$ are adsorbed on different sites (NCLH2.2). It was found that NCLH1.2 and NCLH2.2 were the most probable models, and the prediction capacity of these models was higher compared to the other. 
This paper showed the benefit to using such reaction mixture system for the production of GVL. From an industrial viewpoint, the hydrogenation of levulinic acid and alkyl levulinate can be consecutive to the alcoholysis process. Quantum mechanics calculation could give more information concerning the adosption mechanism. 


\section{Notation}

$\begin{array}{ll}\mathrm{Ea}_{\mathrm{i}} & \text { activation energy of reaction } i\left[\mathrm{~J}_{\mathrm{m}} \mathrm{mol}^{-1}\right] \\ f(\partial) & \text { estimated concentration } \\ \mathrm{He} & \text { Henry's coefficient }\left[\mathrm{mol} \cdot \mathrm{m}^{-3} \cdot \mathrm{bar}^{-1}\right] \\ \mathrm{k}_{\mathrm{i}} & \text { rate constant of reaction } i \\ \mathrm{Ki} & \text { adsorption rate of specie } \mathrm{i} \\ \mathrm{k}_{\mathrm{L} \cdot \mathrm{a}} & \text { polumetric mass transfer coefficient }\left[\mathrm{s}^{-1}\right] \\ \mathrm{P} & \text { reaction rate } i\left[\mathrm{~mol} \cdot \mathrm{m}^{-3} \cdot \mathrm{s}^{-1}\right] \\ \mathrm{R}_{\mathrm{i}} & \text { gas constant }\left[\mathrm{J} \cdot \mathrm{K}^{-1} \cdot \mathrm{mol}^{-1}\right] \\ \mathrm{R} & \text { objective funtion } \\ S(\partial) & \text { temperature }[\mathrm{K}] \\ \mathrm{T} & \text { determinant of the covariance matrix of responses } \\ |v(\partial)| & \text { experimental concentration of specie i } \\ \mathrm{Y}_{\mathrm{i}} & \end{array}$

Greek letters

$\Theta$

catalyst active sites

$\theta_{i} \quad$ active sites occupied by specie $\mathrm{i}$

$\omega_{\text {Cat }} \quad$ catalyst loading $\left[\mathrm{kg} \cdot \mathrm{m}^{-3}\right]$

Subscripts and superscripts
Ref
reference
* interfacial value 
Abbreviations

AIC

AL

Amb

BL

BHP

ER

GC

GVL

HPA

HDP

LA

LCB

LH1

LH2

NCLH1.1

NCLH1.2
Akaike information criterion

Alkyl levulinate

Amberlite IR-120

Butyl levulinate

Butyl 4-hydroxypentanoate

Eley-Rideal kinetic model without hydrogen adsorption

Gas chromatography

$\gamma$-valerolactone

4-hydroxypentanoic acid

Highest Posterior Density

Levulinic acid

Lignocellulosic biomass

Langmuir-Hinshelwood kinetic model without hydrogen dissociation

Langmuir-Hinshelwood kinetic model with hydrogen dissociation

Non-competitive Langmuir-Hinshelwood kinetic model without

hydrogen dissociation, where BL and LA are in competitive adsorption on the same site but not hydrogen

Non-competitive Langmuir-Hinshelwood kinetic model without hydrogen dissociation, where BL, LA and hydrogen are adsorbed on different sites 
NCLH2.1 Non-competitive Langmuir-Hinshelwood kinetic model with hydrogen dissociation, where BL and LA are in competitive adsorption on the same site but not hydrogen

NCLH2.2 Non-competitive Langmuir-Hinshelwood kinetic model with hydrogen dissociation, where BL, LA and hydrogen are adsorbed on different sites

ODEs Ordinary differential equation system

$\mathrm{ROH}$ Co-product of the ciclyzation step(water or butanol)

$\mathrm{Ru} / \mathrm{C} \quad$ Ruthenium on activated carbon

SSR Sum of squared residuals 


\section{Acknowledgments}

The authors thank the Maitrise des Risques et Environementaux department, and the Erasmus programme to make the research project of Giulia Bronzetti possible. The authors thank the Ministry of High Education, Science and Technology of Dominican Republic (MESCYT). For the analytical part, the authors thank University of Rouen Normandy, INSA Rouen Normandy, the Centre National de la Recherche Scientifique (CNRS), European Regional Development Fund (ERDF) N HN0001343, Labex SynOrg (ANR-11-LABX-0029), Carnot Institute I2C, the graduate school for reasearch XL-Chem (ANR-18-EURE-0020 XL CHEM) and Region Normandie for their support. GC/FID was financed by FEDER RIN Green Chem 2019NU01FOBC08 N 17P04374.

This research was funded, in whole or in part, by [ANR-DFG, ANR-20-CE92-0002 Deutsche Forschungsgemeinschaft (DFG) - Project number 446436621]. 


\section{References}

[1] A.K. Chandel, V.K. Garlapati, S.P. Jeevan Kumar, M. Hans, A.K. Singh, S. Kumar, The role of renewable chemicals and biofuels in building a bioeconomy, Biofuels, Bioprod. Biorefining. 14 (2020) 830-844. https://doi.org/10.1002/bbb.2104.

[2] B. Kumar, P. Verma, Biomass-based biorefineries: An important architype towards a circular economy, Fuel. 288 (2021) 119622. https://doi.org/10.1016/J.FUEL.2020.119622.

[3] D. Sengupta, R.W. Pike, Chemicals from biomass: Integrating bioprocesses into chemical production complexes for sustainable development, CRC Press, Boca Raton, FL, USA, 2012. https://doi.org/10.1201/b12341.

[4] P.B. Thompson, The agricultural ethics of biofuels: The food vs. fuel debate, Agric. 2 (2012) 339-358. https://doi.org/10.3390/agriculture2040339.

[5] F.H. Isikgor, C.R. Becer, Lignocellulosic biomass: a sustainable platform for the production of bio-based chemicals and polymers, Polym. Chem. 6 (2015) 4497-4559. https://doi.org/10.1039/c5py00263j.

[6] S. Takkellapati, T. Li, M.A. Gonzalez, An overview of biorefinery-derived platform chemicals from a cellulose and hemicellulose biorefinery, Clean Technol. Environ. Policy 2018 207. 20 (2018) 1615-1630. https://doi.org/10.1007/S10098-018-1568-5.

[7] K. Kohli, R. Prajapati, B.K. Sharma, Bio-Based Chemicals from Renewable Biomass for Integrated Biorefineries, Energies 2019, Vol. 12, Page 233. 12 (2019) 233. https://doi.org/10.3390/EN12020233.

[8] R. Liu, J. Chen, X. Huang, L. Chen, L. Ma, X. Li, Conversion of fructose into 5- 
hydroxymethylfurfural and alkyl levulinates catalyzed by sulfonic acid-functionalized carbon materials, Green Chem. $15 \quad$ (2013) 2895-2903. https://doi.org/10.1039/C3GC41139G.

[9] S.-H. Pyo, S.J. Glaser, N. Rehnberg, R. Hatti-Kaul, Clean Production of Levulinic Acid from Fructose and Glucose in Salt Water by Heterogeneous Catalytic Dehydration, ACS Omega. 5 (2020) 14275-14282. https://doi.org/10.1021/ACSOMEGA.9B04406.

[10] Levulinic Acid Market Size, Share \& Trends | 2021 - 2026, (n.d.). https://www.marketdataforecast.com/market-reports/levulinic-acid-market (accessed August 28, 2021).

[11] Levulinic Acid Market Size | Industry Trends, Growth and Forecast to 2020-2030, (n.d.). https://www.psmarketresearch.com/market-analysis/levulinic-acid-market ～(accessed August 28, 2021).

[12] D.M. Alonso, S.G. Wettstein, J.A. Dumesic, Gamma-valerolactone, a sustainable platform molecule derived from lignocellulosic biomass, Green Chem. 15 (2013) 584-595. https://doi.org/10.1039/C3GC37065H.

[13] K. Yan, Y. Yang, J. Chai, Y. Lu, Catalytic reactions of gamma-valerolactone: A platform to fuels and value-added chemicals, Appl. Catal. B Environ. 179 (2015) 292-304. https://doi.org/10.1016/j.apcatb.2015.04.030.

[14] I.T. Horváth, H. Mehdi, V. Fábos, L. Boda, L.T. Mika, $\gamma$-Valerolactone—a sustainable liquid for energy and carbon-based chemicals, Green Chem. 10 (2008) 238-242. https://doi.org/10.1039/B712863K. 
[15] A.K. Chew, T.W. Walker, Z. Shen, B. Demir, L. Witteman, J. Euclide, G.W. Huber, J.A. Dumesic, R.C. Van Lehn, Effect of Mixed-Solvent Environments on the Selectivity of AcidCatalyzed Dehydration Reactions, ACS Catal. $10 \quad$ (2020) 1679-1691. https://doi.org/10.1021/acscatal.9b03460.

[16] C. Laurence, S. Mansour, D. Vuluga, J. Legros, Measurement of the hydrogen bond acceptance of ionic liquids and green solvents by the $19 \mathrm{~F}$ solvatomagnetic comparison method, Green Chem. 23 (2021) 1816-1822. https://doi.org/10.1039/D0GC04104A.

[17] H. Lin, J. Chen, Y. Zhao, S. Wang, Conversion of C5 Carbohydrates into Furfural Catalyzed by SO3H-Functionalized Ionic Liquid in Renewable $\gamma$-Valerolactone, Energy \& Fuels. 31 (2017) 3929-3934. https://doi.org/10.1021/acs.energyfuels.6b01975.

[18] C. Liu, M. Wei, J. Wang, J. Xu, J. Jiang, K. Wang, Facile Directional Conversion of Cellulose and Bamboo Meal Wastes over Low-Cost Sulfate and Polar Aprotic Solvent, ACS Sustain. Chem. Eng. 8 (2020) 5776-5786. https://doi.org/10.1021/acssuschemeng.0c01280.

[19] H. Ariba, Y. Wang, C. Devouge-Boyer, R.P. Stateva, S. Leveneur, Physicochemical Properties for the Reaction Systems: Levulinic Acid, Its Esters, and $\gamma$-Valerolactone, J. Chem. Eng. Data. 65 (2020) 3008-3020. https://doi.org/10.1021/acs.jced.9b00965.

[20] V. Pokorný, V. Štejfa, M. Fulem, C. Červinka, K. Růžička, Vapor Pressures and Thermophysical Properties of Ethylene Carbonate, Propylene Carbonate, $\gamma$-Valerolactone, and $\gamma$-Butyrolactone, J. Chem. Eng. Data. 62 (2017) 4174-4186. https://doi.org/10.1021/acs.jced.7b00578.

[21] W.R.H. Wright, R. Palkovits, Development of heterogeneous catalysts for the conversion of 
levulinic acid to $\gamma$-valerolactone, ChemSusChem. 5 (2012) 1657-1667. https://doi.org/10.1002/cssc.201200111.

[22] J.Q. Bond, D.M. Alonso, D. Wang, R.M. West, J.A. Dumesic, Integrated Catalytic Conversion of $\gamma$-Valerolactone to Liquid Alkenes for Transportation Fuels, Science (80-. ). 327 (2010) 1110-1114. https://doi.org/10.1126/SCIENCE.1184362.

[23] J. Han, Integrated process for simultaneous production of jet fuel range alkenes and Nmethylformanilide using biomass-derived gamma-valerolactone, J. Ind. Eng. Chem. 48 (2017) 173-179. https://doi.org/10.1016/J.JIEC.2016.12.036.

[24] Z. Zhang, Synthesis of $\gamma$-Valerolactone from Carbohydrates and its Applications, ChemSusChem. 9 (2016) 156-171. https://doi.org/10.1002/CSSC.201501089.

[25] Z. Yu, X. Lu, C. Liu, Y. Han, N. Ji, Synthesis of $\gamma$-valerolactone from different biomassderived feedstocks: Recent advances on reaction mechanisms and catalytic systems, Renew. Sustain. Energy Rev. 112 (2019) 140-157. https://doi.org/10.1016/J.RSER.2019.05.039.

[26] M.G. Al-Shaal, W.R.H. Wright, R. Palkovits, Exploring the ruthenium catalysed synthesis of $\gamma$-valerolactone in alcohols and utilisation of mild solvent-free reaction conditions, Green Chem. 14 (2012) 1260-1263. https://doi.org/10.1039/C2GC16631C.

[27] H. Xu, D. Hu, M. Zhang, Y. Wang, Z. Zhao, Z. Jiang, H.F. Garces, K. Yan, Bimetallic NiCu Alloy Catalysts for Hydrogenation of Levulinic Acid, ACS Appl. Nano Mater. 4 (2021) 3989-3997. https://doi.org/10.1021/acsanm.1c00339.

[28] S. Capecci, Y. Wang, V. Casson Moreno, C. Held, S. Leveneur, Solvent effect on the kinetics of the hydrogenation of n-butyl levulinate to $\gamma$-valerolactone, Chem. Eng. Sci. 231 (2021) 
116315. https://doi.org/10.1016/j.ces.2020.116315.

[29] S. Capecci, Y. Wang, J. Delgado, V.C. Moreno, M. Mignot, H. Grénman, D.Y. Murzin, S. Leveneur, Bayesian Statistics to Elucidate the Kinetics of $\gamma$-Valerolactone from n-Butyl Levulinate Hydrogenation over Ru/C, Ind. Eng. Chem. Res. 60 (2021) 11725-11736. https://doi.org/10.1021/ACS.IECR.1C02107.

[30] A.S. Piskun, H.H. van de Bovenkamp, C.B. Rasrendra, J.G.M. Winkelman, H.J. Heeres, Kinetic modeling of levulinic acid hydrogenation to $\gamma$-valerolactone in water using a carbon supported $\mathrm{Ru}$ catalyst, Appl. Catal. A Gen. $525 \quad$ (2016) 158-167. https://doi.org/10.1016/j.apcata.2016.06.033.

[31] A.M. Hengne, C. V Rode, $\mathrm{Cu}-\mathrm{ZrO} 2$ nanocomposite catalyst for selective hydrogenation of levulinic acid and its ester to $\gamma$-valerolactone, Green Chem. 14 (2012) 1064-1072. https://doi.org/10.1039/C2GC16558A.

[32] W. Luo, U. Deka, A.M. Beale, E.R.H. van Eck, P.C.A. Bruijnincx, B.M. Weckhuysen, Ruthenium-catalyzed hydrogenation of levulinic acid: Influence of the support and solvent on catalyst selectivity and stability, J. Catal. 301 (2013) 175-186. https://doi.org/10.1016/j.jcat.2013.02.003.

[33] H. Mehdi, V. Fábos, R. Tuba, A. Bodor, L.T. Mika, I.T. Horváth, Integration of Homogeneous and Heterogeneous Catalytic Processes for a Multi-step Conversion of Biomass: From Sucrose to Levulinic Acid, $\gamma$-Valerolactone, 1,4-Pentanediol, 2-Methyltetrahydrofuran, and Alkanes, Top. Catal. 48 (2008) 49-54. https://doi.org/10.1007/s11244008-9047-6. 
[34] K. Shimizu, S. Kanno, K. Kon, Hydrogenation of levulinic acid to $\gamma$-valerolactone by Ni and MoOx co-loaded carbon catalysts, Green Chem. $16 \quad$ (2014) 3899-3903. https://doi.org/10.1039/C4GC00735B.

[35] O.A. Abdelrahman, A. Heyden, J.Q. Bond, Analysis of kinetics and reaction pathways in the aqueous-phase hydrogenation of levulinic acid to form $\gamma$-Valerolactone over $\mathrm{Ru} / \mathrm{C}$, ACS Catal. 4 (2014) 1171-1181. https://doi.org/10.1021/cs401177p.

[36] Y. Wang, I. Plazl, L. Vernières-Hassimi, S. Leveneur, From calorimetry to thermal risk assessment: $\gamma$-Valerolactone production from the hydrogenation of alkyl levulinates, Process Saf. Environ. Prot. (2020). https://doi.org/10.1016/j.psep.2020.07.017.

[37] Y. Wang, L. Vernières-Hassimi, V. Casson-Moreno, J.-P. Hébert, S. Leveneur, Thermal Risk Assessment of Levulinic Acid Hydrogenation to $\gamma$-Valerolactone, Org. Process Res. Dev. 22 (2018) 1092-1100. https://doi.org/10.1021/acs.oprd.8b00122.

[38] Y. Wang, M. Cipolletta, L. Vernières-Hassimi, V. Casson-Moreno, S. Leveneur, Application of the concept of Linear Free Energy Relationships to the hydrogenation of levulinic acid and its corresponding esters, Chem. Eng. J. $374 \quad$ (2019) 822-831. https://doi.org/10.1016/j.cej.2019.05.218.

[39] P.A. Son, S. Nishimura, K. Ebitani, Production of $\gamma$-valerolactone from biomass-derived compounds using formic acid as a hydrogen source over supported metal catalysts in water solvent, RSC Adv. 4 (2014) 10525-10530. https://doi.org/10.1039/C3RA47580H.

[40] J. Yuan, S.-S. Li, L. Yu, Y.-M. Liu, Y. Cao, H.-Y. He, K.-N. Fan, Copper-based catalysts for the efficient conversion of carbohydrate biomass into $\gamma$-valerolactone in the absence of 
externally added hydrogen, Energy Environ. Sci. 6 (2013) 3308-3313. https://doi.org/10.1039/C3EE40857D.

[41] L. Deng, J. Li, D.-M. Lai, Y. Fu, Q.-X. Guo, Catalytic Conversion of Biomass-Derived Carbohydrates into $\gamma$-Valerolactone without Using an External H2 Supply, Angew. Chemie Int. Ed. 48 (2009) 6529-6532. https://doi.org/10.1002/anie.200902281.

[42] L. Deng, Y. Zhao, J. Li, Y. Fu, B. Liao, Q.-X. Guo, Conversion of Levulinic Acid and Formic Acid into $\gamma$-Valerolactone over Heterogeneous Catalysts, ChemSusChem. 3 (2010) 11721175. https://doi.org/10.1002/cssc.201000163.

[43] V. Fábos, L.T. Mika, I.T. Horváth, Selective Conversion of Levulinic and Formic Acids to $\gamma$-Valerolactone with the Shvo Catalyst, Organometallics. 33 (2014) 181-187. https://doi.org/10.1021/om400938h.

[44] C. Fellay, P.J. Dyson, G. Laurenczy, A Viable Hydrogen-Storage System Based On Selective Formic Acid Decomposition with a Ruthenium Catalyst, Angew. Chemie Int. Ed. 47 (2008) 3966-3968. https://doi.org/10.1002/anie.200800320.

[45] H. Heeres, R. Handana, D. Chunai, C.B. Rasrendra, B. Girisuta, H.J. Heeres, Combined dehydration/(transfer)-hydrogenation of C6-sugars (D-glucose and D-fructose) to $\gamma$ valerolactone using ruthenium catalysts, Green Chem. 11 (2009) 1247-1255. https://doi.org/10.1039/B904693C.

[46] A.M. Hengne, A. V Malawadkar, N.S. Biradar, C. V Rode, Surface synergism of an Ag$\mathrm{Ni} / \mathrm{ZrO} 2$ nanocomposite for the catalytic transfer hydrogenation of bio-derived platform molecules, RSC Adv. 4 (2014) 9730-9736. https://doi.org/10.1039/C3RA46495D. 
[47] A.M. Ruppert, M. Jędrzejczyk, O. Sneka-Płatek, N. Keller, A.S. Dumon, C. Michel, P. Sautet, J. Grams, Ru catalysts for levulinic acid hydrogenation with formic acid as a hydrogen source, Green Chem. $18 \quad$ (2016) 2014-2028. https://doi.org/10.1039/C5GC02200B.

[48] H. Li, Z. Fang, S. Yang, Direct Conversion of Sugars and Ethyl Levulinate into $\gamma$ Valerolactone with Superparamagnetic Acid-Base Bifunctional ZrFeOx Nanocatalysts, ACS Sustain. Chem. $\quad$ Eng. $4 \quad$ (2016) 236-246. https://doi.org/10.1021/acssuschemeng.5b01480.

[49] M. Chia, J.A. Dumesic, Liquid-phase catalytic transfer hydrogenation and cyclization of levulinic acid and its esters to $\gamma$-valerolactone over metal oxide catalysts, Chem. Commun. 47 (2011) 12233-12235. https://doi.org/10.1039/C1CC14748J.

[50] H. Li, Z. Fang, S. Yang, Direct Catalytic Transformation of Biomass Derivatives into Biofuel Component $\gamma$-Valerolactone with Magnetic Nickel-Zirconium Nanoparticles, Chempluschem. 81 (2016) 135-142. https://doi.org/10.1002/cplu.201500492.

[51] E. Ramírez, R. Bringué, C. Fité, M. Iborra, J. Tejero, F. Cunill, Assessment of ion exchange resins as catalysts for the direct transformation of fructose into butyl levulinate, Appl. Catal. A Gen. 612 (2021) 117988. https://doi.org/10.1016/J.APCATA.2021.117988.

[52] J.N. Appaturi, M.R. Johan, R.J. Ramalingam, H.A. Al-Lohedan, J.J. Vijaya, Efficient synthesis of butyl levulinate from furfuryl alcohol over ordered mesoporous Ti-KIT-6 catalysts for green chemistry applications, RSC Adv. (2017). https://doi.org/10.1039/c7ra10289e. 
[53] C. Moreno-Marrodan, P. Barbaro, Energy efficient continuous production of $\gamma$-valerolactone by bifunctional metal/acid catalysis in one pot, Green Chem. 16 (2014) 3434-3438. https://doi.org/10.1039/C4GC00298A.

[54] A.M.R. Galletti, C. Antonetti, V. De Luise, M. Martinelli, A sustainable process for the production of $\gamma$-valerolactone by hydrogenation of biomass-derived levulinic acid, Green Chem. 14 (2012) 688-694. https://doi.org/10.1039/C2GC15872H.

[55] J. Kopyscinski, J. Choi, J.M. Hill, Comprehensive kinetic study for pyridine hydrodenitrogenation on (Ni)WP/SiO2 catalysts, Appl. Catal. A Gen. 445-446 (2012) 5060. https://doi.org/10.1016/j.apcata.2012.08.027.

[56] S.H. Hsu, S.D. Stamatis, J.M. Caruthers, W.N. Delgass, V. Venkatasubramanian, G.E. Blau, M. Lasinski, S. Orcun, Bayesian framework for building kinetic models of catalytic systems, Ind. Eng. Chem. Res. 48 (2009) 4768-4790. https://doi.org/10.1021/ie801651y.

[57] J. Kopyscinski, T.J. Schildhauer, F. Vogel, S.M.A. Biollaz, A. Wokaun, Applying spatially resolved concentration and temperature measurements in a catalytic plate reactor for the kinetic study of CO methanation, J. Catal. $271 \quad$ (2010) 262-279. https://doi.org/10.1016/j.jcat.2010.02.008.

[58] N. Thakar, R.J. Berger, F. Kapteijn, J.A. Moulijn, Modelling kinetics and deactivation for the selective hydrogenation of an aromatic ketone over Pd/SiO2, Chem. Eng. Sci. 62 (2007) 5322-5329. https://doi.org/10.1016/j.ces.2007.01.059.

[59] J.P. Bernacki, R.M. Murphy, Model discrimination and mechanistic interpretation of kinetic data in protein aggregation studies, Biophys. J. 96 (2009) 2871-2887. 
https://doi.org/10.1016/j.bpj.2008.12.3903.

[60] M.A. McDonald, L. Bromig, M.A. Grover, R.W. Rousseau, A.S. Bommarius, Kinetic model discrimination of penicillin $\mathrm{G}$ acylase thermal deactivation by non-isothermal continuous activity assay, Chem. Eng. Sci. 187 (2018) 79-86. https://doi.org/10.1016/j.ces.2018.04.046.

[61] Y. Slotboom, M.J. Bos, J. Pieper, V. Vrieswijk, B. Likozar, S.R.A. Kersten, D.W.F. Brilman, Critical assessment of steady-state kinetic models for the synthesis of methanol over an industrial $\mathrm{Cu} / \mathrm{ZnO} / \mathrm{Al} 2 \mathrm{O} 3$ catalyst, $\quad$ Chem. Eng. J. $389 \quad(2020) 124181$. https://doi.org/10.1016/J.CEJ.2020.124181.

[62] W.E. Stewart, M. Caracotsios, Computer-Aided Modeling of Reactive Systems, Wiley \& So, Wiley \& Sons, New Jersey, 2008.

[63] W.E. Stewart, M. Caracotsios, Athena Visual Studio, (n.d.). www.athenavisual.com.

[64] W.E. Stewart, M. Caracotsios, J.P. Sørensen, Parameter estimation from multiresponse data, AIChE J. 38 (1992) 641-650. https://doi.org/10.1002/aic.690380502.

[65] M.A.J.S. VAN BOEKEL, Statistical Aspects of Kinetic Modeling for Food Science Problems, J. Food Sci. 61 (1996) 477-486. https://doi.org/10.1111/J.13652621.1996.TB13138.X.

[66] M. Caracotsios, W.E. Stewart, Sensitivity analysis of initial value problems with mixed odes and algebraic equations, Comput. Chem. Eng. 9 (1985) 359-365. https://doi.org/10.1016/0098-1354(85)85014-6. 


\section{Supporting information}

\section{Synergy effect of dual catalysts for the synthesis of $\boldsymbol{\gamma}$-valerolactone from $\boldsymbol{n}$-butyl levulinate}

hydrogenation over Ru/C and Amberlite IR-120.

Jose Delgado $^{1,4 \pm}$, Wenel Naudy Vasquez Salcedo ${ }^{1 \pm}$, Giulia Bronzetti $^{1,2}$, Valeria Casson Moreno ${ }^{2}$, Mélanie Mignot ${ }^{3}$, Julien Legros ${ }^{3}$, Christoph Held ${ }^{5}$, Henrik Grénman ${ }^{4}$, Sébastien Leveneur ${ }^{1 *}$

${ }^{\text {I} N o r m a n d i e ~ U n i v, ~ I N S A ~ R o u e n, ~ U N I R O U E N, ~ L S ~ P C, ~ E A 4704, ~} 76000$ Rouen, France, E-mail: sebastien.leveneur@insa-rouen.fr

${ }^{2}$ Dipartimento di Ingegneria Chimica, Civile, Ambientale e dei Materiali, Alma Mater StudiorumUniversità di Bologna, via Terracini 28, 40131 Bologna, Italy

${ }^{3}$ COBRA UMR CNRS 6014, Normandie Université, INSA de Rouen, avenue de l'Université, SaintEtienne-du-Rouvray, 76800, France

${ }^{4}$ Laboratory of Industrial Chemistry \& Reaction Engineering, Department of Chemical Engineering, Johan Gadolin Process Chemistry Centre, Åbo Akademi University, FI-20500 Åbo-Turku, Finland

${ }^{5}$ Laboratory of Thermodynamics, TU Dortmund, Germany

${ }^{ \pm}$These authors contributed equally to the work. 


\section{S1. Derivation of hydrogenation rate expression}

Langmuir Hinshelwood with molecular adsorption of $\mathrm{H}_{2}$ (LH1)

$$
\begin{aligned}
& \mathrm{BL}+*(\text { vacant site }) \rightleftharpoons * \mathrm{BL} \\
& \mathrm{H} 2+*(\text { vacant site }) \rightleftharpoons * \mathrm{H} 2 \text { (molecular adsorption }) \\
& \mathrm{LA}+*(\text { vacant site }) \rightleftharpoons * \mathrm{LA} \\
& * \mathrm{BL}+* \mathrm{H} 2 \rightleftharpoons * \mathrm{BHP} \\
& * \mathrm{LA}+* \mathrm{H} 2 \rightleftharpoons * \mathrm{HPA} \\
& * \mathrm{HPA} \rightleftharpoons *+\mathrm{HPA} \\
& \mathrm{BHP} \rightarrow \mathrm{GVL}+\mathrm{BuOH} \\
& \mathrm{HPA} \rightarrow \mathrm{GVL}+\mathrm{H}_{2} \mathrm{O}
\end{aligned}
$$

The adsorption and desorption steps are considered to be very fast reaching quasi-equilibria. Thus,

$K_{B L *}=\frac{\theta_{* B L}}{[B L] \cdot \theta_{*}}$

$K_{L A *}=\frac{\theta_{* L A}}{[L A] \cdot \theta_{*}}$

$K_{H 2 \cdot}=\frac{\theta \cdot H 2}{[H 2] \cdot \theta}$

$K_{B H P *}=\frac{\theta_{* B H P}}{[B H P] \cdot \theta_{*}}$

$K_{H P A *}=\frac{\theta_{* H P A}}{[H P A] \cdot \theta_{*}}$

$K_{B L *}, K_{L A *}, K_{H 2}, \mathrm{~K}_{\mathrm{BL}}, K_{B H P *}$ and $K_{H P A *}$ are adsorption constants.

Reactions (S4) and (S5) are considered to be the rate-determining steps for the hydrogenation steps.

All the reaction determining steps will be assumed to be irreversible ones.

$R_{B L \_ \text {hyd }}=R_{4}=k_{4} * \theta_{H 2} * \theta_{B L} * \omega_{\text {Cat. }}=k_{4} * K_{H 2} *\left[H_{2}\right] * \theta_{*} * K_{B L *} *[B L] * \theta_{*} * \omega_{C a t .}(\mathrm{S} 14)$ 
$R_{L A \_h y d}=R_{5}=k_{5} * \theta_{H 2} * \theta_{L A} * \omega_{C a t .}=k_{5} * K_{H 2} *\left[H_{2}\right] * \theta_{*} * K_{L A *} *[L A] * \theta_{*} * \omega_{C a t .}$.

The mass balance for active sites leads to

$1=\theta_{H 2}+\theta_{B L}+\theta_{B H P}+\theta_{L A}+\theta_{H P A}+\theta_{*}$

By introducing eqs (S9)-(S13) in eq (S16), one gets

$1=K_{H 2 \cdot} *\left[H_{2}\right] * \theta_{*}+K_{B L *} *[B L] * \theta_{*}+K_{B H P *} *[B H P] * \theta_{*}+K_{L A *} *[L A] * \theta_{*}+K_{H P A *} *[H P A] *$

$\theta_{*}+\theta_{*}$

Resulting in

$\theta_{*}=\frac{1}{K_{H 2} *\left[H_{2}\right]+K_{B L} *[B L]+K_{B H P} *[B H P]++K_{L A *} *[L A]+K_{H P A *} *[H P A]+1}$

Hence, the rate of hydrogenation can be expressed as

$R_{B L \_h y d}=k_{B L_{-} h y d} * \frac{\left[H_{2}\right] *[B L]}{\left(1+K_{H 2} *\left[H_{2}\right]+K_{B L} *[B L]+K_{B H P} *[B H P]+K_{L A *} *[L A]+K_{H P A *} *[H P A]\right)^{2}} * \omega_{C a t}$.

with, $k_{B L_{-} h y d}=k_{4} * K_{H 2} * K_{B L *}$

$R_{L A \_h y d}=k_{L A_{-} h y d} * \frac{\left[H_{2}\right] *[L A]}{\left(1+K_{H 2} *\left[H_{2}\right]+K_{B L} *[B L]+K_{B H P} *[B H P]+K_{L A *} *[L A]+K_{H P A *} *[H P A]\right)^{2}} * \omega_{C a t}$.

with, $k_{L A \_ \text {hyd }}=k_{5} * K_{H 2} * K_{L A *}$

Langmuir Hinshelwood with hydrogen dissociation (LH2)

$\mathrm{BL}+* \rightleftharpoons * \mathrm{BL}$

$\mathrm{LA}+* \rightleftharpoons * \mathrm{BL}$

$\mathrm{H} 2+2 * \rightleftharpoons 2 * \mathrm{H}$ (dihydrogen dissociation)

$* \mathrm{BL}+{ }^{*} \mathrm{H} \rightleftharpoons * \mathrm{BLH}+*$

${ }^{*} \mathrm{LA}+* \mathrm{H} \rightleftharpoons * \mathrm{LAH}+*$ 


$$
\begin{aligned}
& * \mathrm{BLH}+{ }^{*} \mathrm{H} \rightarrow{ }^{*} \mathrm{BHP}+* \\
& * \mathrm{LAH}+* \mathrm{H} \rightarrow * \mathrm{HPA}+* \\
& * \mathrm{BHP} \rightleftharpoons *+\mathrm{BHP} \\
& * \mathrm{HPA} \rightleftharpoons *+\mathrm{HPA} \\
& \mathrm{BHP} \rightarrow \mathrm{GVL}+\mathrm{BuOH} \\
& \mathrm{HPA} \rightarrow \mathrm{GVL}+\mathrm{H}_{2} \mathrm{O} \\
& K_{B L}=\frac{\theta_{B L}}{[B L] \cdot \theta_{*}} \\
& K_{H}=\frac{\theta_{H}^{2}}{[H 2] \cdot \theta_{*}^{2}} \\
& K_{B H P}=\frac{\theta_{B H P}}{[B H P] \cdot \theta_{*}}
\end{aligned}
$$

$K_{25}=\frac{\theta_{L A H} \cdot \theta_{*}}{\theta_{L A} \cdot \theta_{H}}$ equivalent to $\theta_{L A H}=K_{25} * \frac{\theta_{L A} \cdot \theta_{H}}{\theta_{*}}=K_{25} * K_{L A} *[L A] \cdot \theta_{*} * \sqrt{K_{H} *\left[H_{2}\right]}$

Material balance on active site leads to

$1=\theta_{H}+\theta_{B L}+\theta_{B H P}+\theta_{B L H}+\theta_{L A}+\theta_{H P A}+\theta_{L A H}+\theta_{*}$

By introducing eqs (S32)-(S34) and (S36)-(S38) in eq (S39), we get 
$1=\sqrt{K_{H} *\left[H_{2}\right]} * \theta_{*}+K_{B L} *[B L] * \theta_{*}+K_{B H P} *[B H P] * \theta_{*}+K_{24} * K_{B L} *[B L] * \sqrt{K_{H} *\left[H_{2}\right]} * \theta_{*}+$ $K_{L A} *[L A] * \theta_{*}+K_{H P A} *[H P A] * \theta_{*}+K_{25} * K_{L A} *[L A] * \sqrt{K_{H} *\left[H_{2}\right]} * \theta_{*}+\theta_{*}$ equivalent to

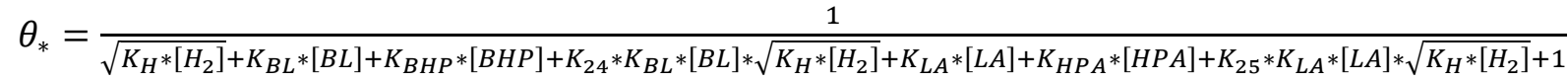
(S40)

Hence, the rates of hydrogenation can be expressed as

$$
R_{B L \_ \text {hyd }}=k_{26} \cdot K_{H} \cdot\left[H_{2}\right] \cdot K_{24} \cdot K_{B L} \cdot[B L] .
$$

$\frac{1}{\left(1+\sqrt{K_{H^{*}}\left[H_{2}\right]}+K_{B L} *[B L]+K_{B H P} *[B H P]+K_{24} * K_{B L} *[B L] * \sqrt{K_{H} *\left[H_{2}\right]}+K_{L A} *[L A]+K_{H P A} *[H P A]+K_{25} * K_{L A} *[L A] * \sqrt{K_{H^{*}} *\left[H_{2}\right]}\right)^{2}} *$

$\omega_{\text {Cat. }}(\mathrm{S} 41)$

$$
R_{L A \_h y d}=k_{27} \cdot K_{H} \cdot\left[H_{2}\right] \cdot K_{25} \cdot K_{L A} \cdot[L A] .
$$

$\frac{1}{\left(1+\sqrt{K_{H} *\left[H_{2}\right]}+K_{B L} *[B L]+K_{B H P} *[B H P]+K_{24} * K_{B L} *[B L] * \sqrt{K_{H} *\left[H_{2}\right]}+K_{L A} *[L A]+K_{H P A} *[H P A]+K_{25} * K_{L A} *[L A] * \sqrt{K_{H^{*}}\left[H_{2}\right]}\right)^{2}} *$

$\omega_{\text {Cat. }}(\mathrm{S} 42)$

The following notations are introduced: $k_{B L \_h y d}=k_{26} \cdot K_{H} \cdot K_{24} \cdot K_{B L}, k_{L A \_h y d}=k_{27} \cdot K_{H} \cdot K_{25} \cdot K_{L A}$, $K_{H}=\sqrt{K_{H}}, K_{i}=K_{24} * K_{B L} * \sqrt{K_{H}}$ and $K_{i 2}=K_{25} * K_{L A} * \sqrt{K_{H}}$. Hence, Equations (S41) and (S42) become

$R_{B L_{-} h y d}=k_{B L_{-} h y d} \cdot\left[H_{2}\right] .[B L]$.

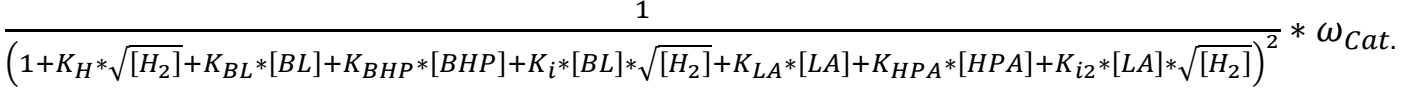

$R_{L A_{-} h y d}=k_{L A_{\_} h y d} \cdot\left[H_{2}\right] .[L A]$.

$\frac{1}{\left(1+K_{H^{*}} * \sqrt{\left[H_{2}\right]}+K_{B L} *[B L]+K_{B H P} *[B H P]+K_{i} *[B L] * \sqrt{\left[H_{2}\right]}+K_{L A^{*}}[L A]+K_{H P A} *[H P A]+K_{i 2} *[L A] * \sqrt{\left[H_{2}\right]}\right)^{2}} * \omega_{C a t .}$ 
$\mathrm{BL}+*($ vacant site $) \rightleftharpoons * \mathrm{BL}$

$\mathrm{LA}+*($ vacant site $) \rightleftharpoons *$ LA

$\mathrm{H}_{2}$ (liquid phase) $+*$ BL $\rightleftharpoons *$ BHP

$\mathrm{H}_{2}$ (liquid phase) $+*$ LA $\rightleftharpoons *$ HPA

$* \mathrm{BHP} \rightleftharpoons *+\mathrm{BHP}$

${ }^{*} \mathrm{HPA} \rightleftharpoons *+\mathrm{HPA}$

$\mathrm{BHP} \rightarrow \mathrm{GVL}+\mathrm{BuOH}$

$\mathrm{HPA} \rightarrow \mathrm{GVL}+\mathrm{H}_{2} \mathrm{O}$

$K_{B L}=\frac{\theta_{B L}}{[B L] \cdot \theta_{*}}$

$K_{B H P}=\frac{\theta_{B H P}}{[B H P] \cdot \theta_{*}}$

$K_{L A}=\frac{\theta_{L A}}{[L A] \cdot \theta_{*}}$

$K_{H P A}=\frac{\theta_{H P A}}{[H P A] \cdot \theta_{*}}$

$\mathrm{K}_{\mathrm{BL}}, \mathrm{K}_{\mathrm{BHP}}, \mathrm{K}_{\mathrm{LA}}$ and $\mathrm{K}_{\mathrm{BHP}}$, are adsorption constants.

Reactions (S47)-(S48) are rate-determining steps

$R_{B L \_h y d}=R_{47}=k_{47} *\left[H_{2}\right] * \theta_{B L} * \omega_{C a t .}=k_{47} *\left[H_{2}\right] * K_{B L} *[B L] * \theta_{*} * \omega_{C a t}$.

(S57)

$R_{\text {LA_hyd }}=R_{48}=k_{48} *\left[H_{2}\right] * \theta_{L A} * \omega_{\text {Cat. }}=k_{48} *\left[H_{2}\right] * K_{L A} *[L A] * \theta_{*} * \omega_{\text {Cat. }}$

(S58)

Material balance on active site leads to 
$1=\theta_{B L}+\theta_{B H P}+\theta_{L A}+\theta_{H P A}+\theta_{*}$

By introducing eqs (S53)-(S56) in eq (S59), we get

$1=K_{B L} *[B L] * \theta_{*}+K_{B H P} *[B H P] * \theta_{*}+K_{L A} *[L A] * \theta_{*}+K_{H P A} *[H P A] * \theta_{*}+\theta_{*}$ equivalent to

$\theta_{*}=\frac{1}{K_{B L^{*}[B L]+K_{B H P} *[B H P]+K_{L A} *[L A]+K_{H P A} *[H P A]+1}}$

Hence, the rates of hydrogenation can be expressed as

$R_{B L_{-} h y d}=k_{47} *\left[H_{2}\right] * K_{B L} *[B L] * \frac{1}{\left(1+K_{B L} *[B L]+K_{B H P} *[B H P]+K_{L A^{*}}[L A]+K_{H P A^{*}}[H P A]\right)} * \omega_{C a t .}$

(S61)

$R_{L A \_h y d}=k_{48} *\left[H_{2}\right] * K_{L A} *[L A] * \frac{1}{\left(1+K_{B L^{*}}[B L]+K_{B H P} *[B H P]+K_{L A^{*}}[L A]+K_{H P A^{*}}[H P A]\right)} * \omega_{C a t .}$

(S62) 
Non-competitive Langmuir Hinshelwood with no dissociation of hydrogen (NCLH1.1)

Here we consider that $\mathrm{BL}$ and LA adsorb on a same site ${ }^{\wedge}$, and $\mathrm{H}_{2}$ adsorb on a different site *

$\mathrm{BL}+{ }^{\wedge}($ vacant site $) \rightleftharpoons{ }^{\wedge} \mathrm{BL}$

$\mathrm{LA}+{ }^{\wedge}($ vacant site $) \rightleftharpoons{ }^{\wedge} \mathrm{LA}$

$\mathrm{H}_{2}+*($ vacant site $) \rightleftharpoons * \mathrm{H}_{2}$ (no dihydrogen dissociation)

${ }^{\wedge} \mathrm{BL}+{ }^{*} \mathrm{H}_{2} \rightleftharpoons{ }^{\wedge} \mathrm{BHP}+*$

${ }^{\wedge} \mathrm{LA}+{ }^{*} \mathrm{H}_{2} \rightleftharpoons{ }^{\wedge} \mathrm{HPA}+*$

${ }^{\wedge} \mathrm{BHP} \rightleftharpoons^{\wedge}+\mathrm{BHP}$

${ }^{\wedge} \mathrm{HPA} \rightleftharpoons{ }^{\wedge}+\mathrm{HPA}$

$\mathrm{BHP} \rightarrow \mathrm{GVL}+\mathrm{BuOH}$

$\mathrm{HPA} \rightarrow \mathrm{GVL}+\mathrm{H}_{2} \mathrm{O}$

The adsorption and desorption steps are considered to be very fast. Thus,

$K_{B L^{\wedge}}=\frac{\theta_{\wedge} B L}{[B L] \cdot \theta_{\wedge}}$

$K_{L A^{\wedge}}=\frac{\theta_{\wedge} L A}{[L A] \cdot \theta_{\wedge}}$

$K_{H 2}=\frac{\theta_{H 2}}{[H 2] \cdot \theta_{*}}$

$K_{B H P^{\wedge}}=\frac{\theta_{\wedge} B H P}{[B H P] \cdot \theta_{\wedge}}$

$K_{H P A^{\wedge}}=\frac{\theta_{\wedge} H P A}{[H P A] \cdot \theta_{\wedge}}$

$K_{B L^{\wedge}}, K_{L A^{\wedge}}, K_{H 2}, K_{B H P^{\wedge}}$ and $K_{H P A^{\wedge}}$ are adsorption constants. 
Reactions (S66)-(S67) are considered to be the rate-determining steps for the hydrogenation steps.

From the experiments, the system is not reversible, so all the reaction determining steps will be assumed to be direct reactions.

$R_{B L_{-} \text {hyd }}=R_{66}=k_{66} * \theta_{H 2} * \theta_{\wedge} B L * \omega_{\text {Cat. }}=k_{66} * K_{H 2} *\left[H_{2}\right] * \theta_{*} * K_{B L^{\wedge}} *[B L] * \theta_{\wedge} * \omega_{\text {Cat }}$.

$R_{L A \_ \text {hyd }}=R_{67}=k_{67} * \theta_{H 2} * \theta_{\wedge} L A * \omega_{\text {Cat. }}=k_{67} * K_{H 2} *\left[H_{2}\right] * \theta_{*} * K_{L A^{\wedge}} *[L A] * \theta_{\wedge} * \omega_{\text {Cat. }}$

Material balance on active site $^{\wedge}$ leads to

$1=\theta_{\wedge_{B L}}+\theta_{\wedge_{B H P}}+\theta_{\wedge_{L A}}+\theta_{\wedge^{\wedge} H A}+\theta_{\wedge}$

Material balance on active site * leads to

$1=\theta_{H 2}+\theta_{*}$

By introducing eq (S74) in eq (S80), we get

$1=K_{H 2} *\left[H_{2}\right] * \theta_{*}+\theta_{*}$ equivalent to

$\theta_{*}=\frac{1}{K_{H 2} *\left[H_{2}\right]+1}$

By introducing eqs (S72), (S73), (S75) and (S76) in eq (S80), we get

$1=K_{B L^{\wedge}} *[B L] * \theta_{\wedge}+K_{B H P^{\wedge}} *[B H P] * \theta_{\wedge}+K_{L A^{\wedge}} *[L A] * \theta_{\wedge}+K_{H P A^{\wedge}} *[H P A] * \theta_{\wedge}+\theta_{\wedge}$

equivalent to

$\theta_{\wedge}=\frac{1}{K_{B L^{\wedge} *[B L]+K_{B H P^{\wedge}} *[B H P]+K_{L A^{\wedge}} *[L A]+K_{H P A^{\wedge}} *[H P A]+1}}$

Hence, the rate of hydrogenation can be expressed as

$$
\begin{aligned}
& R_{B L \_h y d}=R_{66}=k_{66} * K_{H 2} *\left[H_{2}\right] * \frac{1}{\left(1+K_{H 2} *\left[H_{2}\right]\right)} * K_{\wedge_{B L}} *[B L] * \\
& \frac{1}{\left(1+K_{B L^{\wedge}}[B L]+K_{\left.B H P^{\wedge} *[B H P]+K_{L A^{\wedge}}[L A]+K_{H P A^{\wedge}}[H P A]\right)}\right.} * \omega_{C a t} .
\end{aligned}
$$


$R_{B L_{-} h y d}=k_{B L_{-} h y d} *\left[H_{2}\right] * \frac{1}{\left(1+K_{H 2} *\left[H_{2}\right]\right)} *[B L] * \frac{1}{\left(1+K_{B L^{\wedge}} *[B L]+K_{B H P^{\wedge}} *[B H P]+K_{L A^{\wedge}} *[L A]+K_{H P A^{\wedge} *[H P A]}\right)} *$

$\omega_{\text {Cat }}$

(S83)

with $k_{B L_{-} h y d}=k_{66} * K_{H 2} * K_{\wedge_{B L}}$

$R_{L A_{-} \text {hyd }}=R_{67}=k_{67} * K_{H 2} *\left[H_{2}\right] * \frac{1}{\left(1+K_{H 2} *\left[H_{2}\right]\right)} * K_{\wedge} L A *[L A] *$

$\frac{1}{\left(1+K_{B L^{\wedge}}[B L]+K_{\left.B H P^{\wedge} *[B H P]+K_{L A^{\wedge}}[L A]+K_{H P A^{\wedge}}[H P A]\right)}\right.} * \omega_{C a t}$.

Equivalent to

$$
\begin{array}{rl}
R_{L A \_h y d}=k_{L A \_} h y d & *\left[H_{2}\right] * \frac{1}{\left(1+K_{H 2} *\left[H_{2}\right]\right)} *[L A] \\
& * \frac{1}{\left(1+K_{B L^{\wedge}} *[B L]+K_{B H P^{\wedge}} *[B H P]+K_{L A^{\wedge}} *[L A]+K_{H P A^{\wedge}} *[H P A]\right)} * \omega_{C a t .} .
\end{array}
$$

(S84)

With $k_{L A \_h y d}=k_{67} * K_{H 2} * K_{\wedge}{ }_{L A}$ 
Non-competitive Langmuir Hinshelwood with no dissociation of hydrogen (NCLH1.2)

Here we consider that $\mathrm{BL}, \mathrm{LA}$ and $\mathrm{H} 2$ adsorb on different sites ${ }^{\wedge}, 0$ and $*$, respectively

$\mathrm{BL}++^{\wedge}($ vacant site $) \rightleftharpoons{ }^{\wedge} \mathrm{BL}$

$\mathrm{LA}+0($ vacant site $) \rightleftharpoons 0 \mathrm{LA}$

$\mathrm{H}_{2}+*($ vacant site $) \rightleftharpoons * \mathrm{H}_{2}$ (no dihydrogen dissociation)

${ }^{\wedge} \mathrm{BL}+{ }^{*} \mathrm{H}_{2} \rightleftharpoons{ }^{\wedge} \mathrm{BHP}+*$

$0 \mathrm{LA}+* \mathrm{H}_{2} \rightleftharpoons 0 \mathrm{HPA}+*$

${ }^{\wedge} \mathrm{BHP} \rightleftharpoons{ }^{\wedge}+\mathrm{BHP}$

$0 \mathrm{HPA} \rightleftharpoons 0+\mathrm{HPA}$

$\mathrm{BHP} \rightarrow \mathrm{GVL}+\mathrm{BuOH}$

$\mathrm{HPA} \rightarrow \mathrm{GVL}+\mathrm{H}_{2} \mathrm{O}$

The adsorption and desorption steps are considered to be very fast. Thus,

$K_{B L^{\wedge}}=\frac{\theta_{\wedge} B L}{[B L] \cdot \theta_{\wedge}}$

$K_{L A 0}=\frac{\theta_{0 L A}}{[L A] \cdot \theta_{0}}$

$K_{H 2}=\frac{\theta_{H 2}}{[H 2] \cdot \theta_{*}}$

$K_{B H P^{\wedge}}=\frac{\theta_{\wedge B H P}}{[B H P] \cdot \theta_{\wedge}}$

$K_{H P A 0}=\frac{\theta_{0 H P A}}{[H P A] \cdot \theta_{0}}$

$K_{B L^{\wedge}}, K_{L A 0}, K_{H 2}, K_{B H P^{\wedge}}$ and $K_{H P A 0}$ are adsorption constants. 
Reactions (S88)-(S89) are considered to be the rate-determining steps for the hydrogenation steps.

From the experiments, the system is not reversible, so all the reaction determining steps will be assumed to be direct reactions.

$R_{B L \_h y d}=R_{88}=k_{88} * \theta_{H 2} * \theta_{\wedge B L} * \omega_{C a t .}=k_{88} * K_{H 2} *\left[H_{2}\right] * \theta_{*} * K_{B L^{\wedge}} *[B L] * \theta_{\wedge} * \omega_{C a t .}$

(S99)

$R_{\text {LA_hyd }}=R_{89}=k_{89} * \theta_{H 2} * \theta_{0 L A} * \omega_{\text {Cat. }}=k_{89} * K_{H 2} *\left[H_{2}\right] * \theta_{*} * K_{L A 0} *[L A] * \theta_{0} * \omega_{\text {Cat. }}$

$(\mathrm{S} 100)$

Material balance on active site $^{\wedge}$ leads to

$1=\theta_{\wedge_{B L}}+\theta_{\wedge B H P}+\theta_{\wedge}$

Material balance on active site 0 leads to

$1=\theta_{0 L A}+\theta_{0 H P A}+\theta_{0}$

Material balance on active site * leads to

$1=\theta_{H 2}+\theta_{*}$

By introducing eq (S96) in eq (S103), we get

$1=K_{H 2} *\left[H_{2}\right] * \theta_{*}+\theta_{*}$ equivalent to

$\theta_{*}=\frac{1}{K_{H 2} *\left[H_{2}\right]+1}$

By introducing eqs (S94) and (S97) in eq (S101), we get

$1=K_{B L^{\wedge}} *[B L] * \theta_{\wedge}+K_{B H P^{\wedge}} *[B H P] * \theta_{\wedge}+\theta_{\wedge}$ equivalent to

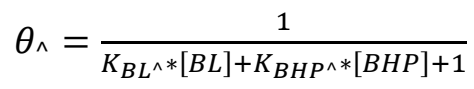

By introducing eqs (S95) and (S98) in eq (S102), we get

$1=K_{B L 0} *[B L] * \theta_{0}+K_{B H P 0} *[B H P] * \theta_{0}+\theta_{0}$ equivalent to 
$\theta_{0}=\frac{1}{K_{B L 0} *[B L]+K_{B H P 0} *[B H P]+1}$

Hence, the rates of hydrogenation can be expressed as

$R_{B L \_} h y d=R_{88}=k_{88} * K_{H 2} *\left[H_{2}\right] * \frac{1}{\left(1+K_{H 2} *\left[H_{2}\right]\right)} * K_{\wedge}{ }_{B L} *[B L] * \frac{1}{\left(1+K_{B L^{\wedge}} *[B L]+K_{B H P^{\wedge}} *[B H P]\right)} * \omega_{C a t}$.

Equivalent to

$R_{B L_{-} h y d}=k_{B L_{-} h y d} *\left[H_{2}\right] * \frac{1}{\left(1+K_{H 2} *\left[H_{2}\right]\right)} *[B L] * \frac{1}{\left(1+K_{B L^{\wedge}} *[B L]+K_{B H P^{\wedge}} *[B H P]\right)} * \omega_{C a t}$.

(S107)

With $k_{B L_{-} h y d}=k_{88} * K_{H 2} * K_{\wedge_{B L}}$

$R_{L A \_h y d}=R_{89}=k_{89} * K_{H 2} *\left[H_{2}\right] * \frac{1}{\left(1+K_{H 2} *\left[H_{2}\right]\right)} * K_{0 L A} *[L A] * \frac{1}{\left(1+K_{L A^{\wedge}} *[L A]+K_{H P A^{\wedge}} *[H P A]\right)} * \omega_{C a t}$.

Equivalent to

$R_{L A_{-} h y d}=k_{L A_{-} h y d} *\left[H_{2}\right] * \frac{1}{\left(1+K_{H 2} *\left[H_{2}\right]\right)} *[L A] * \frac{1}{\left(1+K_{L A^{\wedge}} *[L A]+K_{H P A^{\wedge}} *[H P A]\right)} * \omega_{C a t .}$

(S108)

With $k_{L A \_h y d}=k_{89} * K_{H 2} * K_{0 L A}$ 
$\underline{\text { Non-competitive Langmuir Hinshelwood with hydrogen dissociation (NCLH2.1) }}$

Here we consider that BL-LA and $\mathrm{H}_{2}$ adsorb on 2 different sites * and ${ }^{\wedge}$

$\mathrm{BL}+{ }^{\wedge}($ vacant site $) \rightleftharpoons{ }^{\wedge} \mathrm{BL}$

$\mathrm{LA}++^{\wedge}($ vacant site $) \rightleftharpoons{ }^{\wedge} \mathrm{LA}$

$\mathrm{H}_{2}+2 *($ vacant site $) \rightleftharpoons 2 \mathrm{H}^{*}($ dihydrogen dissociation $)$

${ }^{\wedge} \mathrm{BL}+\mathrm{H}^{*} \rightleftharpoons{ }^{\wedge} \mathrm{BLH}+*$

${ }^{\wedge} \mathrm{LA}+\mathrm{H}^{*} \rightleftharpoons{ }^{\wedge} \mathrm{LAH}+*$

${ }^{\wedge} \mathrm{BLH}+\mathrm{H}^{*} \rightleftharpoons{ }^{\wedge} \mathrm{BHP}+*$

${ }^{\wedge} \mathrm{LAH}+\mathrm{H}^{*} \rightleftharpoons{ }^{\wedge} \mathrm{HPA}+*$

${ }^{\wedge} \mathrm{BHP} \rightleftharpoons \wedge+\mathrm{BHP}$

${ }^{\wedge} \mathrm{HPA} \rightleftharpoons{ }^{\wedge}+\mathrm{HPA}$

$\mathrm{BHP} \rightarrow \mathrm{GVL}+\mathrm{BuOH}$

$\mathrm{HPA} \rightarrow \mathrm{GVL}+\mathrm{H}_{2} \mathrm{O}$

The adsorption and desorption steps are considered to be very fast. Thus,

$K_{B L^{\wedge}}=\frac{\theta_{\wedge B L}}{[B L] \cdot \theta_{\wedge}}$

$K_{L A^{\wedge}}=\frac{\theta_{\wedge L A}}{[L A] \cdot \theta_{\wedge}}$

$K_{H}=\frac{\theta_{H}^{2}}{[H 2] \cdot \theta_{*}^{2}}$

$K_{B H P^{\wedge}}=\frac{\theta_{\wedge B H P}}{[B H P] \cdot \theta_{\wedge}}$

$K_{H P A^{\wedge}}=\frac{\theta_{\wedge} H P A}{[H P A] \cdot \theta_{\wedge}}$ 
$K_{B L^{\wedge}}, K_{L A^{\wedge}}, K_{H P A^{\wedge}}, K_{H}$ and $K_{B H P^{\wedge}}$ are adsorption constants.

Steps (S112) and (S113) are supposed to be very fast and in equilibrium

$K_{112}=\frac{\theta_{\wedge B L H} \cdot \theta_{*}}{\theta_{\wedge_{B L} \cdot \theta_{H}}}=\frac{\theta_{\wedge B L H} \cdot \theta_{*}}{\theta_{\wedge B L} \cdot \sqrt{K_{H} *\left[H_{2}\right] * \theta_{*}}}$

$\theta_{\wedge} B L H=K_{112} \cdot \sqrt{K_{H} *\left[H_{2}\right]} \cdot K_{B L^{\wedge}} \cdot[B L] \cdot \theta_{\wedge}$

$K_{113}=\frac{\theta_{\wedge L A H} \cdot \theta_{*}}{\theta_{\wedge_{L A}} \cdot \theta_{H}}=\frac{\theta_{\wedge L A H} \cdot \theta_{*}}{\theta_{\wedge L A} \cdot \sqrt{K_{H^{*}}\left[H_{2}\right]} * \theta_{*}}$

$\theta_{\wedge_{L A H}}=K_{112} \cdot \sqrt{K_{H} *\left[H_{2}\right]} \cdot K_{L A^{\wedge} \cdot[L A] \cdot \theta_{\wedge}}$

Reactions (S114)-(S115) are considered to be rate-determining steps for hydrogenation steps. From the kinetic experiments, we did not observe that hydrogenation was a reversible step, so direct reaction was considered.

$$
\begin{aligned}
& R_{B L \_ \text {hyd }}=R_{114}=k_{114} * \theta_{H} * \theta_{\wedge_{B L H}} * \omega_{\text {Cat. }}=k_{114} * \sqrt{K_{H} *\left[H_{2}\right]} * \theta_{*} *
\end{aligned}
$$

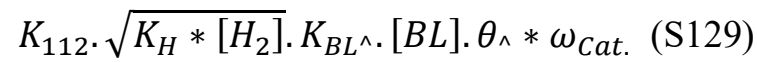

$$
\begin{aligned}
& R_{\text {LA_hyd }}=R_{115}=k_{115} * \theta_{H} * \theta_{\wedge_{L A H}} * \omega_{\text {Cat. }}=k_{115} * \sqrt{K_{H} *\left[H_{2}\right]} * \theta_{*} *
\end{aligned}
$$

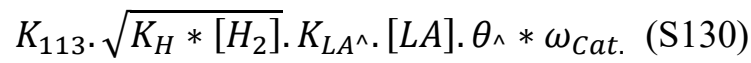

Material balance on active site $^{\wedge}$ leads to

$$
\begin{aligned}
& 1=\theta_{\wedge_{B L}}+\theta_{\wedge_{B L H}}+\theta_{\wedge_{B H P}}+\theta_{\wedge_{L A}}+\theta_{\wedge_{L A H}}+\theta_{\wedge_{H P A}}+\theta_{\wedge}
\end{aligned}
$$

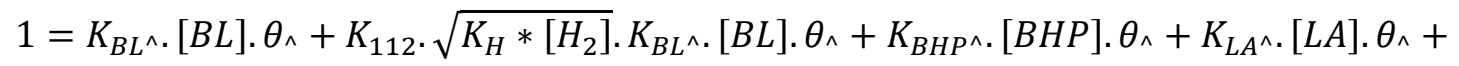

$$
\begin{aligned}
& K_{113} \cdot \sqrt{K_{H} *\left[H_{2}\right]} \cdot K_{L A^{\wedge}} \cdot[L A] \cdot \theta_{\wedge}+K_{H P A^{\wedge}} \cdot[H P A] \cdot \theta_{\wedge}+\theta_{\wedge}
\end{aligned}
$$

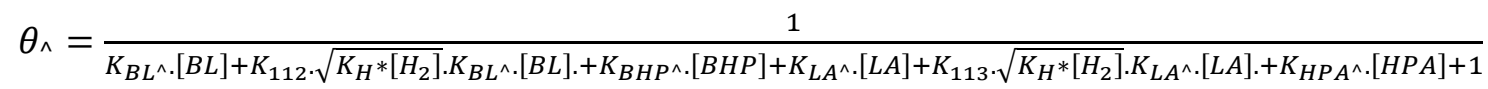

Material balance on active site * leads to

$$
1=\theta_{H}+\theta_{*} \Leftrightarrow \theta_{*}=\frac{1}{\sqrt{K_{H^{*}\left[H_{2}\right]}+1}}
$$


Hence, the rates of hydrogenation can be expressed as

$R_{B L_{-} h y d}=k_{114} \cdot K_{H} \cdot K_{112} \cdot K_{B L^{\wedge}} \cdot\left[H_{2}\right] \frac{1}{\sqrt{K_{H} *\left[H_{2}\right]}+1}[B L]$

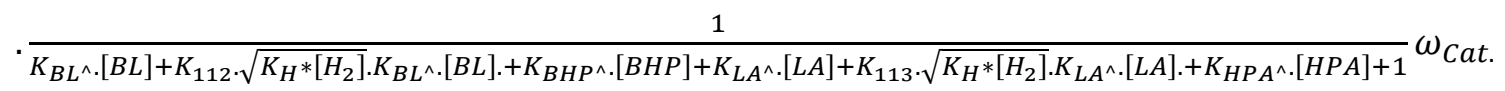

Equivalent to

$R_{B L_{-} h y d}=k_{B L_{-} h y d} \cdot\left[H_{2}\right] \cdot[B L] \frac{1}{\sqrt{K_{H} *\left[H_{2}\right]}+1}$

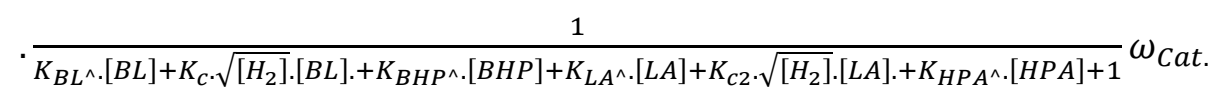

With $k_{B L_{-} h y d}=k_{114} \cdot K_{H} \cdot K_{112} \cdot K_{B L^{\wedge}}, K_{C}=K_{112} \cdot \sqrt{K_{H}} \cdot K_{B L^{\wedge}}$ and $K_{C 2}=K_{113} \cdot \sqrt{K_{H}} \cdot K_{L A^{\wedge}}$

$R_{L A \_h y d}=k_{115} \cdot K_{H} \cdot K_{113} \cdot K_{L A^{\wedge} .}\left[H_{2}\right] \frac{1}{\sqrt{K_{H} *\left[H_{2}\right]}+1}[B L]$

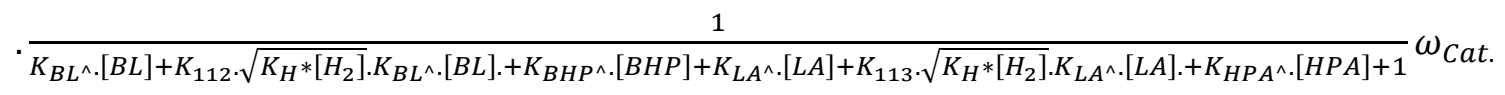

Equivalent to

$R_{L A \_h y d}=k_{L A \_h y d} \cdot\left[H_{2}\right] .[L A] \frac{1}{\sqrt{K_{H} *\left[H_{2}\right]}+1}$

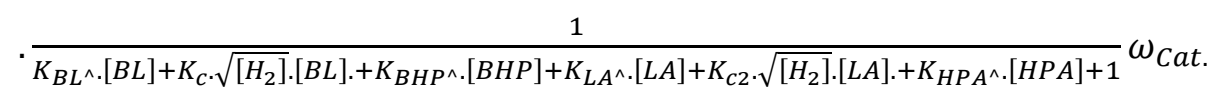

With $k_{L A \_h y d}=k_{115} \cdot K_{H} \cdot K_{113} \cdot K_{L A^{\wedge}}$ 
Non-competitive Langmuir Hinshelwood with hydrogen dissociation (NCLH2.2)

Here we consider that $\mathrm{BL}, \mathrm{LA}$ and $\mathrm{H}_{2}$ adsorb on different sites ${ }^{\wedge}, 0$ and*

$\mathrm{BL}+{ }^{\wedge}($ vacant site $) \rightleftharpoons{ }^{\wedge} \mathrm{BL}$

$\mathrm{LA}+0($ vacant site $) \rightleftharpoons 0 \mathrm{LA}$

$\mathrm{H}_{2}+2 *($ vacant site $) \rightleftharpoons 2 \mathrm{H}^{*}$ (dihydrogen dissociation $)$

${ }^{\wedge} \mathrm{BL}+\mathrm{H}^{*} \rightleftharpoons{ }^{\wedge} \mathrm{BLH}+*$

$0 \mathrm{LA}+\mathrm{H}^{*} \rightleftharpoons 0 \mathrm{LAH}+*$

${ }^{\wedge} \mathrm{BLH}+\mathrm{H}^{*}{ }^{\wedge} \mathrm{BHP}+{ }^{*}$

$0 \mathrm{LAH}+\mathrm{H}^{*} \rightleftharpoons 0 \mathrm{HPA}+*$

${ }^{\wedge} \mathrm{BHP} \rightleftharpoons{ }^{\wedge}+\mathrm{BHP}$

$0 \mathrm{HPA} \rightleftharpoons 0+\mathrm{HPA}$

$\mathrm{BHP} \rightarrow \mathrm{GVL}+\mathrm{BuOH}$

$\mathrm{HPA} \rightarrow \mathrm{GVL}+\mathrm{H}_{2} \mathrm{O}$

The adsorption and desorption steps are considered to be very fast. Thus,

$K_{B L^{\wedge}}=\frac{\theta_{\wedge B L}}{[B L] \cdot \theta_{\wedge}}$

$K_{L A 0}=\frac{\theta_{0 L A}}{[L A] \cdot \theta_{0}}$

$K_{H}=\frac{\theta_{H}^{2}}{[H 2] \cdot \theta_{*}^{2}}$

$K_{B H P^{\wedge}}=\frac{\theta_{\wedge B H P}}{[B H P] \cdot \theta_{\wedge}}$

$K_{H P A 0}=\frac{\theta_{0 H P A}}{[H P A] \cdot \theta_{0}}$ 
$K_{B L^{\wedge}}, K_{L A 0}, K_{H P A 0}, K_{H}$ and $K_{B H P^{\wedge}}$ are adsorption constants.

Steps (S139) and (S140) are supposed to be very fast and in equilibrium

$K_{139}=\frac{\theta_{\wedge B L H} \cdot \theta_{*}}{\theta_{\wedge B L} \cdot \theta_{H}}=\frac{\theta_{\wedge B L H} \cdot \theta_{*}}{\theta_{\wedge B L} \cdot \sqrt{K_{H} *\left[H_{2}\right] * \theta_{*}}}$

$\theta_{\wedge} B L H=K_{139} \cdot \sqrt{K_{H} *\left[H_{2}\right]} \cdot K_{B L^{\wedge} \cdot[B L] . \theta_{\wedge}}$

$K_{140}=\frac{\theta_{0 L A H} \cdot \theta_{*}}{\theta_{0 L A} \cdot \theta_{H}}=\frac{\theta_{0 L A H} \cdot \theta_{*}}{\theta_{0 L A} \cdot \sqrt{K_{H^{*}}\left[H_{2}\right] * \theta_{*}}}$

$\theta_{0 L A H}=K_{140} \cdot \sqrt{K_{H} *\left[H_{2}\right]} \cdot K_{L A 0} \cdot[L A] \cdot \theta_{0}$

Reactions (S141)-(S142) are considered to be rate-determining steps for hydrogenation steps. From the kinetic experiments, we did not observe that hydrogenation was a reversible step, so direct reaction was considered.

$$
\begin{aligned}
& R_{B L \_h y d}=R_{141}=k_{141} * \theta_{H} * \theta_{\wedge_{B L H}} * \omega_{C a t .}=k_{141} * \sqrt{K_{H} *\left[H_{2}\right]} * \theta_{*} *
\end{aligned}
$$

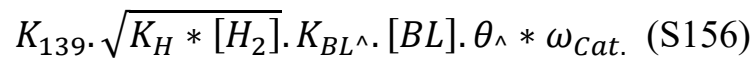

$$
\begin{aligned}
& R_{L A \_ \text {hyd }}=R_{142}=k_{142} * \theta_{H} * \theta_{0 L A H} * \omega_{C a t .}=k_{142} * \sqrt{K_{H} *\left[H_{2}\right]} * \theta_{*} * \\
& K_{140} \cdot \sqrt{K_{H} *\left[H_{2}\right]} \cdot K_{L A 0} \cdot[L A] \cdot \theta_{0} * \omega_{\text {Cat. }}(\mathrm{S} 157)
\end{aligned}
$$

Material balance on active site $^{\wedge}$ leads to

$$
\begin{aligned}
& 1=\theta_{\wedge_{B L}}+\theta_{\wedge_{B L H}}+\theta_{\wedge_{B H P}}+\theta_{\wedge} \\
& 1=K_{B L^{\wedge}} \cdot[B L] \cdot \theta_{\wedge}+K_{139} \cdot \sqrt{K_{H} *\left[H_{2}\right]} \cdot K_{B L^{\wedge}}[B L] . \theta_{\wedge}+K_{B H P^{\wedge}} \cdot[B H P] . \theta_{\wedge}+\theta_{\wedge}
\end{aligned}
$$

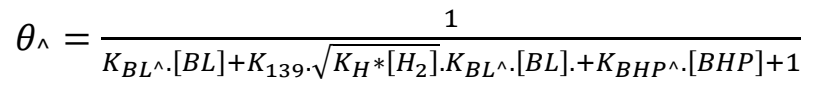

Material balance on active site 0 leads to

$$
\begin{aligned}
& 1=\theta_{0 L A}+\theta_{0 L A H}+\theta_{0 H P A}+\theta_{0} \\
& 1=K_{L A 0} \cdot[L A] \cdot \theta_{0}+K_{140} \cdot \sqrt{K_{H} *\left[H_{2}\right]} \cdot K_{L A 0} \cdot[L A] \cdot \theta_{0}+K_{H P A 0} \cdot[H P A] \cdot \theta_{0}+\theta_{0}
\end{aligned}
$$


$\theta_{0}=\frac{1}{K_{L A 0} \cdot[L A]+K_{140} \cdot \sqrt{K_{H} *\left[H_{2}\right]} \cdot K_{L A 0} \cdot[L A]+K_{H P A 0} \cdot[H P A]+1}$

Material balance on active site * leads to

$1=\theta_{H}+\theta_{*} \Leftrightarrow \theta_{*}=\frac{1}{\sqrt{K_{H^{*}}\left[H_{2}\right]}+1}$

Hence, the rates of hydrogenation can be expressed as

$R_{B L \_h y d}=k_{141} \cdot K_{H} \cdot K_{139} \cdot K_{B L^{\wedge}} \cdot\left[H_{2}\right] \frac{1}{\sqrt{K_{H} *\left[H_{2}\right]}+1}[B L]$

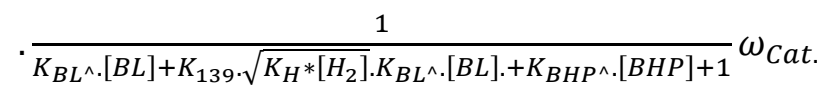

Equivalent to

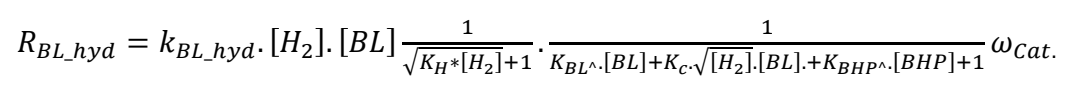

With $k_{B L \_n y d}=k_{141} \cdot K_{H} \cdot K_{139} \cdot K_{B L^{\wedge}}, K_{C}=K_{139} \cdot \sqrt{K_{H}} \cdot K_{B L^{\wedge}}$

$R_{L A_{-} h y d}=k_{142} \cdot K_{H} \cdot K_{140} \cdot K_{L A 0} \cdot\left[H_{2}\right] \frac{1}{\sqrt{K_{H^{*}}\left[H_{2}\right]}+1}[L A] \cdot \frac{1}{K_{L A 0} \cdot[L A]+K_{140} \cdot \sqrt{K_{H^{*}}\left[H_{2}\right]} \cdot K_{L A 0} \cdot[L A] \cdot+K_{H P A 0} \cdot[H P A]+1} \omega_{C a t}$.

Equivalent to

$R_{L A_{-} h y d}=k_{L A_{-} h y d} \cdot\left[H_{2}\right] .[L A] \frac{1}{\sqrt{K_{H^{*}\left[H_{2}\right]}}+1} \cdot \frac{1}{K_{L A 0} \cdot[L A]+K_{C 2} \cdot \sqrt{\left[H_{2}\right]} \cdot[L A] \cdot+K_{H P A 0} \cdot[H P A]+1} \omega_{C a t}$.

With $k_{L A \_h y d}=k_{142} \cdot K_{H} \cdot K_{140} \cdot K_{L A 0}$ and $K_{c 2}=K_{140} \cdot \sqrt{K_{H}} \cdot K_{L A 0}$ 


\section{S2. Derivation of cyclization rate expression}

\section{$\underline{\text { Non-catalytic effect }}$}

In this route, the cyclization of HPA or BHP to GVL is not catalyzed.

$\mathrm{BHP} \rightarrow \mathrm{GVL}+\mathrm{BuOH}$

$\mathrm{HPA} \rightarrow \mathrm{GVL}+\mathrm{H}_{2} \mathrm{O}$

The rate equations can be expressed as

$R_{B H P \_n o n c a t}=k_{B H P \_n o n c a t} \cdot[B H P]$

$R_{H P A \_n o n c a t}=k_{H P A \_n o n c a t} \cdot[H P A]$

\section{Catalyzed route by $\mathrm{Ru} / \mathrm{C}$}

A Langmuir-Hinshelwood model was assumed and by considering that each site has the same affinity towards BL or LA. The following steps can be assumed

$\mathrm{HPA}+\mathbf{\square} \rightleftharpoons \mathrm{HPA}$

$\mathrm{BHP}+\mathbf{\square} \rightleftharpoons \mathrm{BHP}$

$\mathrm{HPA} \varpi \mathrm{GVL} \square+\mathrm{H}_{2} \mathrm{O}$

$\mathrm{BHP} \square \rightleftharpoons \mathrm{GVL} \square+\mathrm{BuOH}$

$\mathrm{GVL} \square \rightleftharpoons \mathrm{GVL}+$

Reactions (S167), (S168) and (S171) are assumed to be fast and reversible, thus the adsorption can be expressed as

$K_{\square} H P A=\frac{\theta_{\square} H P A}{[H P A] \cdot \theta_{\square}}$

$K_{\mathbf{\square} B P}=\frac{\theta_{\mathbf{\square} B P}}{[B H P] \cdot \theta_{\mathbf{\bullet}}}$ 
$K_{\mathbf{m} G V L}=\frac{\theta_{\mathbf{m} G V L}}{[G V L] \cdot \theta_{\mathbf{\square}}}$

Rate determining steps are (S169) and (S170), thus the rates

$R_{\text {BHP_RuC }}=R_{169}=k_{169} \cdot \theta_{\mathbf{\square} B H P} \cdot \omega_{\text {Cat } . R u C}$

$R_{H P A \_R u C}=R_{170}=k_{170} \cdot \theta_{\mathbf{m} H P A} \cdot \omega_{\text {Cat } . R u C}$

Mass balance on active site $\boldsymbol{\square}$ leads to

$1=\theta_{\mathbf{\square} H A}+\theta_{\mathbf{\square} B H P}+\theta_{\mathbf{\bullet}}$

Thus,

$1=K_{\mathbf{\square} H P A} \cdot[H P A] \cdot \theta_{\mathbf{q}}+K_{\mathbf{\square} B H P} \cdot[B H P] \cdot \theta_{\mathbf{q}}+\theta_{\mathbf{\square}}$

$\Leftrightarrow \theta_{\mathbf{\Perp}}=\frac{1}{K_{\mathbf{m} H P A} \cdot[H P A]+K_{\mathbf{m} B H P} \cdot[B H P]+1}$

The following notations are introduced $k_{B H P_{-} R u C}=k_{169} \cdot K_{\mathbf{m} B H P}$ and $k_{H P A_{-} R u C}=k_{70} \cdot K_{\mathbf{m} H P A}$. By combining (S178) with (S172), (S173), (S175) and (S176), the rates of cyclization catalyzed by Ru/C can be expressed as

$R_{B H P_{-} R u C}=k_{B H P_{-} R u C} \cdot[B H P] \cdot \frac{1}{K_{\mathbf{n} H P A} \cdot[H P A]+K_{\mathbf{m} B H P} \cdot[B H P]+1} \cdot \omega_{C a t . R u C}$

$R_{H P A_{-} R u C}=k_{H P A_{-} R u C} \cdot[H P A] \cdot \frac{1}{K_{\mathbf{n} H P A} \cdot[H P A]+K_{\mathbf{m}} B H P \cdot[B H P]+1} \cdot \omega_{C a t . R u C}$

Cyclization catalyzed route by Amberlite IR120

The active site of Amberlite IR120 is $-\mathrm{SO}_{3} \mathrm{H}$. The following mechanism was assumed

$\mathrm{HPA}+-\mathrm{SO}_{3} \mathrm{H} \rightleftharpoons \mathrm{HPA}-\mathrm{SO}_{3} \mathrm{H}$

$\mathrm{BHP}+-\mathrm{SO}_{3} \mathrm{H} \rightleftharpoons \mathrm{BHP}-\mathrm{SO}_{3} \mathrm{H}$

$\mathrm{HPA}-\mathrm{SO}_{3} \mathrm{H} \rightleftharpoons \mathrm{GVL}-\mathrm{SO}_{3} \mathrm{H}+\mathrm{H}_{2} \mathrm{O}$ 
$\mathrm{BHP}-\mathrm{SO}_{3} \mathrm{H} \rightleftharpoons \mathrm{GVL}-\mathrm{SO}_{3} \mathrm{H}+\mathrm{BuOH}$

$\mathrm{GVL}-\mathrm{SO}_{3} \mathrm{H} \rightleftharpoons \mathrm{GVL}+-\mathrm{SO}_{3} \mathrm{H}$

Reactions (S181), (S182) and (S185) are assumed to be fast and reversible, thus the adsorption can be expressed as

$K_{S O 3 H-H P A}=\frac{\theta_{S O 3 H-H P A}}{[H P A] \cdot \theta_{S O 3 H-}}$

$K_{S O 3 H-B H P}=\frac{\theta_{S O 3 H-B H P}}{[B H P] \cdot \theta_{S O 3 H}}$

$K_{S O 3 H-G V L}=\frac{\theta_{S O 3 H-G V L}}{[G V L] \cdot \theta_{S O 3 H}}$

Rate determining steps are (S181) and (S182), thus the rates

$R_{\text {BHP_SO3H}}=R_{181}=k_{181} \cdot \theta_{\text {SO3H-BHP }} \cdot \omega_{\text {Cat.Amberlite }}$

$R_{H P A \_S O 3 H}=R_{182}=k_{182} \cdot \theta_{\text {SO3H-HPA }} \cdot \omega_{\text {Cat.Amberlite }}$

Mass balance on active site $-\mathrm{SO} H \mathrm{H}$ leads to

$1=\theta_{S O 3 H-H P A}+\theta_{S O 3 H-B H P}+\theta_{S O 3 H-}$

Thus,

$1=K_{S O 3 H-H P A} \cdot[H P A] \cdot \theta_{S O 3 H}+K_{S O 3 H-B H P} \cdot[B H P] \cdot \theta_{S O 3 H}+\theta_{S O 3 H}$

$\Leftrightarrow \theta_{S O 3 H}=\frac{1}{K_{S O 3 H-H P A} \cdot[H P A]+K_{S O 3 H-B H P} \cdot[B H P]+1}$

The following notations are introduced $k_{\text {BHP_SO3H }}=k_{181} \cdot K_{S O 3 H-B H P}$ and $k_{H P A_{-} S O 3 H}=k_{182}$. $K_{S O 3 H-H P A}$. By combining (S192) with (S186), (S187), (S189) and (S190), the rates of cyclization catalyzed by $\mathrm{Ru} / \mathrm{C}$ can be expressed as

$R_{\text {BHP_SO3H }}=k_{\text {BHP_SO3H }} \cdot[B H P] \cdot \frac{1}{K_{S O 3 H-H P A} \cdot[H P A]+K_{S O 3 H-B H P} \cdot[B H P]+1} \cdot \omega_{C a t . A m b}$ 
$R_{H P A_{-} S O 3 H}=k_{H P A_{-} S O 3 H} \cdot[H P A] \cdot \frac{1}{K_{S O 3 H-H P A} \cdot[H P A]+K_{S O 3 H-B H P} \cdot[B H P]+1} \cdot \omega_{C a t . R u C}$

Cyclization catalyzed route by LA dissociation

The dissociation of LA produces protons that can catalyze the cyclization reactions. The following mechanism is assumed 
<smiles>CC(=O)CCC(=O)C=CC(=O)CCC(=O)O</smiles><smiles>CC(O)CCC(=O)O</smiles>

$\mathrm{H} \square \mathrm{A}$<smiles>CC(O)CCC(=O)Br</smiles><smiles>[B]C(C)CCC(=[OH+])[18OH]</smiles><smiles>[B-][O+]=C([18O])CCC(C)C</smiles><smiles>CC1BC([Hg])CC1</smiles><smiles>[B]C1([Hg])CCC(C)[Ge]1C1([Hg])CCC(C)O1</smiles><smiles>[B]C1([Hg])CCC(C)O1</smiles><smiles>CC1CCC(=CP)O1</smiles><smiles></smiles>

ntermediate 1<smiles>C=CCCC(=[OH+])CCC(C)O</smiles><smiles>[BH]C1([Hg])CCC(C)[Te]1</smiles>

$\square 198 \square$<smiles>CC1CCC(Br)([Hg])[Hg]1</smiles>

$\square 199$<smiles>C=C[TeH]C1([HgH])CCC(C)O1</smiles><smiles>C=C[Ga]C1([Hg])CCC(C)O1</smiles><smiles>C=CP=C1CCC(C)O1</smiles><smiles>C=C[O+]=C1CCC(C)O1</smiles><smiles>C=C[CH]C(C)C1CCC(=O)S1</smiles>

Reactions (S196)-(S197) are assumed to be fast and reversible, thus the equilibrium constants can be expressed as

$K_{195}=\frac{\left[L A^{-}\right] \cdot\left[H^{+}\right]}{[L A]}(\mathrm{S} 205)$ 
$K_{196}=\frac{[\text { Intermediate }]}{\left[H^{+}\right] \cdot[H P A]}(\mathrm{S} 206)$

$K_{197}=\frac{[\text { Intermediate } 2]}{\left[H^{+}\right] \cdot[\text { BHP }]}(\mathrm{S} 207)$

The rate determining steps are (S198) and (S199), and can be expressed as

$R_{B H P_{-} \text {diss }}=k_{B H P_{-} \text {diss }} \cdot[B H P] \cdot[L A]$

$R_{H P A_{-} \text {diss }}=k_{H P A_{-} d i s S} \cdot[H P A] \cdot[L A]$ 


\section{S3. Modeling results}

\section{NCLH1.1.}

Table S3.1. Estimated values et $\mathrm{T}_{\mathrm{ref}}=392.15 \mathrm{~K}$ and statistical data for NCLH1.1.

\begin{tabular}{|c|c|c|c|c|}
\hline \multicolumn{2}{|r|}{ Parameters } & Units & Estimates & HDP\% \\
\hline Par1 & $k_{B L_{-} h y d}\left(T_{R e f}\right)$ & $\mathrm{m}^{3} \cdot \mathrm{mol}^{-1} \cdot \mathrm{s}^{-1} \cdot \mathrm{kg}$ _dry basis $\mathrm{RuC}^{-1}$ & $3.57 \mathrm{E}-06$ & 13.65 \\
\hline Par2 & $E a_{B L_{-} h y d}$ & $\mathrm{~J}^{\mathrm{mol}} \mathrm{m}^{-1}$ & $3.20 \mathrm{E}+04$ & 10.55 \\
\hline Par3 & $K_{H 2}$ & $\mathrm{~m}^{3} \cdot \mathrm{mol}^{-1}$ & $1.87 \mathrm{E}-03$ & 151.37 \\
\hline Par4 & $K_{B L^{\wedge}}$ & $\mathrm{m}^{3} \cdot \mathrm{mol}^{-1}$ & 9.79E-04 & 23.77 \\
\hline Par5 & $K_{B H P^{\wedge}}$ & $\mathrm{m}^{3} \cdot \mathrm{mol}^{-1}$ & Fixed to zero & - \\
\hline Par6 & $k_{B H P_{-} c a t \_A m b}^{\prime}\left(T_{R e f}\right)$ & $\mathrm{s}^{-1} \cdot \mathrm{kg} \_$dry basis $\mathrm{Amb}^{-1}$ & 4.30E-05 & 48.27 \\
\hline Par7 & $E a_{B H P_{-} c a t \_A m b}^{\prime}$ & $\mathrm{J}^{\mathrm{mol}}{ }^{-1}$ & Fixed to zero & - \\
\hline Par8 & $k_{\text {BHP_noncat }}\left(T_{R e f}\right)$ & $\mathrm{s}^{-1}$ & $6.35 \mathrm{E}-05$ & 32.62 \\
\hline Par9 & $E a_{\text {BHP_noncat }}$ & $\mathrm{J} . \mathrm{mol}^{-1}$ & $7.74 \mathrm{E}+04$ & 40.02 \\
\hline Par10 & $k_{\text {LA_hyd }}\left(T_{R e f}\right)$ & $\mathrm{m}^{3} \cdot \mathrm{mol}^{-1} \cdot \mathrm{s}^{-1} \cdot \mathrm{kg} \_$dry basis $\mathrm{RuC}^{-1}$ & 7.79E-06 & 13.97 \\
\hline Par11 & $E a_{L A_{-} h y d}$ & $\mathrm{~J}^{\mathrm{mol}}{ }^{-1}$ & $5.49 \mathrm{E}+04$ & 7.01 \\
\hline Par12 & $K_{L A^{\wedge}}$ & $\mathrm{m}^{3} \cdot \mathrm{mol}^{-1}$ & $3.54 \mathrm{E}-04$ & 53.75 \\
\hline Par13 & $K_{H P A^{\wedge}}$ & $\mathrm{m}^{3} \cdot \mathrm{mol}^{-1}$ & Fixed to zero & - \\
\hline Par14 & $k_{H P A_{-} \text {cat_Amb }}^{\prime}\left(T_{R e f}\right)$ & $\mathrm{s}^{-1} \cdot \mathrm{kg}$ _dry basis $\mathrm{Amb}^{-1}$ & $5.21 \mathrm{E}-04$ & 54.44 \\
\hline Par15 & $E a_{H P A_{-}}^{\prime} c a t_{-} A m b$ & J.mol ${ }^{-1}$ & Fixed to zero & - \\
\hline Par16 & $k_{H P A \_n o n c a t}\left(T_{R e f}\right)$ & $\mathrm{s}^{-1}$ & 5.39E-07 & 255.52 \\
\hline Par17 & $E a_{H P A_{-} \text {noncat }}$ & $\mathrm{J} \mathrm{mol}^{-1}$ & $4.56 \mathrm{E}+05$ & 39.09 \\
\hline Par18 & $K_{B H P-S O 3 H}$ & $\mathrm{~m}^{3} \cdot \mathrm{mol}^{-1}$ & Fixed to zero & - \\
\hline Par19 & $K_{H P A-S O 3 H}$ & $\mathrm{~m}^{3} \cdot \mathrm{mol}^{-1}$ & Fixed to zero & - \\
\hline
\end{tabular}




\begin{tabular}{|c|c|c|c|c|}
\hline Par20 & $k_{B H P_{-} R u C}\left(T_{R e f}\right)$ & $\mathrm{s}^{-1} \cdot \mathrm{kg}$ _dry basis $\mathrm{RuC}^{-1}$ & 2.20E-05 & 20.80 \\
\hline Par21 & $E a_{B_{H} P_{-} R u C}$ & J.mol ${ }^{-1}$ & Fixed to zero & - \\
\hline Par22 & $k_{H P A \_R u C}\left(T_{R e f}\right)$ & $\mathrm{s}^{-1} \cdot \mathrm{kg} \_d r y$ basis $\mathrm{RuC}^{-1}$ & $6.96 \mathrm{E}-05$ & 8.77 \\
\hline Par23 & $E a_{H P A_{-} R u C}$ & $\mathrm{~J}^{\mathrm{m} \mathrm{mol}^{-1}}$ & Fixed to zero & - \\
\hline Par24 & $K_{\mathbf{\square} B H P}$ & $\mathrm{~m}^{3} \cdot \mathrm{mol}^{-1}$ & Fixed to zero & - \\
\hline Par25 & $K_{\square}$ & $\mathrm{m}^{3} \cdot \mathrm{mol}^{-1}$ & Fixed to zero & - \\
\hline Par26 & $k_{\text {BHP_diss }}\left(T_{R e f}\right)$ & $\mathrm{m}^{3} \cdot \mathrm{mol}^{-1} \cdot \mathrm{s}^{-1}$ & $1.36 \mathrm{E}-06$ & 15.61 \\
\hline Par27 & $E a_{B H P_{-} d i s s}$ & $\mathrm{~J}^{\mathrm{mol}}{ }^{-1}$ & $1.04 \mathrm{E}+05$ & 12.86 \\
\hline Par28 & $k_{H P A_{-} d i s s}\left(T_{R e f}\right)$ & $\mathrm{m}^{3} \cdot \mathrm{mol}^{-1} \cdot \mathrm{s}^{-1}$ & $3.71 \mathrm{E}-06$ & 7.08 \\
\hline Par29 & $E a_{H P A_{-} d i s s}$ & ${\mathrm{~J} . \mathrm{mol}^{-1}}^{-1}$ & $7.41 \mathrm{E}+04$ & 7.93 \\
\hline
\end{tabular}

Table S3.2. Normalized parameter covariance matrix for NCLH1.1.

\begin{tabular}{|c|c|c|c|c|c|c|c|c|c|c|c|c|c|c|c|c|c|c|c|}
\hline & Par1 & Par2 & Par3 & Par4 & Par6 & Par8 & Par9 & Par10 & Par11 & Par12 & Par14 & Par16 & Par17 & Par20 & Par22 & Par26 & Par27 & Par28 & Par29 \\
\hline $\begin{array}{l}\text { Par1 } \\
\end{array}$ & 1 & & & & & & & & & & & & & & & & & & \\
\hline $\begin{array}{l}\text { Par2 } \\
\end{array}$ & 0.082 & 1 & & & & & & & & & & & & & & & & & \\
\hline $\begin{array}{l}\text { Par3 } \\
\end{array}$ & 0.662 & -0.064 & 1 & & & & & & & & & & & & & & & & \\
\hline $\begin{array}{l}\text { Par4 } \\
\end{array}$ & 0.618 & 0.369 & -0.081 & 1 & & & & & & & & & & & & & & & \\
\hline Par6 & 0.027 & 0.007 & 0.022 & 0.015 & 1 & & & & & & & & & & & & & & \\
\hline $\begin{array}{l}\text { Par8 } \\
\end{array}$ & 0.048 & 0.105 & -0.029 & 0.066 & 0.006 & 1 & & & & & & & & & & & & & \\
\hline $\begin{array}{l}\text { Par9 } \\
\end{array}$ & -0.073 & -0.192 & 0.013 & $\begin{array}{l}-0.115 \\
\end{array}$ & -0.006 & -0.938 & 1 & & & & & & & & & & & & \\
\hline Par10 & 0.911 & -0.028 & 0.62 & 0.531 & 0.015 & 0.07 & -0.079 & 1 & & & & & & & & & & & \\
\hline Par11 & $\begin{array}{l}-0.021 \\
\end{array}$ & 0.047 & -0.019 & 0.015 & -0.005 & -0.08 & 0.112 & 0.083 & 1 & & & & & & & & & & \\
\hline Par12 & 0.266 & -0.547 & 0.262 & -0.23 & -0.01 & 0.078 & -0.021 & 0.446 & -0.135 & 1 & & & & & & & & & \\
\hline Par14 & 0.007 & 0.005 & 0.013 & 0 & 0 & 0 & 0 & 0.013 & 0.005 & -0.006 & 1 & & & & & & & & \\
\hline Par16 & 0.018 & 0.003 & -0.007 & 0.029 & 0.003 & 0.026 & -0.039 & -0.039 & $\begin{array}{l}-0.346 \\
\end{array}$ & 0.021 & -0.002 & 1 & & & & & & & \\
\hline $\begin{array}{l}\text { Par17 } \\
\end{array}$ & $\begin{array}{l}-0.008 \\
\end{array}$ & -0.007 & 0.027 & -0.034 & -0.002 & -0.023 & 0.034 & 0.036 & 0.279 & -0.013 & 0.002 & -0.967 & 1 & & & & & & \\
\hline Par20 & 0.027 & 0.021 & 0.055 & 0.02 & -0.002 & $\begin{array}{l}-0.761 \\
\end{array}$ & 0.636 & 0.05 & 0.015 & 0.006 & 0.001 & -0.006 & 0.006 & 1 & & & & & \\
\hline Par22 & 0.273 & 0.04 & 0.169 & 0.208 & 0.008 & -0.022 & 0.016 & 0.187 & 0.211 & 0.034 & -0.006 & -0.347 & 0.306 & 0.017 & 1 & & & & \\
\hline Par26 & 0.039 & -0.2 & -0.119 & 0.029 & -0.036 & -0.134 & 0.156 & 0.177 & 0.298 & 0.186 & 0.007 & -0.121 & 0.093 & -0.108 & -0.059 & 1 & & & \\
\hline Par27 & 0.143 & 0.263 & 0.097 & 0.119 & -0.006 & 0.233 & -0.351 & 0.247 & 0.366 & 0.051 & 0.006 & -0.133 & 0.107 & 0.06 & 0.087 & 0.212 & 1 & & \\
\hline
\end{tabular}




\begin{tabular}{|c|c|c|c|c|c|c|c|c|c|c|c|c|c|c|c|c|c|c|c|}
\hline Par28 & -0.176 & -0.108 & -0.311 & -0.042 & -0.015 & 0.049 & -0.013 & 0.074 & 0.218 & 0.153 & 0.01 & -0.202 & 0.145 & -0.02 & -0.44 & 0.403 & 0.139 & 1 & \\
\hline Par29 & 0.07 & 0.087 & 0.032 & 0.074 & -0.002 & -0.046 & 0.064 & 0.126 & 0.751 & -0.052 & 0.001 & -0.494 & 0.397 & 0.018 & 0.442 & 0.186 & 0.306 & 0.18 & 1 \\
\hline
\end{tabular}


Table S3.3. Estimated values et $\mathrm{T}_{\text {ref }}=392.15 \mathrm{~K}$ and statistical data for $\mathrm{LH} 1$.

\begin{tabular}{|c|c|c|c|c|}
\hline \multicolumn{2}{|r|}{ Parameters } & Units & Estimates & HDP\% \\
\hline Par1 & $k_{B L_{-} h y d}\left(T_{R e f}\right)$ & $\mathrm{m}^{3} \cdot \mathrm{mol}^{-1} \cdot \mathrm{s}^{-1} \cdot \mathrm{kg} \_$dry basis $\mathrm{RuC}^{-1}$ & 3.67E-06 & 14.96 \\
\hline Par2 & $E a_{B L_{-} h y d}$ & ${\mathrm{~J} . \mathrm{mol}^{-1}}^{-1}$ & $3.15 \mathrm{E}+04$ & 10.58 \\
\hline Par3 & $K_{H 2}$ & $\mathrm{~m}^{3} \cdot \mathrm{mol}^{-1}$ & $1.73 \mathrm{E}-03$ & 110.02 \\
\hline Par4 & $K_{B L^{\wedge}}$ & $\mathrm{m}^{3} \cdot \mathrm{mol}^{-1}$ & $3.96 \mathrm{E}-04$ & 17.53 \\
\hline Par5 & $K_{B H P^{\wedge}}$ & $\mathrm{m}^{3} \cdot \mathrm{mol}^{-1}$ & Fixed to zero & - \\
\hline Par6 & $k_{\text {BHP_cat_Amb }}^{\prime}\left(T_{R e f}\right)$ & $\mathrm{s}^{-1} \cdot \mathrm{kg}$ _dry basis $\mathrm{Amb}^{-1}$ & $4.30 \mathrm{E}-05$ & 47.82 \\
\hline Par7 & $E a_{B H P_{-} c a t \_A m b}^{\prime}$ & J.mol ${ }^{-1}$ & Fixed to zero & - \\
\hline Par8 & $k_{\text {BHP_noncat }}\left(T_{R e f}\right)$ & $\mathrm{s}^{-1}$ & $6.36 \mathrm{E}-05$ & 32.33 \\
\hline Par9 & $E a_{\text {BHP_noncat }}$ & $\mathrm{J}^{\mathrm{mol}}{ }^{-1}$ & $7.75 \mathrm{E}+04$ & 39.20 \\
\hline Par10 & $k_{L A \_h y d}\left(T_{R e f}\right)$ & $\mathrm{m}^{3} \cdot \mathrm{mol}^{-1} \cdot \mathrm{s}^{-1} \cdot \mathrm{kg} \_$dry basis $\mathrm{RuC}^{-1}$ & $8.12 \mathrm{E}-06$ & 15.21 \\
\hline Par11 & $E a_{L A_{-} h y d}$ & ${\mathrm{~J} . \mathrm{mol}^{-1}}^{-1}$ & $5.47 \mathrm{E}+04$ & 6.98 \\
\hline Par12 & $K_{L A^{\wedge}}$ & $\mathrm{m}^{3} \cdot \mathrm{mol}^{-1}$ & $1.61 \mathrm{E}-04$ & 41.45 \\
\hline Par13 & $K_{H P A^{\wedge}}$ & $\mathrm{m}^{3} \cdot \mathrm{mol}^{-1}$ & Fixed to zero & - \\
\hline Par14 & $k_{H P A_{-} c a t \_A m b}^{\prime}\left(T_{R e f}\right)$ & $\mathrm{s}^{-1} \cdot \mathrm{kg} \_$dry basis $\mathrm{Amb}^{-1}$ & $5.20 \mathrm{E}-04$ & 52.93 \\
\hline Par15 & $E a_{H P A_{-} c a t \_A m b}^{\prime}$ & ${\mathrm{J} . \mathrm{mol}^{-1}}^{-1}$ & Fixed to zero & - \\
\hline Par16 & $k_{H P A_{\_} \text {noncat }}\left(T_{R e f}\right)$ & $\mathrm{s}^{-1}$ & $4.45 \mathrm{E}-07$ & 263.18 \\
\hline Par17 & $E a_{H P A \_n o n c a t}$ & $\mathrm{~J}_{\mathrm{mol}} \mathrm{m}^{-1}$ & $4.70 \mathrm{E}+05$ & 40.19 \\
\hline Par18 & $K_{B H P-S O 3 H}$ & $\mathrm{~m}^{3} \cdot \mathrm{mol}^{-1}$ & Fixed to zero & - \\
\hline Par19 & $K_{H P A-S O 3 H}$ & $\mathrm{~m}^{3} \cdot \mathrm{mol}^{-1}$ & Fixed to zero & - \\
\hline Par20 & $k_{\text {BHP_RuC }}\left(T_{R e f}\right)$ & $\mathrm{s}^{-1} \cdot \mathrm{kg} \_$dry basis $\mathrm{RuC}^{-1}$ & $2.21 \mathrm{E}-05$ & 20.53 \\
\hline Par21 & $E a_{B H P_{-} R u C}$ & ${\mathrm{~J} . \mathrm{mol}^{-1}}^{-1}$ & Fixed to zero & - \\
\hline
\end{tabular}




\begin{tabular}{|c|c|c|c|c|}
\hline Par22 & $k_{H P A_{-} R u C}\left(T_{R e f}\right)$ & $\mathrm{s}^{-1} \cdot \mathrm{kg} \_$dry basis $\mathrm{RuC}^{-1}$ & 7.08E-05 & 8.43 \\
\hline Par23 & $E a_{H P A_{-} R u C}$ & $\mathrm{~J}^{\mathrm{mol}}{ }^{-1}$ & Fixed to zero & - \\
\hline Par24 & $K_{\square B H P}$ & $\mathrm{~m}^{3} \cdot \mathrm{mol}^{-1}$ & Fixed to zero & - \\
\hline Par25 & $K_{\mathbf{\square} H P A}$ & $\mathrm{~m}^{3} \cdot \mathrm{mol}^{-1}$ & Fixed to zero & - \\
\hline Par26 & $k_{\text {BHP_diss }}\left(T_{R e f}\right)$ & $\mathrm{m}^{3} \cdot \mathrm{mol}^{-1} \cdot \mathrm{s}^{-1}$ & $1.41 \mathrm{E}-06$ & 15.82 \\
\hline Par27 & $E a_{B H P_{-} d i s S}$ & $\mathrm{~J} . \mathrm{mol}^{-1}$ & $1.05 \mathrm{E}+05$ & 12.74 \\
\hline Par28 & $k_{H P A_{-} d i s s}\left(T_{R e f}\right)$ & $\mathrm{m}^{3} \cdot \mathrm{mol}^{-1} \cdot \mathrm{s}^{-1}$ & $3.74 \mathrm{E}-06$ & 7.05 \\
\hline Par29 & $E a_{H P A_{-} d i s S}$ & $\mathrm{~J}^{\mathrm{m} \mathrm{mol}^{-1}}$ & $7.48 \mathrm{E}+04$ & 7.82 \\
\hline
\end{tabular}

Table S3.4 Normalized parameter covariance matrix for LH1.

\begin{tabular}{|c|c|c|c|c|c|c|c|c|c|c|c|c|c|c|c|c|c|c|c|}
\hline & Par1 & Par2 & Par3 & Par4 & Par6 & Par8 & Par9 & Par10 & Par11 & Par12 & Par14 & Par16 & Par17 & Par20 & Par22 & Par26 & Par27 & Par28 & Par29 \\
\hline Par1 & 1 & & & & & & & & & & & & & & & & & & \\
\hline Par2 & 0.039 & 1 & & & & & & & & & & & & & & & & & \\
\hline Par3 & 0.844 & 0.049 & 1 & & & & & & & & & & & & & & & & \\
\hline Par4 & 0.694 & 0.354 & 0.31 & 1 & & & & & & & & & & & & & & & \\
\hline Par6 & 0.028 & 0.007 & 0.022 & 0.023 & 1 & & & & & & & & & & & & & & \\
\hline Par8 & 0.011 & 0.114 & 0.038 & 0.04 & 0.006 & 1 & & & & & & & & & & & & & \\
\hline Par9 & 0.034 & 0.202 & 0.02 & 0.095 & 0.006 & -0.937 & 1 & & & & & & & & & & & & \\
\hline Par10 & 0.925 & 0059 & 0.808 & 0.597 & 0.018 & 0.033 & -0.041 & 1 & & & & & & & & & & & \\
\hline Par11 & 0.023 & 0.02 & 0.016 & 0 & 0.005 & -0.082 & 0.115 & 0.076 & 1 & & & & & & & & & & \\
\hline Par12 & 0.359 & 0.532 & 0.387 & 0.182 & 0.006 & 0.056 & -0.004 & 0.517 & 0.116 & 1 & & & & & & & & & \\
\hline
\end{tabular}




\begin{tabular}{|c|c|c|c|c|c|c|c|c|c|c|c|c|c|c|c|c|c|c|c|}
\hline Par14 & 0.009 & 0.005 & 0.012 & 0.005 & 0 & 0 & 0 & 0.014 & 0.006 & 0.004 & 1 & & & & & & & & \\
\hline Par16 & $\begin{array}{c}- \\
0.001\end{array}$ & 0.004 & $\begin{array}{c}- \\
0.017\end{array}$ & 0.019 & 0.003 & 0.026 & -0.039 & $\begin{array}{c}- \\
0.055\end{array}$ & $\begin{array}{c}- \\
0.359\end{array}$ & 0.008 & $\begin{array}{c}- \\
0.002\end{array}$ & 1 & & & & & & & \\
\hline Par17 & 0.014 & $\begin{array}{c}- \\
0.007\end{array}$ & 0.035 & $\begin{array}{c}- \\
0.016\end{array}$ & $\begin{array}{c}- \\
0.002\end{array}$ & -0.023 & 0.035 & 0.058 & 0.299 & 0 & 0.002 & -0.972 & 1 & & & & & & \\
\hline Par20 & 0.034 & 0.019 & 0.062 & 0.033 & 0.002 & -0.764 & 0.64 & 0.056 & 0.017 & 0.013 & 0.001 & -0.008 & 0.008 & 1 & & & & & \\
\hline Par22 & 0.237 & 0.042 & 0.164 & 0.238 & 0.007 & -0.028 & 0.022 & 0.157 & 0.218 & 0.03 & 0.007 & -0.36 & 0.325 & 0.018 & 1 & & & & \\
\hline Par26 & 0.003 & $\begin{array}{c}- \\
0.209\end{array}$ & $\begin{array}{c}- \\
0.111\end{array}$ & $\begin{array}{c}- \\
0.023\end{array}$ & $\begin{array}{c}- \\
0.036\end{array}$ & -0.136 & 0.157 & 0.135 & 0.308 & 0.167 & 0.008 & -0.127 & 0.101 & -0.105 & -0.064 & 1 & & & \\
\hline Par27 & 0.123 & 0.261 & 0.095 & 0.135 & 0.007 & 0.229 & -0.347 & 0.225 & 0.373 & 0.054 & 0.006 & -0.145 & 0.121 & 0.058 & 0.084 & 0.223 & 1 & & \\
\hline Par28 & $\begin{array}{c}- \\
0.215\end{array}$ & $\begin{array}{c}- \\
0.115\end{array}$ & $\begin{array}{c}- \\
0.299\end{array}$ & $\begin{array}{c}- \\
0.154\end{array}$ & $\begin{array}{c}- \\
0.015\end{array}$ & 0.053 & -0.017 & 0.019 & 0.221 & 0.123 & 0.01 & -0.205 & 0.154 & -0.023 & -0.442 & 0.415 & 0.15 & 1 & \\
\hline Par29 & 0.053 & 0.079 & 0.025 & 0.075 & 0.003 & -0.047 & 0.066 & 0.105 & 0.757 & 0.049 & 0 & -0.511 & 0.426 & 0.019 & 0.447 & 0.192 & 0.314 & 0.18 & 1 \\
\hline
\end{tabular}


Table S3.5. Estimated values et $\mathrm{T}_{\text {ref }}=392.15 \mathrm{~K}$ and statistical data for $\mathrm{LH} 2$.

\begin{tabular}{|c|c|c|c|c|}
\hline \multicolumn{2}{|r|}{ Parameters } & Units & Estimates & $\mathrm{HDP} \%$ \\
\hline Par1 & $k_{B L_{-} h y d}\left(T_{R e f}\right)$ & $\mathrm{m}^{3} \cdot \mathrm{mol}^{-1} \cdot \mathrm{s}^{-1} \cdot \mathrm{kg} \_$dry basis $\mathrm{RuC}^{-1}$ & $3.61 \mathrm{E}-06$ & 23.96 \\
\hline Par2 & $E a_{B L_{-} h y d}$ & J.mol ${ }^{-1}$ & $3.17 \mathrm{E}+04$ & 10.55 \\
\hline Par3 & $K_{H 2 .}$ & $\mathrm{m}^{3} \cdot \mathrm{mol}^{-1}$ & $8.38 \mathrm{E}-03$ & 241.80 \\
\hline Par4 & $K_{B L^{\wedge}}$ & $\mathrm{m}^{3} \cdot \mathrm{mol}^{-1}$ & 3.99E-04 & 19.29 \\
\hline Par5 & $K_{B H P^{\wedge}}$ & $\mathrm{m}^{3} \cdot \mathrm{mol}^{-1}$ & Fixed to zero & - \\
\hline Par6 & $k_{B H P_{-} c a t \_A m b}^{\prime}\left(T_{R e f}\right)$ & $\mathrm{s}^{-1} \cdot \mathrm{kg}$ _dry basis $\mathrm{Amb}^{-1}$ & 4.27E-05 & 48.01 \\
\hline Par7 & $E a_{B H P \_c a t \_A m b}^{\prime}$ & J.mol ${ }^{-1}$ & Fixed to zero & - \\
\hline Par8 & $k_{\text {BHP_noncat }}\left(T_{R e f}\right)$ & $\mathrm{s}^{-1}$ & $6.41 \mathrm{E}-05$ & 32.40 \\
\hline Par9 & $E a_{\text {BHP_noncat }}$ & J.mol ${ }^{-1}$ & $7.66 \mathrm{E}+04$ & 39.69 \\
\hline Par10 & $k_{L A_{-} h y d}\left(T_{R e f}\right)$ & $\mathrm{m}^{3} \cdot \mathrm{mol}^{-1} \cdot \mathrm{s}^{-1} \cdot \mathrm{kg}$ _dry basis $\mathrm{RuC}^{-1}$ & 7.96E-06 & 23.99 \\
\hline Par11 & $E a_{L A \_h y d}$ & $\mathrm{~J}^{\mathrm{m} \mathrm{mol}^{-1}}$ & $5.45 \mathrm{E}+04$ & 7.00 \\
\hline Par12 & $K_{L A^{\wedge}}$ & $\mathrm{m}^{3} \cdot \mathrm{mol}^{-1}$ & $1.47 \mathrm{E}-04$ & 47.35 \\
\hline Par13 & $\overline{K_{H P A^{\wedge}}}$ & $\mathrm{m}^{3} \cdot \mathrm{mol}^{-1}$ & Fixed to zero & - \\
\hline Par14 & $k_{H P A_{-} c a t_{\_} \text {Amb }}^{\prime}\left(T_{\text {Ref }}\right)$ & $\mathrm{s}^{-1} \cdot \mathrm{kg} \_$dry basis $\mathrm{Amb}^{-1}$ & $5.17 \mathrm{E}-04$ & 53.05 \\
\hline Par15 & $E a_{H P A_{-} c a t \_A m b}^{\prime}$ & $\mathrm{J}^{\mathrm{mol}} \mathrm{m}^{-1}$ & Fixed to zero & - \\
\hline Par16 & $k_{H P A \_n o n c a t}\left(T_{R e f}\right)$ & $\mathrm{s}^{-1}$ & 5.20E-07 & 246.56 \\
\hline Par17 & $E a_{H P A_{-} \text {noncat }}$ & J.mol ${ }^{-1}$ & $4.58 \mathrm{E}+05$ & 39.27 \\
\hline Par18 & $K_{B H P-S O 3 H}$ & $\mathrm{~m}^{3} \cdot \mathrm{mol}^{-1}$ & Fixed to zero & - \\
\hline Par19 & $K_{H P A-S O 3 H}$ & $\mathrm{~m}^{3} \cdot \mathrm{mol}^{-1}$ & Fixed to zero & - \\
\hline Par20 & $k_{\text {BHP_RuC }}\left(T_{R e f}\right)$ & $\mathrm{s}^{-1} \cdot \mathrm{kg} \_$dry basis $\mathrm{RuC}^{-1}$ & $2.20 \mathrm{E}-05$ & 20.94 \\
\hline Par21 & $E a_{B H P \_R u C}$ & J.mol ${ }^{-1}$ & Fixed to zero & - \\
\hline
\end{tabular}




\begin{tabular}{|c|c|c|c|c|}
\hline Par22 & $k_{H P A_{\_} R u C}\left(T_{R e f}\right)$ & $\mathrm{s}^{-1} \cdot \mathrm{kg} \_$dry basis $\mathrm{RuC}^{-1}$ & 7.03E-05 & 8.46 \\
\hline Par23 & $E a_{H P A_{-} R u C}$ & ${\mathrm{~J} . \mathrm{mol}^{-1}}^{-1}$ & Fixed to zero & - \\
\hline Par24 & $K_{\mathbf{n} B H P}$ & $\mathrm{~m}^{3} \cdot \mathrm{mol}^{-1}$ & Fixed to zero & - \\
\hline Par25 & $K_{\mathbf{n} H P A}$ & $\mathrm{~m}^{3} \cdot \mathrm{mol}^{-1}$ & Fixed to zero & - \\
\hline Par26 & $\mathrm{K}_{\mathrm{i}}$ & $\mathrm{m}^{9 / 2} \cdot \mathrm{mol}^{-3 / 2}$ & Fixed to zero & - \\
\hline Par27 & $\mathrm{K}_{\mathrm{i} 2}$ & $\mathrm{~m}^{9 / 2} \cdot \mathrm{mol}^{-3 / 2}$ & Fixed to zero & - \\
\hline Par28 & $k_{\text {BHP_diss }}\left(T_{R e f}\right)$ & $\mathrm{m}^{3} \cdot \mathrm{mol}^{-1} \cdot \mathrm{s}^{-1}$ & $1.42 \mathrm{E}-06$ & 15.78 \\
\hline Par29 & $E a_{B H P_{-} d i s S}$ & $\mathrm{~J}^{\mathrm{mol}}{ }^{-1}$ & $1.05 \mathrm{E}+05$ & 12.82 \\
\hline Par30 & $k_{H P A_{-} d i s S}\left(T_{R e f}\right)$ & $\mathrm{m}^{3} \cdot \mathrm{mol}^{-1} \cdot \mathrm{s}^{-1}$ & $3.76 \mathrm{E}-06$ & 7.03 \\
\hline Par31 & $E a_{H P A_{\text {_diss }}}$ & $\mathrm{J}^{\mathrm{mol}} \mathrm{l}^{-1}$ & $7.43 \mathrm{E}+04$ & 7.82 \\
\hline
\end{tabular}

Table S3.6 Normalized parameter covariance matrix for LH2.

\begin{tabular}{|c|c|c|c|c|c|c|c|c|c|c|c|c|c|c|c|c|c|c|c|}
\hline & Par1 & Par2 & Par3 & Par4 & Par6 & $\begin{array}{l}\text { Par8 } \\
\end{array}$ & Par9 & Par10 & $\begin{array}{l}\text { Par11 } \\
\end{array}$ & Par12 & $\begin{array}{l}\text { Par14 } \\
\end{array}$ & Par16 & Par17 & Par20 & Par22 & Par28 & Par29 & Par30 & $\begin{array}{l}\text { Par31 } \\
\end{array}$ \\
\hline Par1 & 1 & & & & & & & & & & & & & & & & & & \\
\hline Par2 & -0.011 & 1 & & & & & & & & & & & & & & & & & \\
\hline Par3 & 0.942 & -0.064 & 1 & & & & & & & & & & & & & & & & \\
\hline Par4 & 0.735 & 0.295 & 0.521 & 1 & & & & & & & & & & & & & & & \\
\hline Par6 & 0.025 & 0.007 & 0.021 & 0.025 & 1 & & & & & & & & & & & & & & \\
\hline $\begin{array}{l}\text { Par8 } \\
\end{array}$ & -0.004 & 0.115 & -0.033 & 0.03 & 0.007 & 1.00 & & & & & & & & & & & & & \\
\hline Par9 & -0.017 & -0.204 & 0.016 & -0.083 & -0.007 & -0.937 & 1 & & & & & & & & & & & & \\
\hline Par10 & 0.97 & -0.072 & 0.927 & 0.682 & 0.019 & 0.01 & -0.022 & 1 & & & & & & & & & & & \\
\hline Par11 & -0.023 & 0.026 & -0.019 & -0.004 & -0.005 & -0.083 & 0.116 & 0.039 & 1 & & & & & & & & & & \\
\hline Par12 & 0.466 & -0.52 & 0.474 & -0.012 & -0.004 & 0.052 & -0.004 & 0.563 & -0.116 & 1 & & & & & & & & & \\
\hline $\begin{array}{l}\text { Par14 } \\
\text { nat1 }\end{array}$ & 0.01 & 0.005 & 0.012 & 0.007 & 0 & 0 & -0.001 & 0.014 & 0.005 & -0.003 & 1 & & & & & & & & \\
\hline Par16 & -0.008 & 0.002 & -0.017 & 0.011 & 0.002 & 0.026 & -0.039 & -0.041 & -0.35 & 0.009 & -0.002 & 1 & & & & & & & \\
\hline Par17 & 0.024 & -0.005 & 0.036 & -0.004 & -0.002 & -0.023 & 0.033 & 0.05 & 0.284 & 0.002 & 0.002 & -0.968 & 1 & & & & & & \\
\hline Par20 & 0.044 & 0.015 & 0.059 & 0.041 & -0.002 & \begin{tabular}{l|l}
-0.77 \\
\end{tabular} & 0.647 & 0.057 & 0.019 & 0.017 & 0.001 & -0.009 & 0.008 & 1 & & & & & \\
\hline Par22 & 0.222 & 0.042 & 0.17 & 0.258 & 0.007 & -0.027 & 0.022 & 0.174 & 0.216 & 0.048 & -0.006 & -0.357 & 0.316 & 0.018 & 1 & & & & \\
\hline
\end{tabular}




\begin{tabular}{|c|c|c|c|c|c|c|c|c|c|c|c|c|c|c|c|c|c|c|c|}
\hline Par28 & -0.05 & -0.206 & -0.118 & -0.049 & -0.036 & -0.139 & 0.161 & 0.033 & 0.306 & 0.142 & 0.008 & -0.122 & 0.093 & -0.099 & -0.065 & 1 & & & \\
\hline Par29 & 0.121 & 0.263 & 0.099 & 0.15 & -0.007 & 0.233 & -0.351 & 0.186 & 0.369 & 0.061 & 0.006 & -0.14 & 0.114 & 0.05 & 0.085 & 0.219 & 1 & & \\
\hline Par30 & -0.267 & -0.108 & -0.309 & -0.214 & -0.014 & 0.052 & -0.017 & -0.122 & 0.219 & 0.079 & 0.01 & -0.198 & 0.142 & -0.023 & -0.442 & 0.413 & 0.146 & 1 & \\
\hline Par31 & 0.053 & 0.086 & 0.034 & 0.082 & -0.002 & -0.048 & 0.066 & 0.086 & 0.753 & -0.044 & 0.001 & -0.502 & 0.407 & 0.02 & 0.447 & 0.189 & 0.312 & 0.177 & 1 \\
\hline
\end{tabular}


Table S3.7. Estimated values et $\mathrm{T}_{\mathrm{ref}}=392.15 \mathrm{~K}$ and statistical data for $\mathrm{ER} 1$.

\begin{tabular}{|c|c|c|c|c|}
\hline \multicolumn{2}{|r|}{ Parameters } & Units & Estimates & HDP\% \\
\hline Par1 & $k_{B L_{-} h y d}\left(T_{R e f}\right)$ & $\mathrm{m}^{3} \cdot \mathrm{mol}^{-1} \cdot \mathrm{s}^{-1} \cdot \mathrm{kg} \_$dry basis $\mathrm{RuC}^{-1}$ & $4.01 \mathrm{E}-06$ & 22.86 \\
\hline Par2 & $E a_{B L_{-} h y d}$ & J.mol ${ }^{-1}$ & $3.14 \mathrm{E}+04$ & 10.88 \\
\hline Par3 & $K_{H 2}$ & $\mathrm{~m}^{3} \cdot \mathrm{mol}^{-1}$ & $5.81 \mathrm{E}-03$ & 115.48 \\
\hline Par4 & $K_{B L^{\wedge}}$ & $\mathrm{m}^{3} \cdot \mathrm{mol}^{-1}$ & $1.13 \mathrm{E}-03$ & 31.80 \\
\hline Par5 & $K_{B H P^{\wedge}}$ & $\mathrm{m}^{3} \cdot \mathrm{mol}^{-1}$ & Fixed to zero & - \\
\hline Par6 & 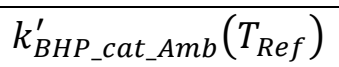 & $\mathrm{s}^{-1} \cdot \mathrm{kg} \_$dry basis $\mathrm{Amb}^{-1}$ & 4.29E-05 & 48.34 \\
\hline Par7 & $E a_{B H P_{C} c a t \_A m b}^{\prime}$ & J.mol ${ }^{-1}$ & Fixed to zero & - \\
\hline Par8 & $k_{\text {BHP_noncat }}\left(T_{R e f}\right)$ & $\mathrm{s}^{-1}$ & $6.33 \mathrm{E}-05$ & 32.79 \\
\hline Par9 & $E a_{\text {BHP_noncat }}$ & $\mathrm{J}_{\mathrm{mol}}{ }^{-1}$ & $7.91 \mathrm{E}+04$ & 38.80 \\
\hline Par10 & $k_{L A_{-} h y d}\left(T_{R e f}\right)$ & $\mathrm{m}^{3} \cdot \mathrm{mol}^{-1} \cdot \mathrm{s}^{-1} \cdot \mathrm{kg} \_$dry basis $\mathrm{RuC}^{-1}$ & 8.88E-06 & 23.01 \\
\hline Par11 & $E a_{L A \_h y d}$ & J.mol ${ }^{-1}$ & $5.49 \mathrm{E}+04$ & 6.94 \\
\hline Par12 & $K_{L A^{\wedge}}$ & $\mathrm{m}^{3} \cdot \mathrm{mol}^{-1}$ & $5.05 \mathrm{E}-04$ & 53.91 \\
\hline Par13 & $K_{H P A^{\wedge}}$ & $\mathrm{m}^{3} \cdot \mathrm{mol}^{-1}$ & Fixed to zero & - \\
\hline Par14 & $k_{H P A_{-} \text {cat_Amb }}^{\prime}\left(T_{R e f}\right)$ & $\mathrm{s}^{-1} \cdot \mathrm{kg} \_$dry basis $\mathrm{Amb}^{-1}$ & $5.20 \mathrm{E}-04$ & 54.14 \\
\hline Par15 & $E a_{H P A_{-} c a t \_A m b}^{\prime}$ & $\mathrm{J}^{\mathrm{mol}}{ }^{-1}$ & Fixed to zero & - \\
\hline Par16 & $k_{H P A \_n o n c a t}\left(T_{R e f}\right)$ & $\mathrm{s}^{-1}$ & $4.25 \mathrm{E}-07$ & 271.12 \\
\hline Par17 & $E a_{H P A_{-} \text {noncat }}$ & J.mol ${ }^{-1}$ & $4.73 E+05$ & 41.25 \\
\hline Par18 & $K_{B H P-S O 3 H}$ & $\mathrm{~m}^{3} \cdot \mathrm{mol}^{-1}$ & Fixed to zero & - \\
\hline Par19 & $K_{H P A-S O 3 H}$ & $\mathrm{~m}^{3} \cdot \mathrm{mol}^{-1}$ & Fixed to zero & - \\
\hline Par20 & $k_{\text {BHP_RuC }}\left(T_{R e f}\right)$ & $\mathrm{s}^{-1} \cdot \mathrm{kg} \_$dry basis $\mathrm{RuC}^{-1}$ & $2.21 \mathrm{E}-05$ & 20.69 \\
\hline Par21 & $E a_{B H P_{-} R u C}$ & J.mol ${ }^{-1}$ & Fixed to zero & - \\
\hline
\end{tabular}




\begin{tabular}{|c|c|c|c|c|}
\hline Par22 & $k_{H P A \_R u C}\left(T_{R e f}\right)$ & $\mathrm{s}^{-1} \cdot \mathrm{kg}$ _dry basis $\mathrm{RuC}^{-1}$ & $6.95 \mathrm{E}-05$ & 8.70 \\
\hline Par23 & $E a_{H P A_{-} R u C}$ & $\mathrm{~J} . \mathrm{mol}^{-1}$ & Fixed to zero & - \\
\hline Par24 & $K_{\mathbf{\square} B H P}$ & $\mathrm{~m}^{3} \cdot \mathrm{mol}^{-1}$ & Fixed to zero & - \\
\hline Par25 & $K_{\square}$ & $\mathrm{m}^{3} \cdot \mathrm{mol}^{-1}$ & Fixed to zero & - \\
\hline Par26 & $k_{\text {BHP_diss }}\left(T_{R e f}\right)$ & $\mathrm{m}^{3} \cdot \mathrm{mol}^{-1} \cdot \mathrm{s}^{-1}$ & $1.37 \mathrm{E}-06$ & 15.80 \\
\hline Par27 & $E a_{B H P_{-} d i s s}$ & $\mathrm{~J} \mathrm{~mol}^{-1}$ & $1.04 \mathrm{E}+05$ & 12.92 \\
\hline Par28 & $k_{H P A_{-} d i s s}\left(T_{R e f}\right)$ & $\mathrm{m}^{3} \cdot \mathrm{mol}^{-1} \cdot \mathrm{s}^{-1}$ & $3.74 \mathrm{E}-06$ & 7.04 \\
\hline Par29 & $E a_{H P A_{-} \text {diss }}$ & $\mathrm{J}^{\mathrm{mol}}{ }^{-1}$ & $7.44 \mathrm{E}+04$ & 7.89 \\
\hline
\end{tabular}

Table S3.8 Normalized parameter covariance matrix for ER1.

\begin{tabular}{|c|c|c|c|c|c|c|c|c|c|c|c|c|c|c|c|c|c|c|c|}
\hline & Par1 & Par2 & Par3 & Par4 & Par6 & Par8 & Par9 & Par10 & Par11 & Par12 & Par14 & Par16 & Par17 & Par20 & Par22 & Par26 & Par27 & Par28 & Par29 \\
\hline Par1 & 1 & & & & & & & & & & & & & & & & & & \\
\hline Par2 & 0.035 & 1 & & & & & & & & & & & & & & & & & \\
\hline Par3 & 0.894 & -0.047 & 1 & & & & & & & & & & & & & & & & \\
\hline Par4 & 0.882 & 0.257 & 0.642 & 1 & & & & & & & & & & & & & & & \\
\hline Par6 & 0.027 & 0.007 & 0.022 & 0.026 & 1 & & & & & & & & & & & & & & \\
\hline Par8 & 0 & 0.104 & $\begin{array}{c}-0.046 \\
\end{array}$ & 0.019 & 0.005 & 1.00 & & & & & & & & & & & & & \\
\hline Par9 & -0.021 & -0.192 & 0.031 & -0.065 & -0.005 & -0.938 & 1 & & & & & & & & & & & & \\
\hline Par10 & 0.967 & -0.033 & 0.878 & 0.835 & 0.02 & 0.014 & -0.026 & 1 & & & & & & & & & & & \\
\hline Par11 & -0.012 & 0.042 & $\begin{array}{l}-0.01 \\
\end{array}$ & 0.008 & -0.004 & -0.077 & 0.108 & 0.05 & 1 & & & & & & & & & & \\
\hline Par12 & 0.564 & -0.476 & 0.575 & 0.237 & 0 & 0.048 & -0.005 & 0.656 & -0.118 & 1 & & & & & & & & & \\
\hline Par14 & 0.007 & 0.005 & 0.01 & 0.006 & 0 & 0 & 0 & 0.011 & 0.006 & -0.002 & 1 & & & & & & & & \\
\hline Par16 & -0.006 & 0.006 & -0.022 & 0.008 & 0.002 & 0.026 & -0.039 & $\begin{array}{l}-0.04 \\
\end{array}$ & -0.352 & 0.006 & -0.002 & 1 & & & & & & & \\
\hline $\begin{array}{l}\text { Par17 } \\
\end{array}$ & 0.019 & -0.009 & 0.04 & 0 & -0.001 & $\begin{array}{l}-0.024 \\
\end{array}$ & 0.035 & 0.048 & 0.295 & 0.006 & 0.002 & -0.973 & 1 & & & & & & \\
\hline Par20 & 0.055 & 0.023 & 0.07 & 0.062 & -0.001 & -0.759 & 0.635 & 0.07 & 0.014 & 0.031 & 0.001 & -0.007 & 0.007 & 1 & & & & & \\
\hline Par22 & 0.23 & 0.043 & 0.156 & 0.263 & 0.007 & -0.025 & 0.021 & 0.181 & 0.216 & 0.076 & -0.007 & -0.359 & 0.325 & 0.018 & 1 & & & & \\
\hline Par26 & -0.006 & -0.207 & $\begin{array}{c}-0.088 \\
\end{array}$ & -0.041 & -0.035 & -0.129 & 0.149 & 0.079 & 0.294 & 0.144 & 0.008 & -0.121 & 0.097 & -0.11 & -0.055 & 1 & & & \\
\hline Par27 & 0.132 & 0.256 & 0.101 & 0.152 & -0.007 & 0.226 & -0.344 & 0.198 & 0.369 & 0.082 & 0.006 & -0.138 & 0.115 & 0.064 & 0.081 & 0.225 & 1 & & \\
\hline Par28 & -0.22 & -0.121 & $\begin{array}{l}-0.276 \\
\end{array}$ & -0.217 & -0.014 & 0.058 & -0.023 & -0.067 & 0.213 & 0.058 & 0.011 & -0.202 & 0.153 & -0.023 & -0.433 & 0.4 & 0.148 & 1 & \\
\hline Par29 & 0.052 & 0.079 & 0.027 & 0.073 & -0.002 & -0.045 & 0.064 & 0.086 & 0.753 & -0.035 & 0 & -0.506 & 0.423 & 0.016 & 0.442 & 0.188 & 0.304 & 0.185 & 1 \\
\hline
\end{tabular}



Table S3.9. Estimated values et $\mathrm{T}_{\mathrm{ref}}=392.15 \mathrm{~K}$ and statistical data for NCLH21.

\begin{tabular}{|c|c|c|c|c|}
\hline \multicolumn{2}{|r|}{ Parameters } & Units & Estimates & $\mathrm{HDP} \%$ \\
\hline Par1 & $k_{B L_{-} h y d}\left(T_{R e f}\right)$ & $\mathrm{m}^{3} \cdot \mathrm{mol}^{-1} \cdot \mathrm{s}^{-1} \cdot \mathrm{kg} \_$dry basis $\mathrm{RuC}^{-1}$ & $3.25 \mathrm{E}-06$ & 9.48 \\
\hline Par2 & $E a_{B L_{-} h y d}$ & $\mathrm{~J}^{\mathrm{m} \mathrm{mol}^{-1}}$ & $3.02 \mathrm{E}+04$ & 10.99 \\
\hline Par3 & $K_{H 2 .}$ & $\mathrm{m}^{3 / 2} \cdot \mathrm{mol}^{-1 / 2}$ & Fixed to zero & - \\
\hline Par4 & $K_{B L^{\wedge}}$ & $\mathrm{m}^{3} \cdot \mathrm{mol}^{-1}$ & Fixed to zero & - \\
\hline Par5 & $K_{B H P^{\wedge}}$ & $\mathrm{m}^{3} \cdot \mathrm{mol}^{-1}$ & Fixed to zero & - \\
\hline Par6 & $k_{B H P_{-} c a t \_A m b}^{\prime}\left(T_{R e f}\right)$ & $\mathrm{s}^{-1} \cdot \mathrm{kg} \_$dry basis $\mathrm{Amb}^{-1}$ & 4.32E-05 & 47.89 \\
\hline Par7 & $E a_{B H P_{-} c a t \_A m b}^{\prime}$ & $\mathrm{J}^{\mathrm{m} \mathrm{mol}^{-1}}$ & Fixed to zero & - \\
\hline Par8 & $k_{\text {BHP_noncat }}\left(T_{R e f}\right)$ & $\mathrm{s}^{-1}$ & $6.32 \mathrm{E}-05$ & 32.20 \\
\hline Par9 & $E a_{\text {BHP_noncat }}$ & $\mathrm{J}^{\mathrm{mol}}{ }^{-1}$ & $7.89 \mathrm{E}+04$ & 38.44 \\
\hline Par10 & $k_{\text {LA_hyd }}\left(T_{R e f}\right)$ & $\mathrm{m}^{3} \cdot \mathrm{mol}^{-1} \cdot \mathrm{s}^{-1} \cdot \mathrm{kg} \_$dry basis $\mathrm{RuC}^{-1}$ & $7.26 \mathrm{E}-06$ & 10.27 \\
\hline Par11 & $E a_{L A \_h y d}$ & ${\mathrm{~J} . \mathrm{mol}^{-1}}^{-1}$ & $5.50 \mathrm{E}+04$ & 6.87 \\
\hline Par12 & $K_{L A^{\wedge}}$ & $\mathrm{m}^{3} \cdot \mathrm{mol}^{-1}$ & $5.41 \mathrm{E}-04$ & 32.58 \\
\hline Par13 & $K_{H P A^{\wedge}}$ & $\mathrm{m}^{3} \cdot \mathrm{mol}^{-1}$ & Fixed to zero & - \\
\hline Par14 & $k_{H P A_{-} \text {cat_Amb }}^{\prime}\left(T_{\text {Ref }}\right)$ & $\mathrm{s}^{-1} \cdot \mathrm{kg} \_$dry basis $\mathrm{Amb}^{-1}$ & $5.32 \mathrm{E}-04$ & 53.92 \\
\hline Par15 & $E a_{H P A_{-} c a t_{2} A m b}^{\prime}$ & $\mathrm{J}^{\mathrm{mol}}{ }^{-1}$ & Fixed to zero & - \\
\hline Par16 & $k_{H P A \_n o n c a t}\left(T_{R e f}\right)$ & $\mathrm{s}^{-1}$ & 2.67E-07 & 355.63 \\
\hline Par17 & $E a_{H P A_{-} \text {noncat }}$ & ${\mathrm{J} . \mathrm{mol}^{-1}}^{-1}$ & $5.05 \mathrm{E}+05$ & 44.16 \\
\hline Par18 & $K_{B H P-S O 3 H}$ & $\mathrm{~m}^{3} \cdot \mathrm{mol}^{-1}$ & Fixed to zero & - \\
\hline Par19 & $K_{H P A-S O 3 H}$ & $\mathrm{~m}^{3} \cdot \mathrm{mol}^{-1}$ & Fixed to zero & - \\
\hline Par20 & $k_{\text {BHP_RuC }}\left(T_{R e f}\right)$ & $\mathrm{s}^{-1} \cdot \mathrm{kg}$ _dry basis $\mathrm{RuC}^{-1}$ & $2.23 \mathrm{E}-05$ & 20.12 \\
\hline Par21 & $E a_{B H P_{-} R u C}$ & J.mol ${ }^{-1}$ & Fixed to zero & - \\
\hline
\end{tabular}




\begin{tabular}{|c|c|c|c|c|}
\hline Par22 & $k_{H P A_{-} R u C}\left(T_{R e f}\right)$ & $\mathrm{s}^{-1} \cdot \mathrm{kg} \_$dry basis $\mathrm{RuC}^{-1}$ & $7.18 \mathrm{E}-05$ & 8.63 \\
\hline Par23 & $E a_{H P A_{-} R u C}$ & ${\mathrm{~J} . \mathrm{mol}^{-1}}^{-1}$ & Fixed to zero & - \\
\hline Par24 & $K_{\mathbf{n} B H P}$ & $\mathrm{~m}^{3} \cdot \mathrm{mol}^{-1}$ & Fixed to zero & - \\
\hline Par25 & $K_{\square}$ & $\mathrm{m}^{3} \cdot \mathrm{mol}^{-1}$ & Fixed to zero & - \\
\hline Par26 & $\mathrm{K}_{\mathrm{c}}$ & $\mathrm{m}^{9 / 2} \cdot \mathrm{mol}^{-3 / 2}$ & $1.43 \mathrm{E}-04$ & 22.64 \\
\hline Par27 & $\mathrm{K}_{\mathrm{c} 2}$ & $\mathrm{~m}^{9 / 2} \cdot \mathrm{mol}^{-3 / 2}$ & Fixed to zero & - \\
\hline Par28 & $k_{\text {BHP_diss }}\left(T_{R e f}\right)$ & $\mathrm{m}^{3} \cdot \mathrm{mol}^{-1} \cdot \mathrm{s}^{-1}$ & $1.38 \mathrm{E}-06$ & 15.88 \\
\hline Par29 & $E a_{B H P_{-} d i s s}$ & $\mathrm{~J}^{\mathrm{mol}}{ }^{-1}$ & $1.07 \mathrm{E}+05$ & 12.61 \\
\hline Par30 & $k_{H P A_{-} \text {diss }}\left(T_{\text {Ref }}\right)$ & $\mathrm{m}^{3} \cdot \mathrm{mol}^{-1} \cdot \mathrm{s}^{-1}$ & $3.70 \mathrm{E}-06$ & 6.96 \\
\hline Par31 & $E a_{H P A_{\text {_diss }}}$ & $\mathrm{J}^{\mathrm{m} \mathrm{mol}^{-1}}$ & $7.60 \mathrm{E}+04$ & 7.85 \\
\hline
\end{tabular}

Table S3.10. Normalized parameter covariance matrix for NCLH21.

\begin{tabular}{|l|c|c|c|c|c|c|c|c|c|c|c|c|c|c|c|c|c|c|}
\hline & Par1 & Par2 & Par6 & Par8 & Par9 & Par10 & Par11 & Par12 & Par14 & Par16 & Par17 & Par20 & Par22 & Par26 & Par28 & Par29 & Par30 & Par31 \\
\hline Par1 & 1 & & & & & & & & & & & & & & & & & \\
\hline Par2 & 0.094 & 1 & & & & & & & & & & & & & & & \\
\hline Par6 & 0.02 & 0.01 & 1 & & & & & & & & & & & & & & \\
\hline Par8 & 0.08 & 0.099 & 0.006 & 1.00 & & & & & & & & & & & & & \\
\hline Par9 & -0.097 & -0.189 & -0.007 & -0.937 & 1 & & & & & & & & & & & & \\
\hline Par10 & $\mathbf{0 . 8 2 5}$ & -0.065 & 0.004 & 0.104 & -0.098 & 1 & & & & & & & & & & & \\
\hline Par11 & -0.031 & 0.019 & -0.005 & -0.08 & 0.11 & 0.116 & 1 & & & & & & & & & & \\
\hline Par12 & 0.352 & -0.49 & -0.014 & 0.102 & -0.046 & 0.588 & -0.127 & 1 & & & & & & & & & \\
\hline Par14 & 0 & 0.008 & 0 & 0 & -0.001 & 0.008 & 0.006 & -0.012 & 1 & & & & & & & & \\
\hline Par16 & 0.027 & 0.014 & 0.003 & 0.026 & -0.041 & -0.063 & -0.378 & 0.02 & -0.002 & 1 & & & & & & & & \\
\hline Par17 & -0.026 & -0.013 & -0.003 & -0.024 & 0.037 & 0.053 & 0.335 & -0.019 & 0.002 & -0.982 & 1 & & & & & & \\
\hline Par20 & -0.005 & 0.035 & -0.002 & -0.753 & $\mathbf{0 . 6 2 6}$ & 0.029 & 0.015 & -0.006 & 0 & -0.006 & 0.005 & 1 & & & & & \\
\hline Par22 & 0.25 & 0.057 & 0.006 & -0.019 & 0.012 & 0.112 & 0.217 & 0.017 & -0.007 & -0.364 & 0.339 & 0.014 & 1 & & & \\
\hline
\end{tabular}




\begin{tabular}{|c|c|c|c|c|c|c|c|c|c|c|c|c|c|c|c|c|c|c|}
\hline Par26 & 0.88 & 0.312 & 0.022 & 0.052 & -0.105 & 0.698 & -0.008 & -0.003 & 0.005 & 0.028 & -0.026 & 0.041 & 0.271 & 1 & & & & \\
\hline Par28 & 0.143 & -0.241 & -0.035 & -0.131 & 0.154 & 0.334 & 0.302 & 0.26 & 0.009 & -0.14 & 0.123 & -0.112 & -0.054 & -0.014 & 1 & & & \\
\hline Par29 & 0.118 & 0.263 & -0.008 & 0.231 & -0.35 & 0.261 & 0.38 & 0.057 & 0.006 & -0.15 & 0.132 & 0.065 & 0.083 & 0.148 & 0.235 & 1 & & \\
\hline Par30 & -0.039 & -0.182 & -0.012 & 0.039 & 0 & 0.326 & 0.221 & 0.277 & 0.013 & -0.227 & 0.191 & -0.009 & -0.442 & -0.178 & 0.404 & 0.167 & 1 & \\
\hline Par31 & 0.065 & 0.065 & -0.002 & -0.047 & 0.065 & 0.138 & $\mathbf{0 . 7 5 9}$ & -0.043 & 0.001 & -0.528 & 0.465 & 0.017 & 0.45 & 0.076 & 0.194 & 0.314 & 0.18 & 1 \\
\hline
\end{tabular}




\section{NCLH1.2.}

Table S3.11. Normalized parameter covariance matrix for Model NCLH1.2.

\begin{tabular}{|c|c|c|c|c|c|c|c|c|c|c|c|c|c|c|c|c|c|c|c|}
\hline & Par1 & Par2 & Par3 & Par4 & Par6 & Par8 & Par9 & \begin{tabular}{|l|} 
Par10 \\
\end{tabular} & $\begin{array}{l}\text { Par11 } \\
\text {. }\end{array}$ & $\begin{array}{l}\text { Par12 } \\
\text {. }\end{array}$ & $\begin{array}{l}\text { Par14 } \\
\end{array}$ & Par16 & $\begin{array}{l}\text { Par17 } \\
\end{array}$ & Par20 & Par22 & Par26 & Par27 & $\begin{array}{l}\text { Par28 } \\
\end{array}$ & Par29 \\
\hline Par1 & 1 & & & & & & & & & & & & & & & & & & \\
\hline Par2 & 0.17 & 1 & & & & & & & & & & & & & & & & & \\
\hline Par3 & 0.453 & 0.069 & 1 & & & & & & & & & & & & & & & & \\
\hline Par4 & 0.834 & 0.16 & -0.072 & 1 & & & & & & & & & & & & & & & \\
\hline Par6 & 0.029 & 0.001 & 0.021 & 0.017 & 1 & & & & & & & & & & & & & & \\
\hline Par8 & \begin{tabular}{|l|}
-0.005 \\
\end{tabular} & 0.112 & \begin{tabular}{|c|}
-0.07 \\
\end{tabular} & 0.035 & 0.005 & 1 & & & & & & & & & & & & & \\
\hline Par9 & -0.028 & -0.175 & 0.049 & -0.066 & -0.005 & -0.932 & 1 & & & & & & & & & & & & \\
\hline Par10 & 0.237 & 0.061 & 0.644 & -0.127 & 0.002 & -0.013 & 0.017 & 1 & & & & & & & & & & & \\
\hline Par11 & 0.013 & 0.095 & 0.039 & -0.021 & -0.006 & -0.033 & 0.07 & 0.06 & 1 & & & & & & & & & & \\
\hline Par12 & -0.002 & 0.025 & 0.114 & -0.081 & -0.009 & 0.022 & -0.011 & \begin{tabular}{|l|l|} 
\\
\end{tabular} & -0.127 & 1 & & & & & & & & & \\
\hline Par14 & 0.006 & 0.001 & 0.016 & $\begin{array}{l}-0.003 \\
\end{array}$ & 0 & 0 & 0 & 0.012 & 0.005 & -0.006 & 1 & & & & & & & & \\
\hline Par16 & \begin{tabular}{|c|}
-0.009 \\
\end{tabular} & -0.013 & -0.033 & 0.012 & 0.002 & 0.012 & -0.024 & \begin{tabular}{|l|l|}
-0.019 \\
\end{tabular} & -0.311 & 0.067 & $\begin{array}{l}-0.002 \\
\end{array}$ & 1 & & & & & & & \\
\hline Par17 & 0.021 & 0.009 & 0.051 & -0.008 & 0 & -0.012 & 0.018 & \begin{tabular}{|l|}
0.015 \\
\end{tabular} & 0.21 & -0.06 & 0.002 & -0.948 & 1 & & & & & & \\
\hline Par20 & 0.061 & 0.074 & 0.052 & 0.066 & 0.002 & -0.728 & 0.593 & 0.067 & -0.014 & 0.059 & 0 & 0.006 & $\begin{array}{l}-0.003 \\
\end{array}$ & 1 & & & & & \\
\hline Par22 & 0.096 & 0.029 & 0.187 & 0.002 & 0.005 & -0.043 & 0.046 & \begin{tabular}{|l|}
0.113 \\
\end{tabular} & 0.234 & 0.099 & -0.005 & -0.314 & 0.256 & 0.013 & 1 & & & & \\
\hline Par26 & 0.102 & -0.083 & -0.123 & 0.14 & $\begin{array}{l}-0.044 \\
\end{array}$ & -0.085 & 0.084 & 0.17 & 0.261 & 0.166 & 0.006 & -0.085 & 0.046 & -0.123 & -0.065 & 1 & & & \\
\hline $\begin{array}{l}\text { Par27 } \\
\end{array}$ & 0.112 & 0.327 & 0.088 & 0.096 & -0.011 & 0.129 & -0.245 & \begin{tabular}{|l|}
0.217 \\
\end{tabular} & 0.392 & 0.13 & 0.005 & -0.118 & 0.077 & 0.133 & 0.08 & 0.328 & 1 & & \\
\hline Par28 & \begin{tabular}{|c|}
-0.188 \\
\end{tabular} & -0.006 & -0.261 & -0.082 & $\begin{array}{l}-0.019 \\
\end{array}$ & 0.059 & -0.031 & 0.305 & 0.189 & 0.377 & 0.005 & -0.165 & 0.078 & 0.001 & -0.368 & 0.381 & 0.187 & 1 & \\
\hline Par29 & 0.009 & 0.053 & 0.046 & $\begin{array}{l}-0.027 \\
\end{array}$ & $\begin{array}{l}-0.005 \\
\end{array}$ & $\begin{array}{l}-0.03 \\
\end{array}$ & 0.061 & 0.14 & 0.764 & 0.042 & 0 & -0.442 & 0.295 & -0.004 & 0.398 & 0.207 & 0.31 & 0.292 & 1 \\
\hline
\end{tabular}


NCLH2.2.

Table S3.12. Normalized parameter covariance matrix for Model NCLH2.2.

\begin{tabular}{|c|c|c|c|c|c|c|c|c|c|c|c|c|c|c|c|c|c|c|}
\hline & Par1 & Par2 & Par6 & Par8 & Par9 & Par10 & Par11 & Par12 & Par14 & Par16 & Par17 & Par20 & Par22 & Par26 & Par28 & Par29 & Par30 & Par31 \\
\hline Par1 & 1 & & & & & & & & & & & & & & & & & \\
\hline Par2 & 0.19 & 1 & & & & & & & & & & & & & & & & \\
\hline Par6 & 0.026 & 0.002 & 1 & & & & & & & & & & & & & & & \\
\hline Par8 & 0.113 & 0.165 & 0.011 & 1 & & & & & & & & & & & & & & \\
\hline Par9 & -0.163 & -0.234 & -0.011 & -0.931 & 1 & & & & & & & & & & & & & \\
\hline Par10 & -0.074 & 0.025 & -0.017 & 0.035 & -0.007 & 1 & & & & & & & & & & & & \\
\hline Par11 & -0.012 & 0.081 & -0.008 & -0.044 & 0.083 & 0.04 & 1 & & & & & & & & & & & \\
\hline Par12 & -0.062 & 0.021 & -0.013 & 0.025 & -0.009 & 0.933 & -0.139 & 1 & & & & & & & & & & \\
\hline Par14 & -0.002 & 0 & 0 & 0.001 & -0.001 & 0.002 & 0.005 & -0.008 & 1 & & & & & & & & & \\
\hline Par16 & 0.009 & -0.007 & 0.003 & 0.014 & -0.027 & 0.006 & -0.3 & 0.073 & -0.001 & 1 & & & & & & & & \\
\hline Par17 & -0.005 & 0.003 & -0.001 & -0.011 & 0.019 & -0.026 & 0.196 & -0.066 & 0.001 & -0.946 & 1 & & & & & & & \\
\hline Par20 & -0.02 & 0.019 & -0.001 & -0.768 & 0.635 & 0.044 & -0.001 & 0.051 & -0.001 & 0.002 & -0.002 & 1 & & & & & & \\
\hline Par22 & -0.002 & 0.01 & 0.001 & -0.035 & 0.042 & -0.009 & 0.229 & 0.079 & -0.008 & -0.308 & 0.242 & 0.01 & 1 & & & & & \\
\hline Par26 & 0.97 & 0.209 & 0.023 & 0.117 & -0.174 & -0.102 & -0.027 & -0.077 & -0.002 & 0.013 & -0.007 & 0.006 & 0 & 1 & & & & \\
\hline Par28 & 0.142 & -0.11 & -0.045 & -0.106 & 0.109 & 0.342 & 0.273 & 0.193 & 0.008 & -0.089 & 0.049 & -0.106 & -0.043 & 0.088 & 1 & & & \\
\hline Par29 & 0.137 & 0.356 & -0.007 & 0.211 & -0.329 & 0.207 & 0.375 & 0.121 & 0.003 & -0.106 & 0.064 & 0.058 & 0.061 & 0.167 & 0.265 & 1 & & \\
\hline Par30 & -0.064 & 0.017 & -0.016 & 0.036 & -0.009 & 0.639 & 0.202 & 0.423 & 0.009 & -0.176 & 0.087 & 0.015 & -0.335 & -0.09 & 0.376 & 0.214 & 1 & \\
\hline Par31 & -0.024 & 0.039 & -0.008 & -0.04 & 0.074 & 0.139 & 0.762 & 0.03 & -0.001 & -0.431 & 0.277 & 0.007 & 0.394 & -0.037 & 0.219 & 0.294 & 0.315 & 1 \\
\hline
\end{tabular}



S4. Parity plots for NCLH1.2 and NCLH2.2
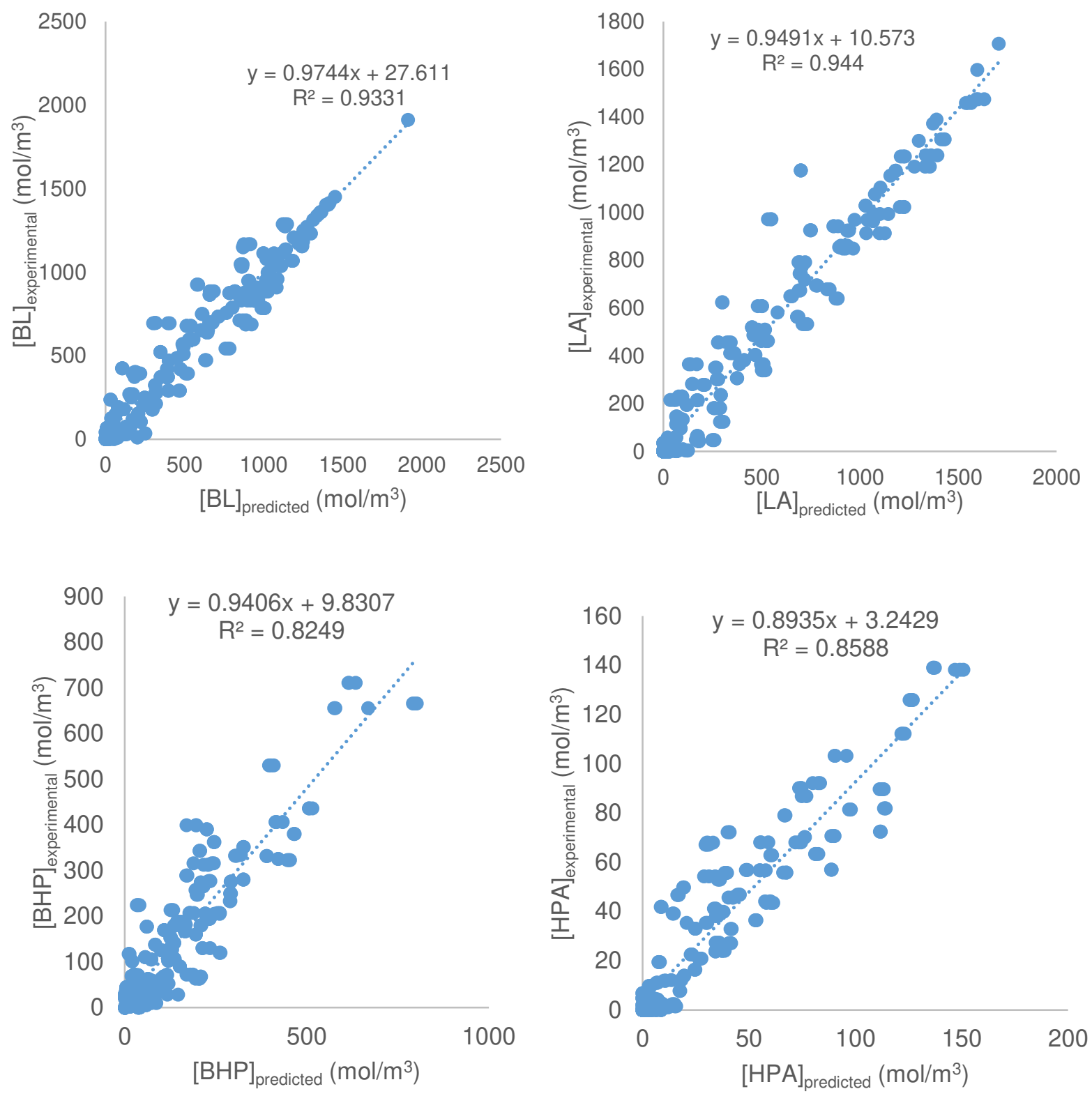

Fig. S4.1. Parity plots for Model NCLH1.2. 

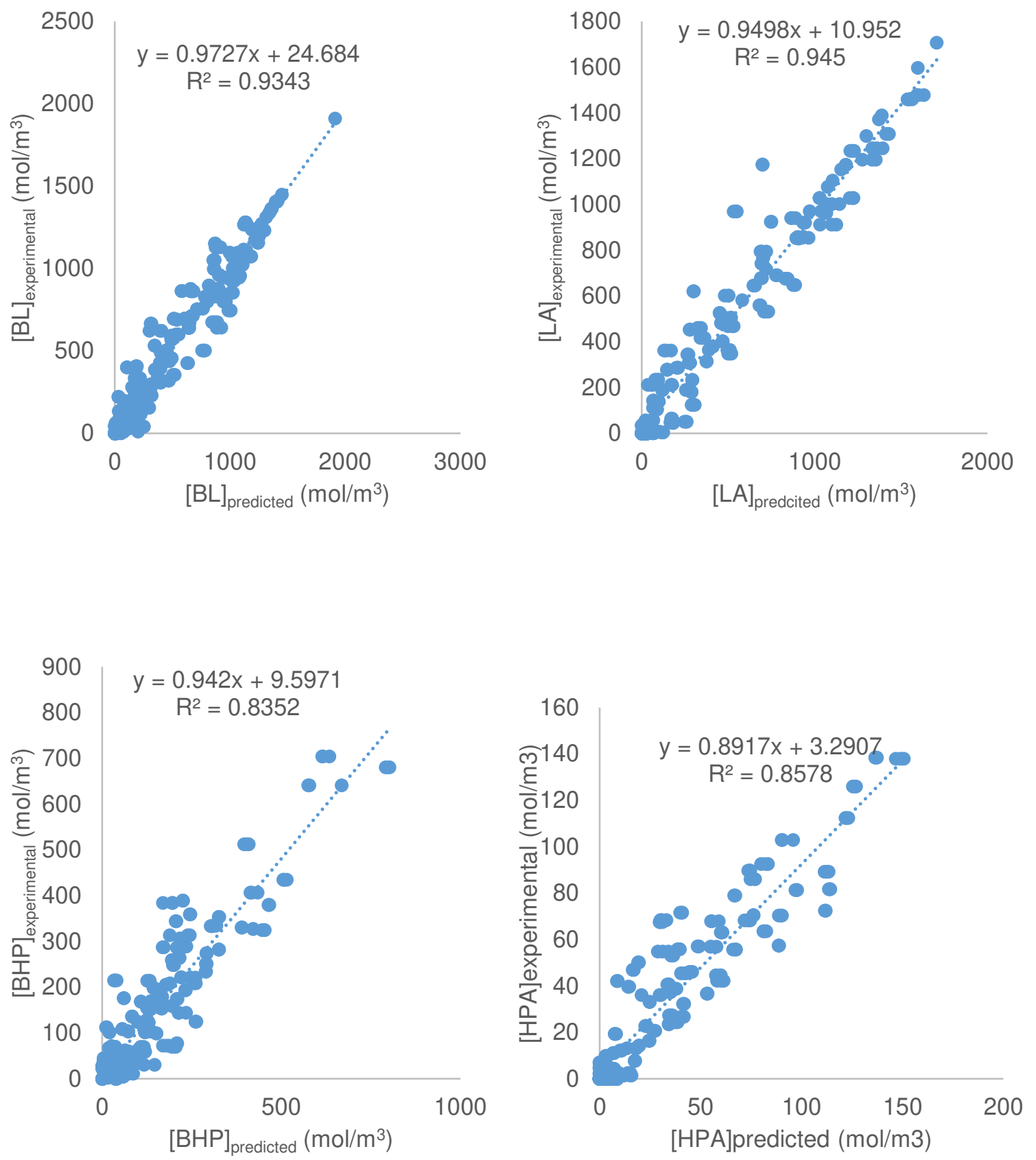

Fig. S4.2. Parity plots for Model NCLH2.2. 
S5. Cross validation
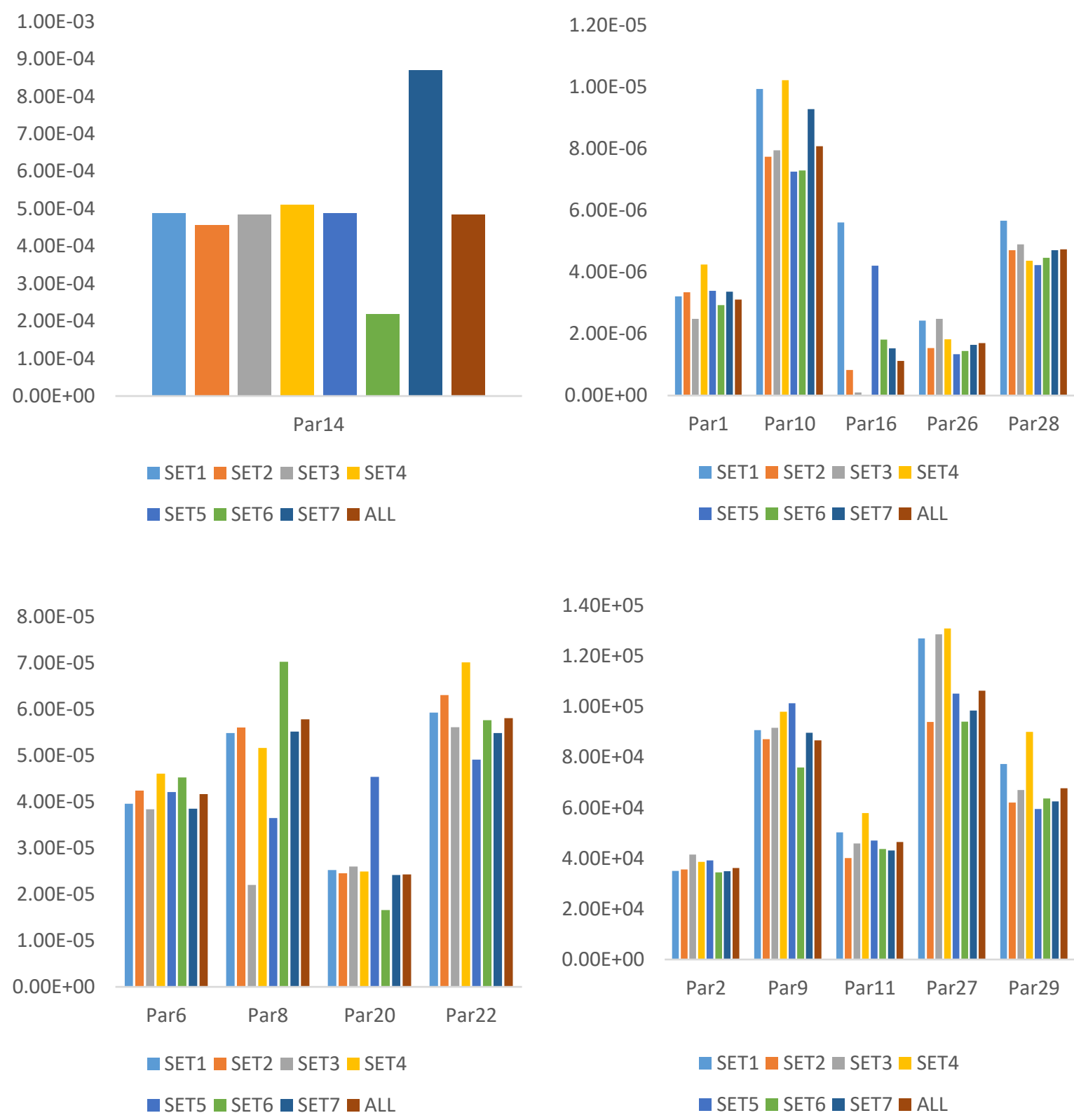

1.40E+05

$1.20 \mathrm{E}+05$

$1.00 \mathrm{E}+05$

$8.00 \mathrm{E}+04$

$6.00 \mathrm{E}+04$

$4.00 \mathrm{E}+04$

$2.00 \mathrm{E}+04$

$0.00 \mathrm{E}+00$

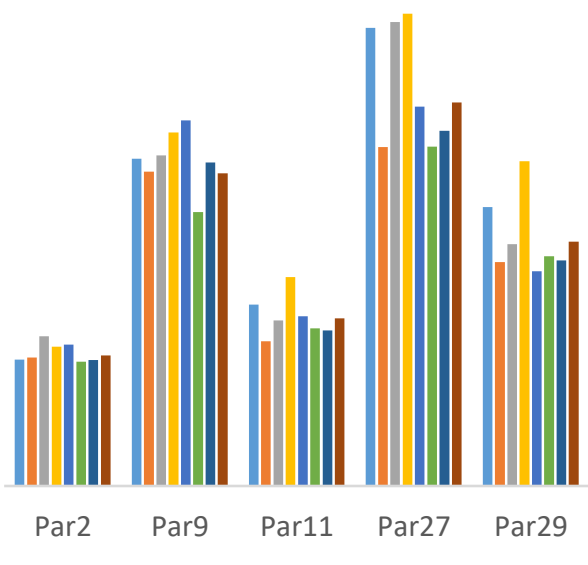

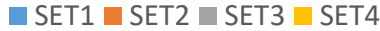

—SET5 — SET6 —SET7 — ALL 


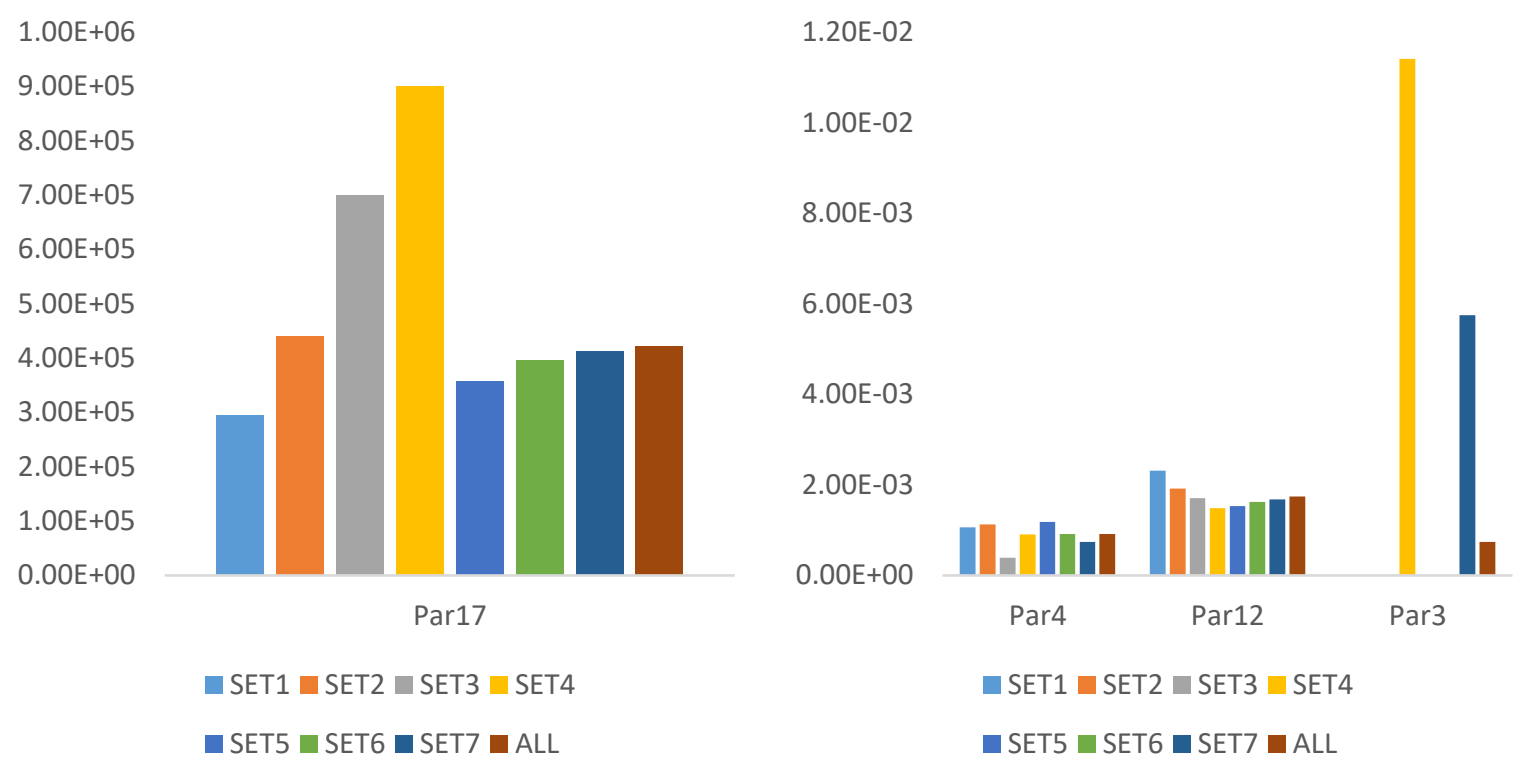

Fig. S5.1. Values of the estimated values for each set and for the whole experiments for NCLH1.2 

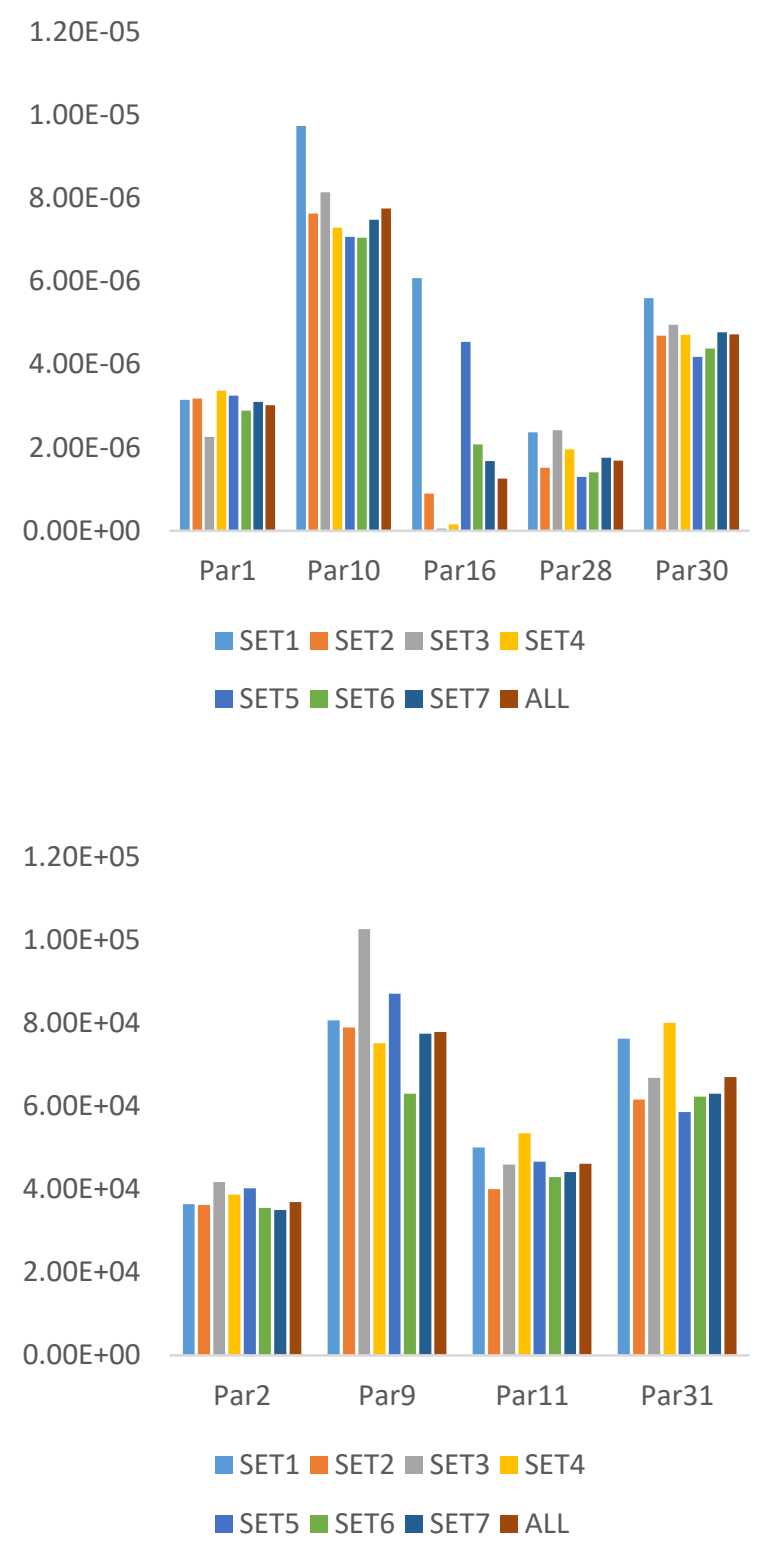
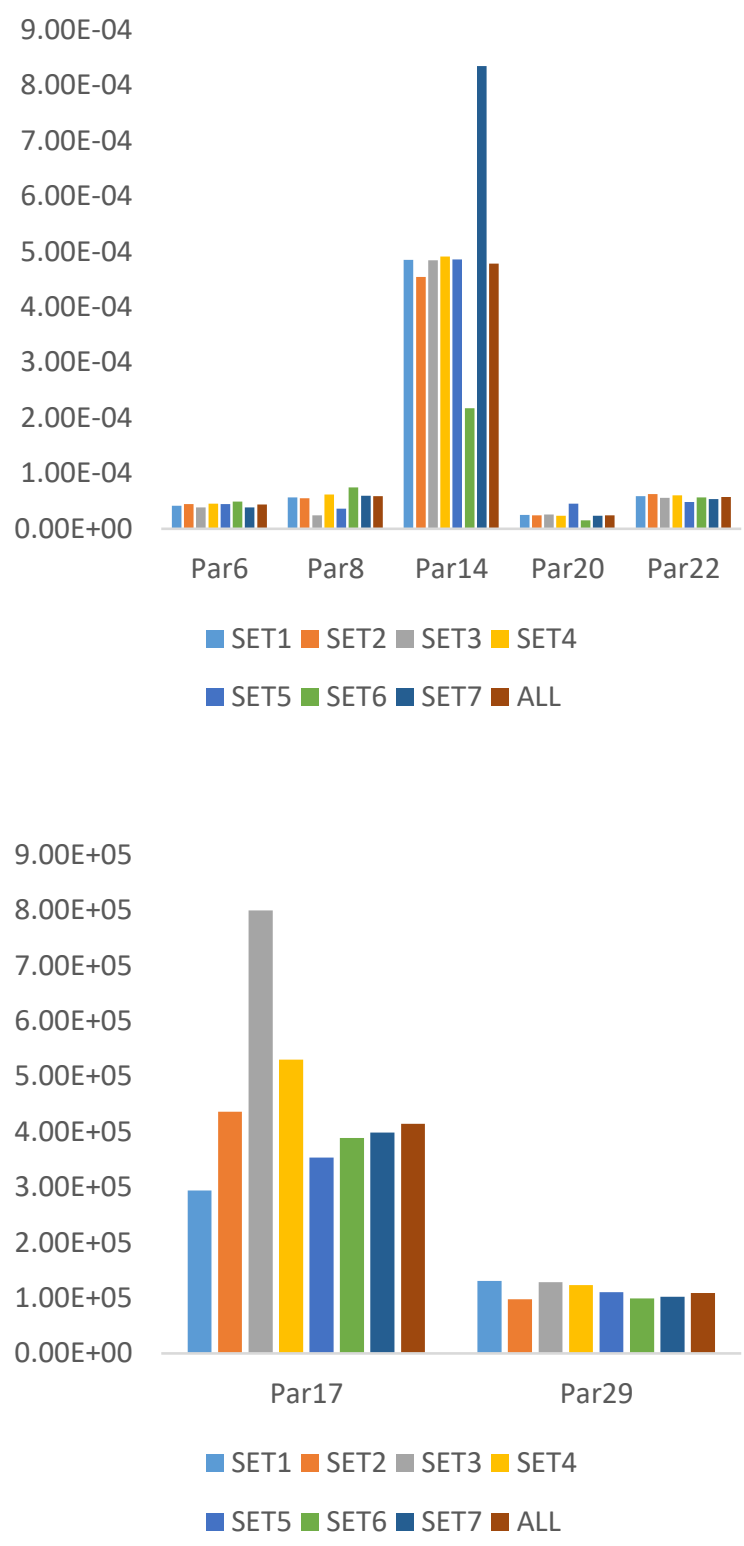

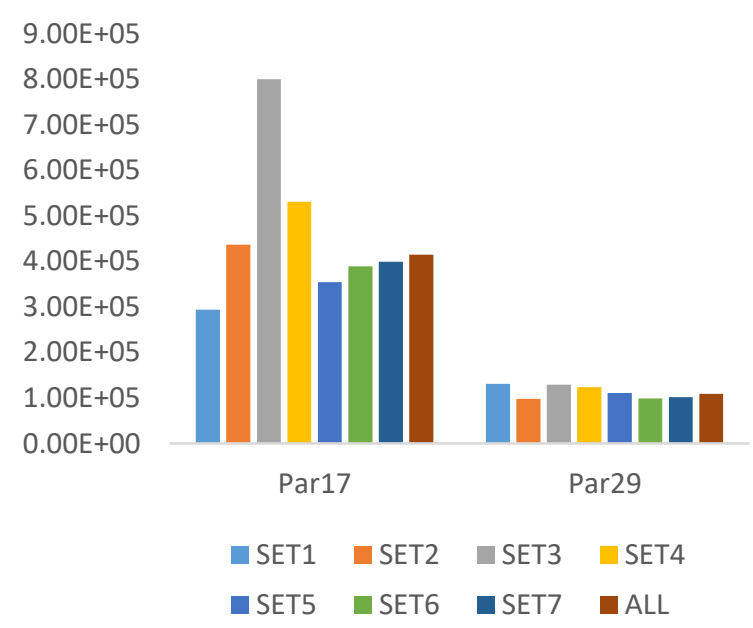

Fig. S5.2. Values of the estimated values for each set and for the whole experiments for NCLH2.2 